\author{
CENTRO UNIVERSITÁRIO FEI \\ RAFAEL MARTINS PEDREIRA CORREA
}

RELAÇÃO IDEAL ENTRE NÍVEL DE ESTOQUE E ÍNDICE DE RUPTURA QUE PROPICIA O MAIOR LUCRO POSSÍVEL EM UMA EMPRESA DE VAREJO DE MODA: estudo do fluxo de estoque entre retaguarda e área de vendas

São Bernardo do campo 

RAFAEL MARTINS PEDREIRA CORREA

\section{RELAÇÃO IDEAL ENTRE NÍVEL DE ESTOQUE E ÍNDICE DE RUPTURA QUE PROPICIA O MAIOR LUCRO POSSÍVEL EM UMA EMPRESA DE VAREJO DE MODA: estudo do fluxo de estoque entre retaguarda e área de vendas}

Dissertação apresentada ao Centro Universitário FEI como parte dos requisitos necessários para obtenção do título de Mestre em Engenharia Mecânica. Orientado pelo Prof. Dr. Alexandre Augusto Massote.

São Bernardo do Campo 
Correa, Rafael Martins Pedreira.

Relação ideal entre nível estoque e índice de ruptura que propicia o maior lucro possível em uma empresa de varejo de moda: estudo do fluxo de estoque entre a retaguarda e área de vendas / Rafael Martins Pedreira Correa. São Bernardo do Campo, 2017.

82 p. : il.

Dissertação - Centro Universitário FEI.

Orientador: Prof. Dr. Alexandre Augusto Massote.

1. Ruptura . 2. Simulação. 3. Varejo de Moda. 4. Moda Rápida. I. Massote, Alexandre Augusto, orient. II. Título.

Elaborada pelo sistema de geração automática de ficha catalográfica da FEI com os dados fornecidos pelo(a) autor(a). 
Aluno: Rafael Martins Pedreira Correa

Matrícula: 215315-3

Título do Trabalho: Relação ideal entre nível de estoque e índice de ruptura que propicia o maior lucro possível em uma empresa de varejo de moda: estudo do fluxo de estoque entre retaguarda e área de vendas.

Área de Concentração: Produção

Orientador: Prof. Dr. Alexandre Augusto Massote

Data da realização da defesa: 19/12/2017

\section{ORIGINAL ASSINADA}

\section{Avaliação da Banca Examinadora:}

São Bernardo do Campo, 19 / 12 / 2017.

\section{MEMBROS DA BANCA EXAMINADORA}

Prof. Dr. Alexandre Augusto Massote

Prof. Dr. Mauro Sampaio

Prof. Dr. Bruno Alvarez Ferreira Ignácio
Ass. :

Ass. :

Ass. :

A Banca Julgadora acima-assinada atribuiu ao aluno o seguinte resultado:

\section{VERSÃO FINAL DA DISSERTAČ̃̃O} APROVO A VERSÃo FINAL DA DISSERTAÇÃO EM QUE FORAM INCLUÍDAS AS RECOMENDAÇÕES DA BANCA EXAMINADORA
Aprovação do Coordenador do Programa de Pós-graduação 


\section{AGRADECIMENTOS}

Agradeço a todos que tornaram este projeto possível. Inicialmente, quero agradecer a Deus, pois o que seria de nós sem a fé que depositamos nele. Ao professor e orientador, Doutor Alexandre Augusto Massote, pela paciência, amizade e incentivo na orientação, tornando possível a conclusão desta dissertação. Finalmente, mas não menos valiosa, foi o apoio de familiares e amigos que não mediram esforços para que eu alcançasse esta vitória. A eles, meu mais sincero agradecimento. 
"Se não puder voar, corra. Se não puder correr, ande. Se não puder andar, rasteje, mas continue em frente de qualquer jeito".

Martin Luther King Jr. 


\section{RESUMO}

Um dos principais problemas enfrentados pelos grandes varejistas está relacionado ao desabastecimento das gôndolas, os chamados pontos de ruptura. Estudos realizados desde a década de sessenta mostram que o progresso relacionado a esse tema foi limitado. Os níveis estimados de ruptura de estoque no varejo tradicional estão em torno de $8,3 \%$. Além disso, a literatura sobre o assunto é insuficiente, pois poucos trabalhos se dedicam a investigar o varejo de moda. O presente estudo tem como finalidades levantar os dados da ruptura de uma grande empresa varejista têxtil para uma determinada categoria de produto e elaborar uma modelagem de simulação a fim de avaliar as estratégias de abastecimento entre a retaguarda e a área de vendas. O objetivo é verificar a relação ideal entre nível de estoque e índice de ruptura que propicia o máximo lucro possivel. Para a realização deste trabalho, utilizou-se a metodologia de análise quantitativa denominada simulação, por meio de um software que permite a geração de vários cenários para os níveis de estoque e suporta o desenvolvimento de sugestões para a melhoria ou redução das taxas de ruptura. Os resultados do estudo mostram que a variação da política de abastecimento da retaguarda para a área de vendas interfere diretamente no índice de ruptura e que há um nível ideal de ruptura que propicia o maior lucro possível.

Palavras-chave: Ruptura. Simulação. Varejo de Moda. Moda Rápida. 


\begin{abstract}
One of the main problems faced by large retailers is related to the product's shortage in the s, denominated like stockout points. Studies conducted since the 1960 s show that the progress in this area has been limited. Traditional retail presents estimated inventory rupture levels around $8.3 \%$. In addition, the literature about this subject is insufficient, since few works are dedicated to investigate the fashion retail. The present study aims to analyze the rupture data of a large textile retailer for a particular product category and design a simulation model to evaluate the supply strategies between back office and sales area in order to verify the ideal relationship between stock level and stock-out index that provides the maximum profit achievable. To carry out this study, the quantitative analysis methodology denominated simulation was used, through a software that allows the generation of several scenarios for the inventory levels and supports the development of suggestions for the improvement or reduction of the rupture rates. The results of the study demonstrate that the variation of the supply policy from the tail end to the sales area directly interferes with the rupture rate and that there is an ideal level of rupture which provides the greatest possible profit.
\end{abstract}

Keywords: Stock-out. Simulation. Fashion Retail. Fast Fashion. 


\section{LISTA DE ILUSTRAÇÕES}

Figura 1 - Agrupamentos de palavras acerca do tópico "stockout" ....................................... 16

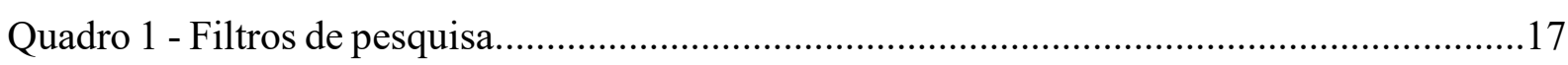

Gráfico 1 - Distribuição anual das publicações acerca do termo "stockout"..............................18

Figura 2 - Esquema para identificação de focos de ruptura....................................................23

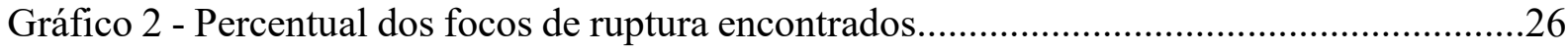

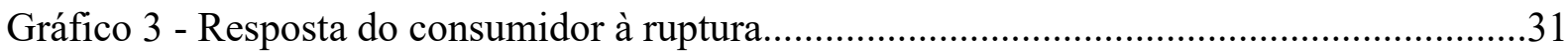

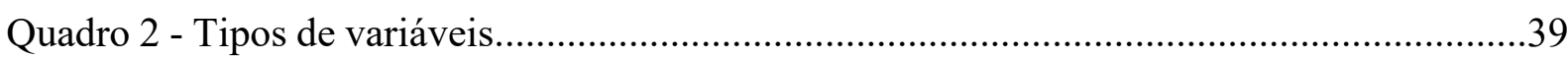

Figura 3 - Processo de desenvolvimento de modelos de simulação...........................................40

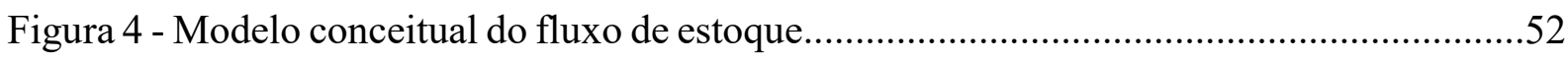

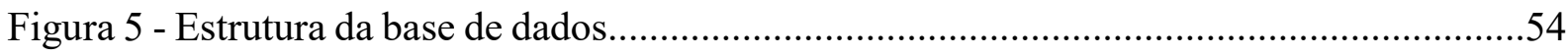

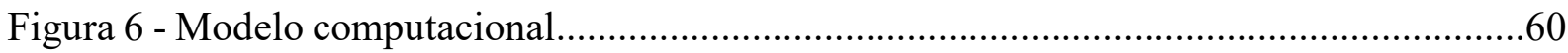

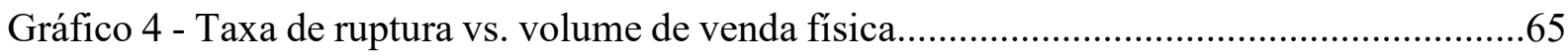

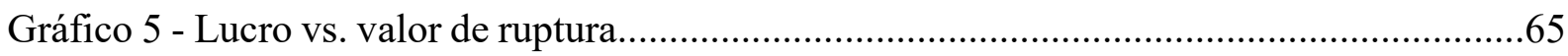

Gráfico 6 - Custo do investimento em estoque versus receita líquida......................................66

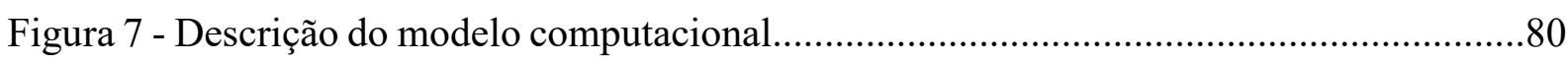




\section{LISTA DE ABREVIATURAS E SIGLAS}

$\begin{array}{ll}\mathrm{C}_{\mathrm{o}} & \text { Custo do estoque em excesso } \\ \mathrm{C}_{\mathrm{u}} & \text { Custo de estoque em falta } \\ \mathrm{ADV} & \text { Área disponível para venda } \\ \mathrm{c} & \text { Custo por unidade } \\ \mathrm{D} & \text { Número de dias analisados } \\ \mathrm{L} & \text { Número de lojas analisadas } \\ \mathrm{Lpr} & \text { Linha de produção e reposição de estoque } \\ \mathrm{NCM} & \text { Nível de serviço de ciclo } \\ \mathrm{NCM} & \text { Nível de serviço de ciclo ideal } \\ \mathrm{O} & \text { Tamanho de pedido } \\ \mathrm{O} * & \text { Tamanho de pedido ideal correspondente } \\ \mathrm{p} & \text { Preço de revenda por unidade } \\ \mathrm{R} & \text { Número de rupturas encontradas } \\ \mathrm{S} & \text { Número de SKU's analisados } \\ \mathrm{s} & \text { Valor residual } \\ \mathrm{SKU} & \text { Unidade de Controle de Estoque } \\ \mathrm{T} & \text { Taxa de Ruptura } \\ \mathrm{Y} & \text { Número total de casos analisados }\end{array}$




\section{SUMÁRIO}

1 INTRODUÇÃO

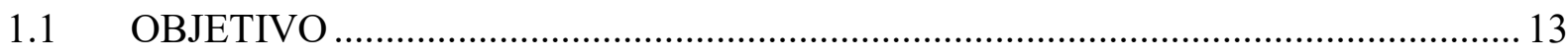

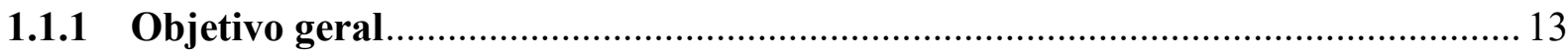

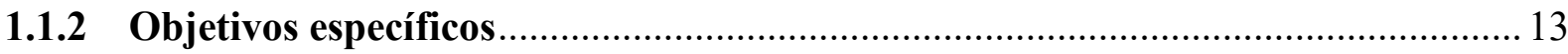

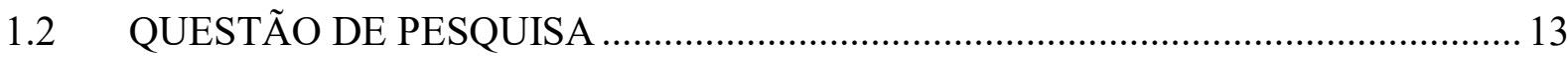

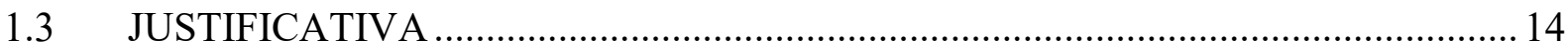

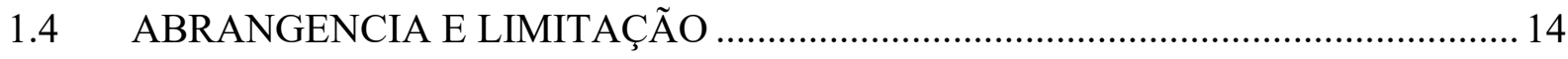

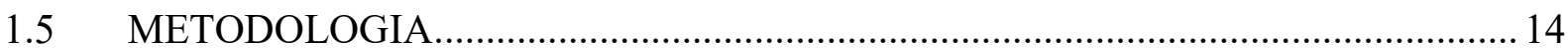

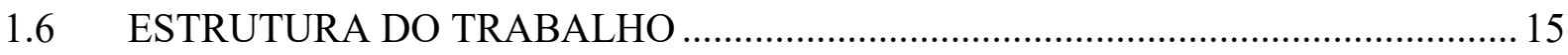

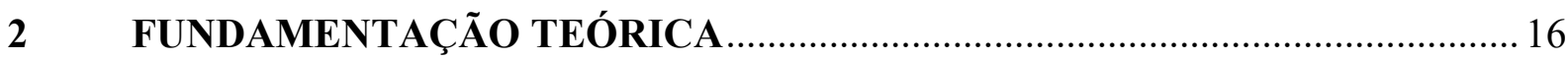

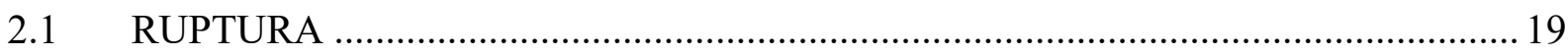

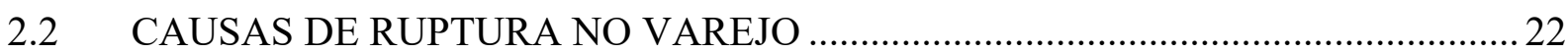

2.3 COMPORTAMENTO DO CONSUMIDOR FRENTE À RUPTURA …………….......28

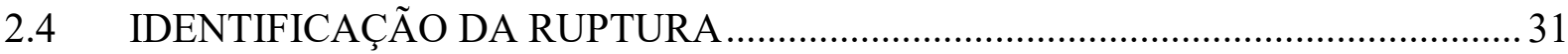

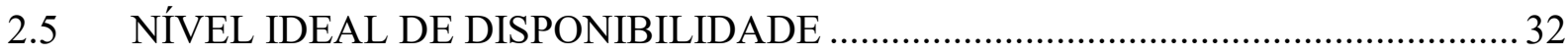

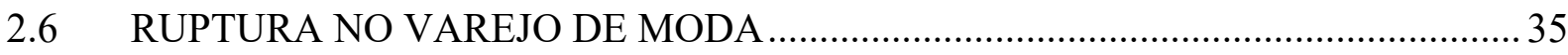

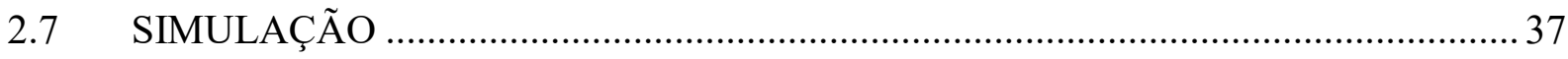

2.7.1 Etapas para o desenvolvimento e aplicação de um modelo de simulação ……........39

2.7.1.1 Formulação do problema - passo 1 ………………................................................. 41

2.7.1.2 Especificação dos critérios de desempenho e parâmetros do sistema - passo 2 ….... 41

2.7.1.3 Desenvolvimento e validação do modelo conceitual - passo 3 .................................. 41

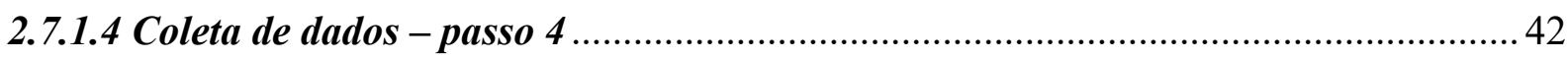

2.7.1.5 Desenvolvimento e verificação do modelo computacional - passo 5 ........................ 42

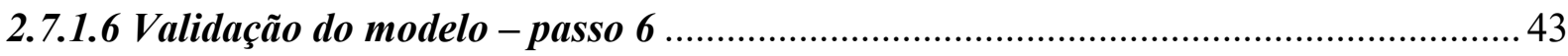

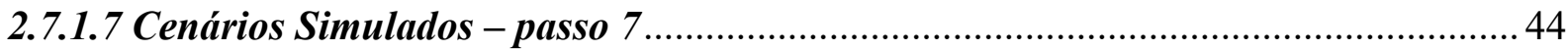

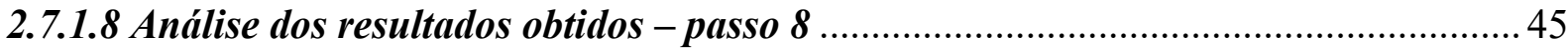




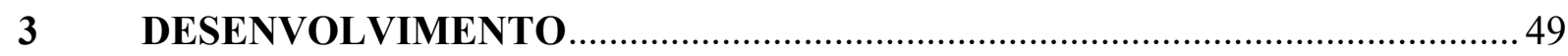

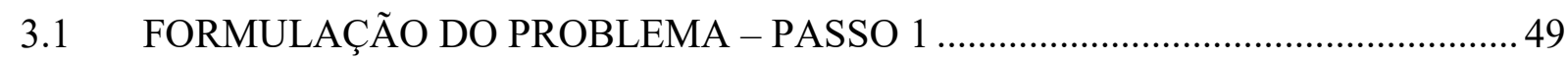

3.2 ESPECIFICAÇÃO DOS CRITÉRIOS DE DESEMPENHO E PARÂMETROS DO

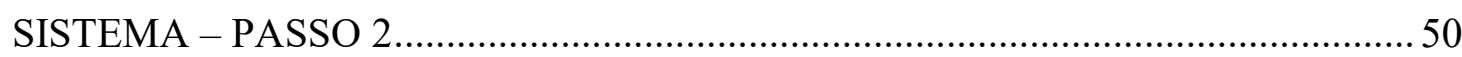

3.3 DESENVOLVIMENTO E VALIDAÇÃO DO MODELO CONCEITUAL - PASSO 3

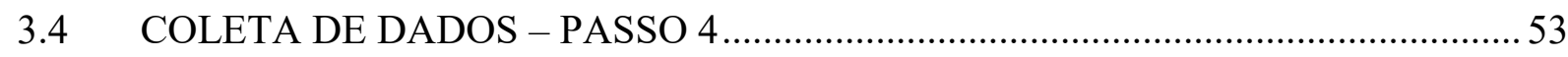

3.5 DESENVOLVIMENTO E VERIFICAÇÃO DO MODELO COMPUTACIONAL

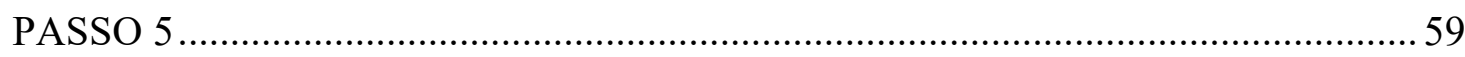

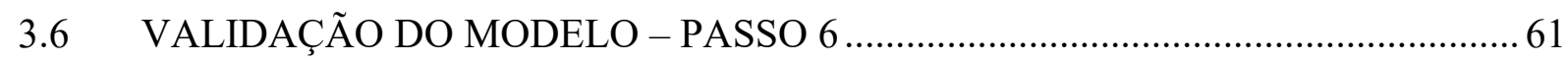

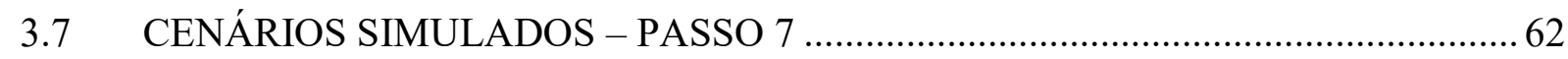

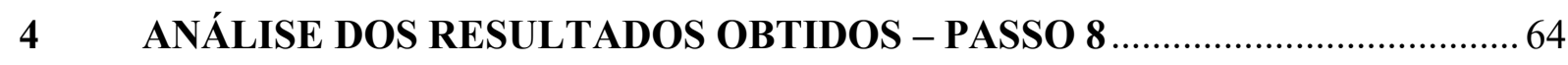

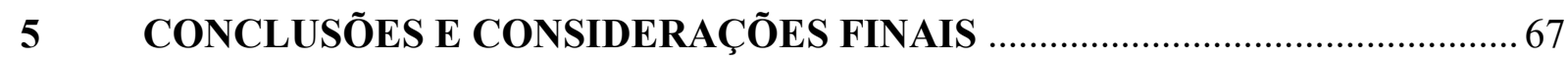

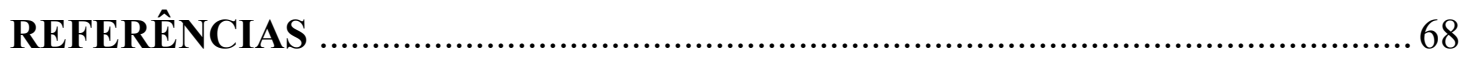

APÊNDICE A - DADOS DA AMOSTRAGEM REALIZADA NA OPERAÇÃO

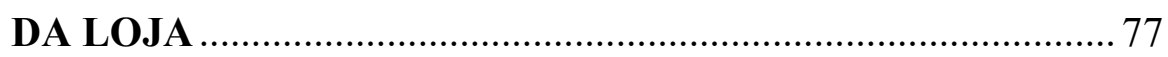

APÊNDICE B - DESCRIÇÃO DO MODELO COMPUTACIONAL .................. 79 


\section{INTRODUÇÃO}

Segundo Martino et al. (2016), o processo de alocar adequadamente vários produtos diferentes em uma rede de lojas é um dos problemas cruciais na indústria de varejo. Outra preocupação de um grande varejista de moda é a tomada de decisão sobre a quantidade das unidades mantidas em estoque ou stock keeping units (SKU's) a serem enviadas entre os agentes da cadeia de abastecimento (CARO; GALLIEN, 2010). O problema de ruptura de estoque é cada vez mais visto como um problema de alta criticidade no varejo (GRUEN; CORSTEN, 2003; FERNIE; GRANT, 2008; AGUIAR; SAMPAIO, 2013). Isso porque, de acordo com Avlijas et al. (2015), a ruptura leva diretamente à diminuição de vendas, redução de lucro e potenciais perdas de clientes. Para Martino et al. (2016), o principal desafio do reabastecimento é a maximização do lucro pretendido, dada pela diferença entre receitas e custos totais, a fim de satisfazer toda a procura do mercado.

Aguiar e Sampaio (2014) definem a ruptura de estoque como o momento em que a empresa de varejo recebe a demanda por um item/produto, mas ele não está disponível para venda. Os autores definem como índice de ruptura a porcentagem do total de itens/produto comercializados que deveriam estar à venda, mas que não são encontrados nas gôndolas (AGUIAR; SAMPAIO, 2013). Em logística, há alguns sinônimos para ruptura, tais como stockout, ou simplesmente "falta de estoque". Independente do termo usado, a ruptura caracteriza-se por ser um processo ineficiente na reposição das gôndolas, resultando em ausência de produtos para o consumidor final (AGUIAR; SAMPAIO, 2013).

De acordo com Zinn e Liu (2001), no segmento varejista, a ruptura ocorre no espaço de tempo em que um item/produto que deveria estar à venda para seus clientes/consumidores não está disponível na área de venda. Essa situação prejudica todos os agentes da cadeia de suprimentos, desde o fabricante e o próprio varejista até o consumidor final. E, dificilmente, consegue-se mensurar o custo real da ruptura, visto que esse valor difere em função da resposta de reação do consumidor frente à falta do produto.

Para Gruen, Corsten e Bharadwaj (2002), no caso de uma ruptura, o consumidor pode decidir entre: substituir o item; adiar a compra do item/produto; sair da loja e desiste da compra; procurar o item/produto em outra loja; ou não comprar o item/produto novamente (perda da venda). Na perspectiva da cadeia de abastecimento, a ruptura distorce a previsão de demanda e pode resultar em investimentos exagerados e desnecessários em estoque e/ou em perdas de receita. 
Além do mais, o evento da ruptura está relacionado a fatores incertos, como, por exemplo, mudanças constantes no mercado. Dessa forma, faz-se necessário um modelo de negócio para definir o ponto de estoque ideal e seu reabastecimento (PAN et al., 2009).

A solução do problema de ruptura poderia ocasionar um aumento de até 5\% de receita para grandes fabricantes e varejistas (GRUEN; CORSTEN; BHARADWAJ, 2002). Um importante exemplo é o estudo contextualizado na varejista ZARA, que reduziu a ruptura, no ano de 2007, e com isso gerou um aumento percentual de $3 \%$ a $4 \%$ na receita, o que equivale a 275 milhões de dólares (CARO; GALLIEN, 2010). Para Martino et al. (2016), a utilização da ferramenta de simulação para reduzir ruptura pode garantir uma melhora média de $10 \%$ nos resultados de redução de ruptura.

A revisão de literatura realizada por Manuj, Mentzer e Bowers (2009) apresenta eminentes de logística e gestão da cadeia de abastecimento, mostrando que muitos estudiosos defendem a realização de mais pesquisas de simulação. Os autores também constatam que o método de pesquisa, a modelagem matemática (incluindo a simulação), é o segundo método mais utilizado nas publicações do Journal of Business Logistics, do International Journal of Physical Distribution, e do Logistics Management, e o terceiro método mais utilizado no Supply Chain Management: an International Journal.

Embora exista uma vasta gama de literatura sobre o planejamento e a otimização da reposição de estoque na cadeia varejista, poucos pesquisadores focalizaram sua atenção no caso particular do varejo de moda (CARO; GALLIEN, 2010; MARTINO et al., 2016) ou em empresas de luxo de moda (DAVOLIO et al., 2015). De acordo com Caro e Gallien (2010), devido às especificidades que o diferem do varejo tradicional, há muitas oportunidades de pesquisas futuras sobre o varejo de moda. Segundo Aguiar e Sampaio (2014), em países em desenvolvimento como o Brasil, existe uma carência de pesquisas dedicadas à investigação da ruptura de estoque. Outra necessidade apontada pelos autores é realizar uma análise quantitativa para identificar a taxa de ruptura, em diferentes produtos, no mercado brasileiro (AGUIAR; SAMPAIO, 2013). Nesse cenário, percebe-se que há uma lacuna na literatura, pois o tema ainda é pouco investigado, principalmente no âmbito brasileiro.

Segundo Fernie e Grant (2008), as principais causas da ruptura estão dentro da própria loja, entre sua retaguarda e a área de venda. Essas conclusões são decorrentes das pesquisas realizadas pelos autores junto a gerentes seniores de uma rede de supermercados escocesa. De maneira análoga, Gruen, Corsten e Bharadwaj (2002) e Aguiar e Sampaio (2013) sugerem que a maior parcela das rupturas que ocorrem na operação de uma loja encontra-se entre a retaguarda e a gôndola. Já segundo a (Divisão de Serviços de Varejo da AC Nielsen Brasil 
(2004), as principais oportunidades de melhorias estão presentes nas prateleiras do varejo. De acordo com Prashar, Parsad e Vijay (2015), um grande número de varejistas e comerciantes acredita que as decisões de compra são geralmente feitas dentro da loja.

Portanto, com base nos argumentos citados acima, o tema ruptura de estoque com ênfase na operação de loja é de suma importância para as grandes empresas varejistas, pois pode possibilitar a melhora na relação de custos e receitas, proporcionando o máximo lucro possível. Nesse contexto, as oportunidades relacionadas ao assunto devem ser exploradas. Por fim, há contribuições acadêmicas, tendo em vista a lacuna teórica sobre o tema no âmbito brasileiro.

\subsection{OBJETIVO}

Neste tópico serão abordados os objetivos gerais e específicos.

\subsubsection{Objetivo geral}

Determinar a melhor relação entre nível de estoque e índice de ruptura que propicia o maior lucro possível em uma empresa de varejo de moda

\subsubsection{Objetivos específicos}

Esta pesquisa tem os seguintes objetivos específicos:

a) investigar a política de abastecimento da retaguarda para a área de vendas que pode propiciar o maior lucro;

b) utilizar a simulação como uma ferramenta de suporte a tomada de decisão na política de reposição/abastecimento, considerando os elementos de nível de estoque e índice de ruptura.

\subsection{QUESTÃO DE PESQUISA}

Em linha com os problemas encontrados e com a revisão da literatura realizada, pretende-se responder à seguinte pergunta de pesquisa:

a) qual a relação ideal entre o nível de estoque e o índice de ruptura que propicia o maior lucro possível? 
b) qual a influência da política de abastecimento entre a retaguarda e a área de vendas no índice de ruptura?

\subsection{JUSTIFICATIVA}

Este trabalho se justifica pela contribuição ao ramo de varejo de moda brasileiro, ao se analisar as possibilidades de melhora na relação de custos e receitas que proporciona o máximo lucro possível. Por fim, há contribuições para o meio acadêmico, tendo em vista a carência de estudos sobre o tema no Brasil.

\subsection{ABRANGENCIA E LIMITAÇÃO}

Embora a literatura aponte outros diversos focos de ruptura, este trabalho se limitará apenas ao foco em loja, ou seja, investigará a política de abastecimento da retaguarda da loja para a área de vendas.

\subsection{METODOLOGIA}

Segundo Dias (2000), a pesquisa quantitativa se mostra mais apropriada quando há possibilidade de conseguir dados que mensurem o objeto ou o estudo a ser investigado. Nos termos do autor, a pesquisa de dados quantitativa tem como principal objetivo identificar e mensurar a frequência e a intensidade com que ocorre o evento estudado.

Guba e Lincoln (1994) pontuam que o método da pesquisa quantitativa se caracteriza pelo emprego da quantificação, tanto na coleta das informações quanto nas análises realizadas por meio de técnicas estatísticas, desde as mais simples, como percentual, média, e desvio padrão até as mais complexas, como coeficiente de correlação, regressão, entre outras.

No planejamento deste tipo de pesquisa, o primeiro passo a ser dado é no sentido de identificar as variáveis envolvidas que serão utilizadas, pois elas são de extrema importância para a explicação das complexas características do problema (RICHARDSON, 1989).

A simulação é uma abordagem quantitativa e tem como finalidade explicar problemas, utilizando equações matemáticas ou modelos de simulação computacional. O presente trabalho é caracterizado como uma pesquisa quantitativa, e o método utilizado é a simulação computacional de eventos discretos. 
Por outro lado, a pesquisa qualitativa possui um caráter exploratório, uma vez que incita o entrevistado a pensar e a se expressar sobre o assunto em questão (GUBA; LINCOLN, 1994).

De acordo com Richardson (1989), na pesquisa qualitativa, os dados, ao invés de serem tabulados e tratados estaticamente, consolidando um resultado preciso, são retratados por meio de relatórios, levando em conta aspectos relevantes dos entrevistados. O autor acrescenta que o método de análise qualitativa se distingue do método quantitativo à medida que não são utilizadas ferramentas estatísticas como base do processo de análise de um problema.

$\mathrm{O}$ aspecto qualitativo pode ser inclusive observado nas informações colhidas por estudos essencialmente quantitativos, não obstante perderem sua característica qualitativa, quando são transformados em dados quantificáveis com o objetivo de assegurar a precisão e a exatidão nos resultados obtidos (RICHARDSON, 1989).

Para Reneker (1993), a pesquisa de dados qualitativa é indutiva e traz ao pesquisador ideias e conceitos que deverão ser estudados e questionados. Piore (1979), por sua vez, defende que o emprego de métodos qualitativos pode conferir um redirecionamento assertivo da investigação que será realizada, possibilitando ao pesquisador argumentos mais sólidos e consistentes.

Segundo Godoy (1995), o método qualitativo de estudo de caso visa a um detalhamento profundo do assunto a ser estudado por todos que procuram saber como e por que certos fenômenos acontecem.

Com base no conteúdo exposto e de acordo com o desenvolvimento do presente trabalho, com uma metodologia que envolve a análise de saídas numéricas de um modelo computacional, reiteramos a escolha do método de pesquisa quantitativa para a realização desta pesquisa.

\subsection{ESTRUTURA DO TRABALHO}

Este trabalho está organizado em cinco seções, incluindo esta introdução. Na seção 2, é realizada a revisão da bibliografia que embasa a pesquisa. A seção 3 mostra os passos para o desenvolvimento do estudo. Na seção 4, é abordada a análise dos resultados obtidos. A seção 5 apresenta as considerações finais e conclusões. 


\section{FUNDAMENTAÇÃO TEÓRICA}

A varredura horizontal é um significativo passo no processo de desenvolvimento de uma pesquisa e consiste no levantamento da literatura preexistente sobre o tema estudado (MIGUEL, 2010).

Primeiramente, foi inserida a palavra-chave "stockout" nas bases de busca Proquest, Scopus e Web of Science com o objetivo de identificar as publicações sobre o tema. Foram encontradas publicações no período entre os anos de 1969 a 2016.

A busca realizada resultou no delineamento do referencial teórico e na identificação das lacunas de pesquisa originadas nos estudos de Caro e Gallien (2010), Aguiar e Sampaio (2013), DAvolio et al. (2015) e Martino et al. (2016).

Os dados extraídos das buscas realizadas nas bases Scopus e Web of Science foram inseridos no programa Vosviwer, resultando no agrupamento de palavras exposto na Figura 1. Posteriormente, foi realizada a seleção das seguintes palavras-chave de destaque para o desenvolvimento desta dissertação: simulation, decision, product, distribution, consumer, retailer, safety stock, stockout period e profit.

Figura 1 - Agrupamentos de palavras acerca do tópico "stockout"

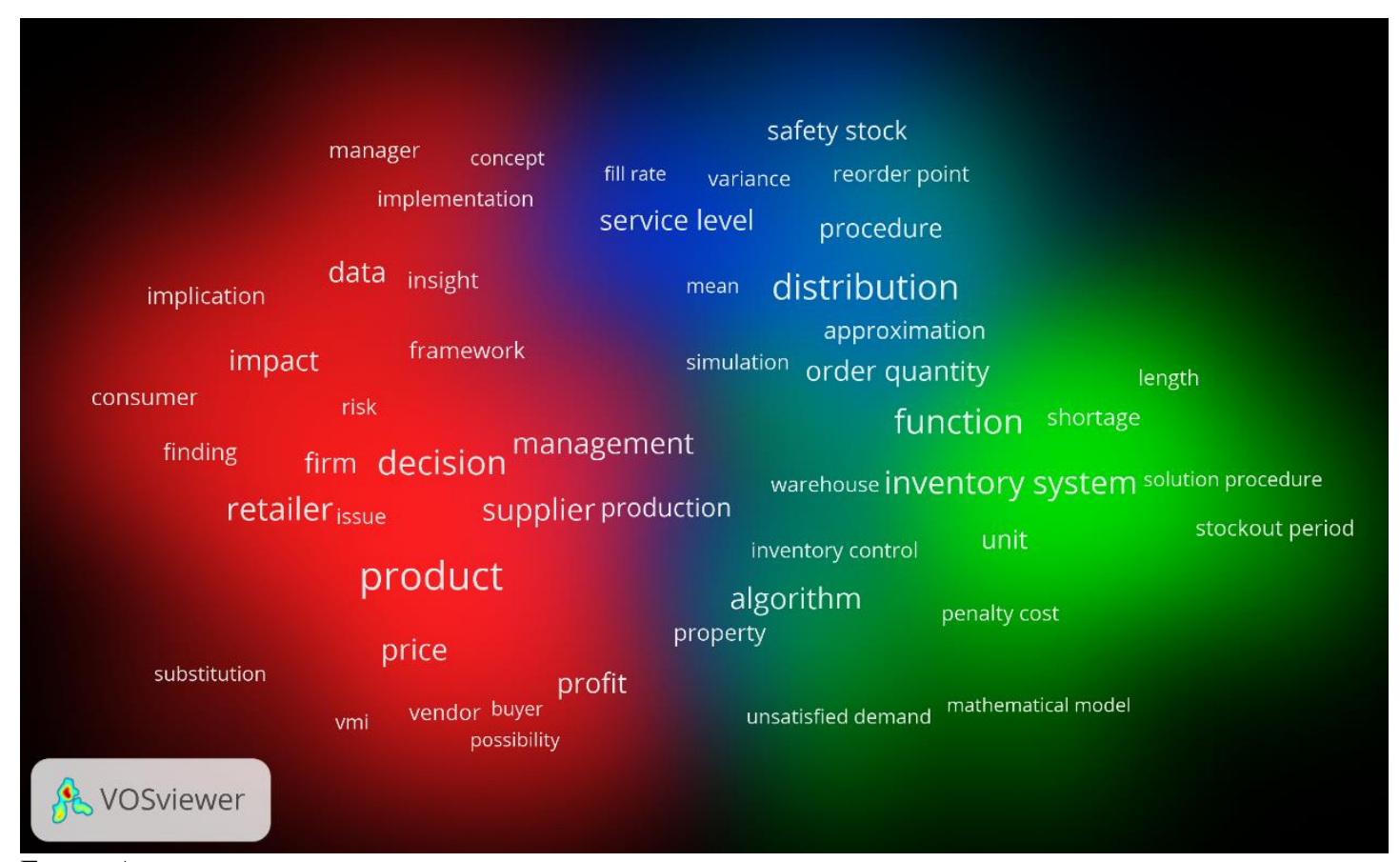

Fonte: Autor

Também foi realizada a busca das palavras-chave utilizadas em artigos direcionados ao varejo de moda, sendo destacadas fashion retail e fast fashion. 
As palavras-chave extraídas da análise do Vosviwer e as palavras-chave direcionadas ao varejo de moda foram combinadas com o termo chave stockout para o desenvolvimento da varredura vertical.

Varredura vertical é a parte da pesquisa que o pesquisador aprofunda o conhecimento sobre o tema do estudo e conhece os modelos já publicados (MIGUEL, 2010).

Com o objetivo de construir um cenário atual da distribuição das publicações (anuais) sobre o tema realizou-se, na base Scopus, a busca da recorrência da palavra-chave stockout nos campos de título do artigo, abstract e palavras chave, com a simultânea aplicação dos filtros de pesquisa apresentados no Quadro 1.

Quadro 1 - Filtros de pesquisa

\begin{tabular}{|l|l|}
\hline Categoria do filtro de pesquisa & Filtro aplicado \\
\hline Tipo de documento & Somente tipo artigo \\
\hline Tipo da fonte & Somente periódicos acadêmicos \\
\hline Idioma & Somente artigos no idioma inglês \\
\hline
\end{tabular}

Fonte: Autor

Deste modo, foram identificados 394 artigos acadêmicos com publicações acerca do tema, distribuídas entre os anos de 1969 a 2017, conforme Gráfico 1. 
Gráfico 1- Distribuição anual das publicações acerca do termo "stockout"

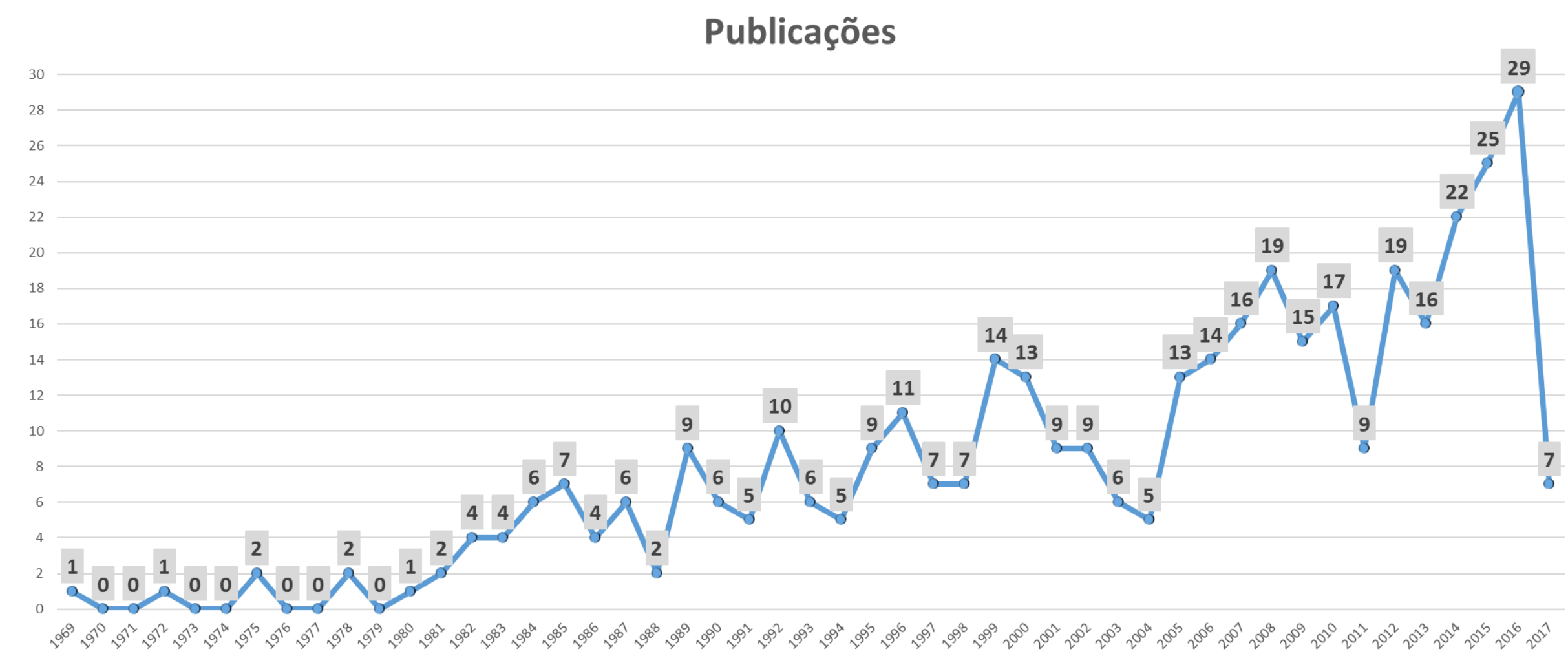

Fonte: Autor 


\subsection{RUPTURA}

De acordo com Fisher e Raman (2010), investidores avaliam os índices de estoque como um indicador antes de realizar investimentos. Muitas vezes, somente após uma investigação é tomada a decisão de investir em ações no varejo. Muitos investidores acreditam que os níveis de estoque predizem o futuro, sugerindo um aumento ou uma redução de venda, receita, lucro e preço da ação.

O primeiro estudo de ruptura foi realizado por Peckham (1963) e relatou taxas de ruptura de $8,5 \%$ no seguimento varejista. Posteriormente, a pesquisa desenvolvida por Corsten e Gruen (2003) apontou uma taxa de ruptura mundial em torno de 8,3\%. Assim sendo, a taxa relatada por Peckham (1963) é similar ao resultado de Corsten e Gruen (2003). Aguiar et al. (2014) argumentam que, apesar de todos os esforços para melhoria dos níveis de serviços logísticos nos últimos cinquenta anos, o nível de ruptura permanece elevado.

Trautrims et al. (2009) apontam que o equilíbrio entre disponibilidade e rentabilidade possui três pontos estratégicos: i) aumentar a disponibilidade dos SKU's com maior rentabilidade; ii) aumentar a rentabilidade de produtos muito disponíveis; e iii) reduzir a disponibilidade de produtos pouco rentáveis, caso uma redução de custos seja alcançada com isso. O estudo foi feito em uma rede varejista alimentícia e contou com dados de observações dos consumidores no ponto de venda e entrevistas com gerentes e funcionários de operações.

Os resultados da pesquisa realizada por Morgan e Dewhurst (2008) apontam para o relacionamento entre compradores e fornecedores como um ponto primordial para as grandes redes varejistas. Os autores concluíram que a utilização de gráficos e ferramentas estatísticas possibilitaria realizar com maior facilidade um monitoramento do nível de estoque, a fim de evitar a ruptura. No estudo, Morgan e Dewhurst (2008) realizaram um estudo exploratório com um banco de dados de uma empresa alimentícia, desenvolvendo gráficos de controles estatísticos para examinar as entregas entre o fornecedor e o centro de distribuição do cliente.

Já para Pramatari, Evgeniou e Doukidis (2009), uma significativa redução na ruptura e aumento nas vendas pode ser obtida por meio de um processo colaborativo entre varejista e fornecedor. Os autores constataram que dados compartilhados de venda e estoque diários permitiram ao fornecedor ajudar na gestão de estoque. Desse modo, simplificou-se o processo de emissão de pedidos, deixando-o com melhores índices de eficácia. Um fornecedor de uma rede de supermercados grega reportou um aumento de 64\% nas vendas após essa prática.

Segundo Prashar, Parsad e Vijay (2015), como os varejistas são incapazes de prever com precisão o comportamento de compra impulsivo de seus clientes, ficam presos em grandes 
volumes de estoque e/ou falta de estoque. Por anos, eles têm feito previsões de venda genéricas para suas lojas, no entanto, apesar das várias técnicas disponíveis, continua havendo uma expressiva taxa de ruptura. Os autores propõem que um bom modelo de previsão pode ajudar os varejistas e os comerciantes a prever as vendas e a gerar "compras não intencionais" adicionais à sua atual base de clientes/consumidores. Assim, as receitas crescem, os custos de vendas perdidas são reduzidos, os custos de estoques são minimizados, aumentando a lucratividade, e, finalmente, reduzindo as taxas de ruptura.

Pibernik (2006), por sua vez, defende que uma organização deve se antecipar à ruptura para conseguir ter uma boa gestão sobre seu estoque. As conclusões do autor devem-se à captação de dados de inventário de uma empresa farmacêutica e de dados relacionados à previsão de vendas de um produto que é vendido em grandes lotes (PIBERNIK, 2006). Com base nos resultados de sua pesquisa, é possível identificar que o principal modo de atenuar a ruptura é a entrega parcial da mercadoria comprada (mantendo uma reserva de estoque no centro de distribuição). Dessa forma podem ser reduzidas as chances da falta de produto na área de venda.

De acordo com Avlijas et al. (2015), se uma loja demanda um SKU que não está disponível no centro de distribuição para entrega imediata, é criada uma situação de ruptura nesta fase do processo (AVLIJAS et al., 2015). A ruptura no centro de distribuição de itens com alto giro e em período de promoção leva à ruptura nas lojas (AVLIJAS et al., 2015). Waller, Tangari e Williams (2008) destacam que as mudanças nas configurações da profundidade de produtos de alto e baixo giro podem influenciar a performance da ruptura.

Na perspectiva do processo varejista, aproximadamente $50 \%$ da incidência de estoques insuficientes são causados por problemas nos processos de reposição/pedidos realizados, como, por exemplo, pedidos de compra atrasados ou pedidos com requisição de quantidades insuficientes e estimativas irreais (AVLIJAS et al., 2015).

Nesse sentido, o desenvolvimento de estimativas da demanda de cada SKU requisitado por loja pode trazer diversos benefícios para a cadeia varejista (CARO; GALLIEN, 2010). Quando a demanda por um específico SKU varia significativamente ao longo do tempo, é complexo determinar a quantidade da reposição para manter o estoque. Ou seja, a habilidade de prevenir rupturas está diretamente relacionada à habilidade de prever a demanda de SKU's (AVLIJAS et al., 2015). Devido ao alto impacto sobre os lucros, as prevenções da ruptura de itens com alto giro podem produzir melhorias significativas nos resultados financeiros dos varejistas (AVLIJAS et al., 2015). Segundo os autores, giros altos de SKU's devem ser 
checados com maior frequência para o lançamento de pedidos/reposição, pois o risco da ruptura é significativamente maior (AVLIJAS et al., 2015).

O estudo de Waller, Tangari e Williams (2008) demonstra que o tamanho do lote de envio do centro de distribuição para a loja interfere na participação de mercado da indústria. Os autores coletaram, no período de dois anos, dados mensais da participação de mercado e a variação do lote de envio de uma indústria americana de cereais para uma posterior análise de regressão.

Atributos do item/produto também podem causar o aumento da ruptura, como, por exemplo, o tamanho. Isso porque produtos com grandes dimensões requerem espaços maiores na prateleira e, portanto, têm baixa disponibilidade para os consumidores/cliente (AVLIJAS et al., 2015). Ainda de acordo com os autores, os produtos com pequenas dimensões têm alta disponibilidade nas prateleiras e consequentemente baixos índices de ruptura. Deste modo, os sistemas de pedidos/reposição devem ser flexíveis para adequar-se a diferentes quantidades de demandas de diferentes quantidades de SKU's em períodos subsequentes, levando-se em conta as limitações das dimensões e outras características dos itens/produtos (AVLIJAS et al., 2015).

A literatura descreve diversas consequências da incidência da ruptura que incluem custo de venda perdida nas políticas de reabastecimento (BIJVANK; BHULAI; HUH, 2015). Na perspectiva da cadeia de suprimentos, Aguiar e Sampaio (2014) destacam que a ruptura prejudica a previsão de demanda, ocasiona investimentos desnecessários em estoque e pode levar a perdas de receita.

De acordo com Parent e Barki (2014), os gestores de compras faceiam uma série de desafios. O primeiro deles é a busca do equilíbrio entre dois objetivos conflitantes, ou seja, minimizar o investimento em estoque e, simultaneamente, minimizar o índice de faltas/ruptura. Outro desafio é lidar com a administração das compras e a gestão dos estoques que constitui um setor vital para as empresas varejistas. Isso porque os estoques absorvem um enorme volume de recursos, constituindo a maior parte do investimento em ativos das empresas varejistas, e as compras representam a maior conta das despesas. Devido à importância simultânea que exercem no volume das vendas e no fluxo de caixa das empresas, as compras vêm recebendo uma atenção especial dos varejistas em suas áreas comercial e financeira (PARENT; BARKI, 2014). A ruptura no segmento do varejo pode ser utilizada como uma medida de performance, monitoramento e estruturação do sistema de suprimento (AVLIJAS et al., 2015). 


\subsection{CAUSAS DE RUPTURA NO VAREJO}

De acordo com Marqui, Alcântara e Christopher (2010), nos últimos cinquenta anos, foram publicados poucos artigos voltados às causas das rupturas. Também a pesquisa de Aguiar e Sampaio (2014) aponta que a literatura é carente em publicações pautadas nas causas da ruptura de estoque.

Pibernik (2006) apresenta como causas de ruptura de estoque os erros na alocação de pedidos, os equívocos na priorização da alocação do abastecimento e as falhas na alocação dos produtos nas gôndolas. Em consonância a esse estudo, Aastrup e Kotzab (2009) mostram que os processos de colocação de pedido e definição de demanda são considerados elementos causadores da ruptura. Assim, as identificações das causas da ruptura podem servir de base para a tomada de decisões gerenciais (AGUIAR; SAMPAIO, 2014).

A Figura 2 apresenta um esquema para a identificação dos focos de ruptura no varejo elaborado por Araujo, Hristov e Correa (2013). 
Figura 2 - Esquema para identificação de focos de ruptura

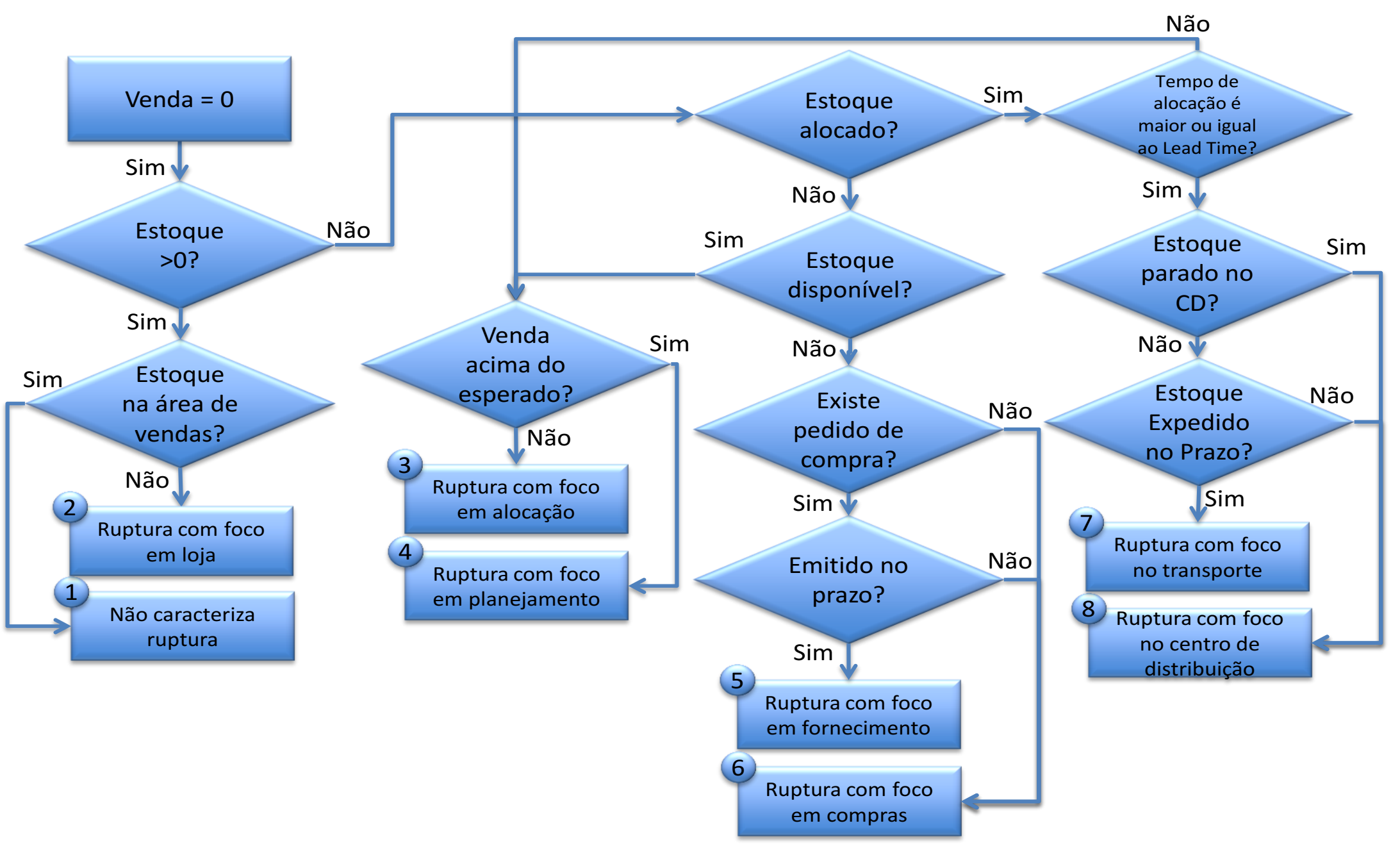

Fonte: Autor "Adaptado de" Araujo, Hristov e Correa 2013, p. 27 
O processo lógico utilizado para a identificação da ruptura está descrito e, para melhor compreensão, os índices podem ser relacionados com a Figura 2:

a) venda igual a zero, estoque na loja maior que zero e estoque na área de vendas maior que zero: este caso não caracterizou ruptura (Figura 2, índice 1), ou seja, a ausência de venda ocorreu por outro motivo e não é pertinente para este estudo;

b) venda igual a zero, estoque na loja maior que zero e estoque na área de vendas igual a zero: este caso caracterizou ruptura com foco em loja (Figura 2, índice 2), ou seja, o estoque estava na loja, mas não estava disponível na prateleira;

c) venda igual a zero, estoque na loja igual a zero, estoque alocado para a loja maior que zero, tempo que o estoque foi alocado menor que o prazo de envio do centro de distribuição para a loja e venda realizada menor ou igual a venda planejada: este caso caracterizou uma ruptura com foco em alocação (Figura 2, índice 3);

d) venda igual a zero, estoque na loja igual a zero, estoque alocado para a loja maior que zero, tempo que o estoque foi alocado menor que o prazo de envio do centro de distribuição para a loja e venda realizada maior que a venda planejada: este caso caracterizou uma ruptura com foco no planejamento (Figura 2, índice 4), ou seja, não foi possível prever uma demanda que esgotasse o estoque em loja antes do seu abastecimento;

e) venda igual a zero, estoque na loja igual a zero, estoque alocado para a loja maior que zero, tempo que o estoque foi alocado maior que o prazo de envio do centro de distribuição para a loja e estoque alocado está parado no centro de distribuição: este caso caracterizou uma ruptura com foco no centro de distribuição (Figura 2, índice $8)$;

f) venda igual a zero, estoque na loja igual a zero, estoque alocado para a loja maior que zero, tempo que o estoque foi alocado maior que o prazo de envio do centro de distribuição para a loja e estoque alocado expedido fora do prazo: este caso caracterizou uma ruptura com foco no centro de distribuição (Figura 2, índice 8);

g) venda igual a zero, estoque na loja igual a zero, estoque alocado para a loja maior que zero, tempo que o estoque foi alocado maior que o prazo de envio do centro de distribuição para a loja e estoque alocado está em trânsito do centro de distribuição para a loja: este caso caracterizou uma ruptura com foco no transporte (Figura 2, índice 7);

h) venda igual a zero, estoque na loja igual a zero, estoque alocado para a loja igual a zero, estoque disponível para envio do centro de distribuição para a loja maior que 
zero e venda realizada maior que a venda planejada: este caso caracterizou uma ruptura com foco no planejamento (Figura 2, índice 4), ou seja, não foi possível prever uma demanda que esgotasse o estoque em loja antes do seu abastecimento;

i) venda igual a zero, estoque na loja igual a zero, estoque alocado para a loja igual a zero, estoque disponível para envio do centro de distribuição para a loja maior que zero e venda realizada menor ou igual à venda planejada: este caso caracterizou uma ruptura com foco em alocação (Figura 2, índice 3);

j) venda igual a zero, estoque na loja igual a zero, estoque alocado para a loja igual a zero, estoque disponível para envio do centro de distribuição para a loja igual a zero, existe pedido de compra emitido e o tempo da emissão do pedido é maior que o prazo de entrega do fornecedor: este caso caracterizou uma ruptura com foco no fornecimento (Figura 2, índice 5);

k) venda igual a zero, estoque na loja igual a zero, estoque alocado para a loja igual a zero, estoque disponível para envio do centro de distribuição para a loja igual a zero, existe pedido de compra emitido e o tempo da emissão do pedido é menor que o prazo de entrega do fornecedor: este caso caracterizou uma ruptura com foco em compras (Figura 2, índice 6);

1) venda igual a zero, estoque na loja igual a zero, estoque alocado para a loja igual a zero, estoque disponível para envio do centro de distribuição para a loja igual a zero e não existe pedido de compra emitido: este caso caracterizou uma ruptura com foco em compras (Figura 2, índice 6).

Foi possível identificar que, das sete causas raízes da ruptura, três delas se destacam: i) ruptura com foco em loja, que representa $38 \%$, caracterizada, na maioria dos casos, quando o estoque está na retaguarda e não disponível na área de venda; ii) ruptura com foco em alocação, que representa $23 \%$, caracterizada, na maior parte dos casos, por falta de alocação motivada por "picos" na demanda de trabalho; e iii) ruptura com foco em planejamento, que representa 17\%, caracterizada, na maior parte dos casos, por inconsistência no planejamento, totalizando aproximadamente $80 \%$ das causas. Essa conclusão converge com as publicações de Gruen, Corsten e Bharadwaj (2002), Fernie e Grant (2008), Aguiar e Sampaio (2013) e Aguiar et al. (2014), que apontam a ruptura com foco em loja como a principal causa de ruptura na área varejista. 
As causas da ruptura têm origem em práticas ineficientes nas operações de lojas, centros de distribuição e fornecedores (AGUIAR; SAMPAIO, 2014). Segundo Marqui, Alcântara e Christopher (2010), é possível separar as causas da ruptura no varejo em três grandes grupos:

a) problemas de planejamento;

b) problemas de processamento de pedido;

c) problemas de reposição.

Já de acordo com estudo mais recente, realizado por Aguiar et al. (2014), é possível segmentar na cadeia varejista as causas de ruptura em 7 grupos:

a) ruptura com foco em loja;

b) ruptura com foco em distribuição;

c) ruptura com foco em transporte;

d) ruptura com foco em alocação;

e) ruptura com foco em planejamento;

f) ruptura com foco em fornecimento;

g) ruptura com foco em compras.

Ainda de acordo com o estudo de Aguiar et al. (2014), o maior percentual dos focos de ruptura é de $38 \%$ e está concentrado na operação da loja, mostrado no Gráfico 2.

Gráfico 2 - Percentual dos focos de ruptura encontrados

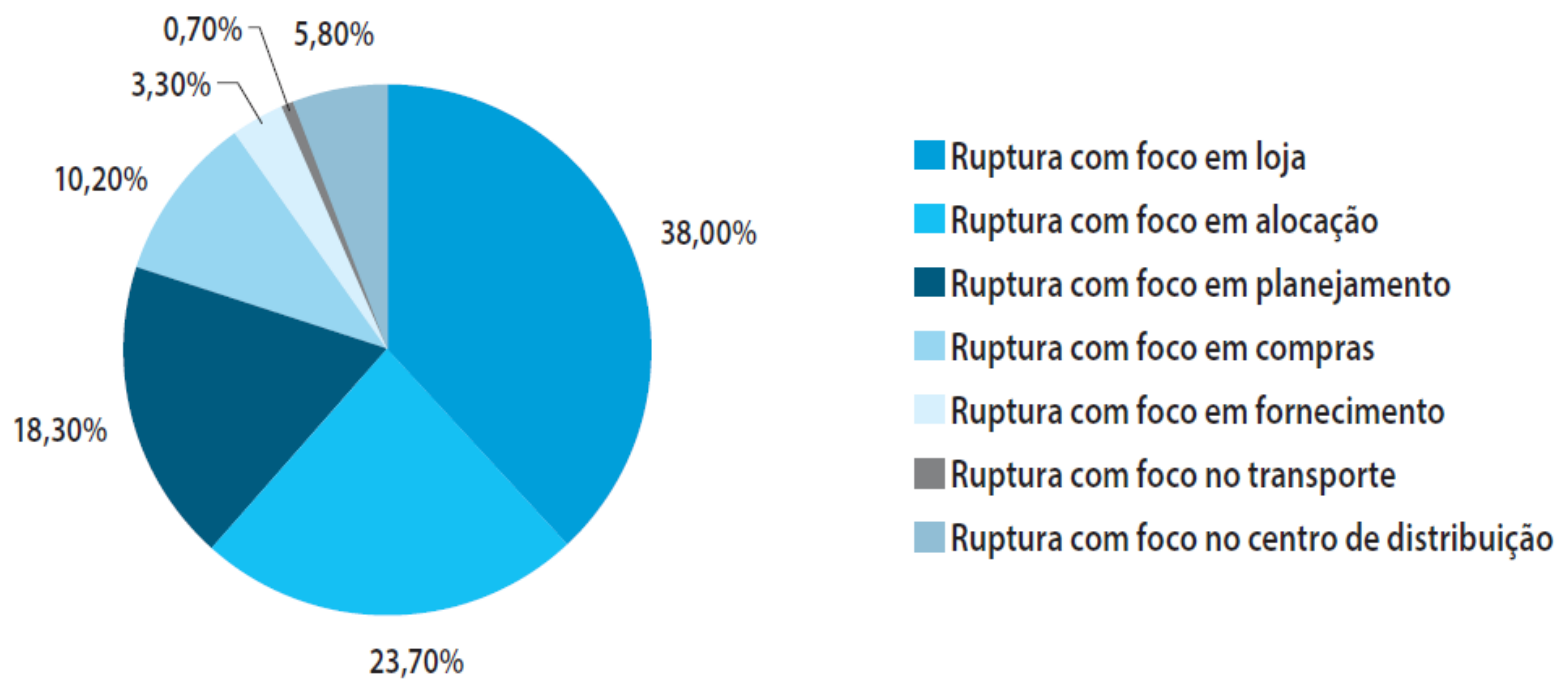

Fonte: Autor "Adaptado de" Aguiar et al. 2014, p. 31

Ambos os estudos de Marqui, Alcântara e Christopher (2010) e Aguiar et al. (2014) convergem na constatação de que o maior foco de ruptura tem foco em loja, ou seja, no 
abastecimento da retaguarda para área de vendas. Uma vez que qualquer ação corretiva pode ser tardia, difícil e custosa (FLORES; BOADA; MOSCOSO, 2014), a incompatibilidade entre demanda e oferta é muito importante no último elo da cadeia de suprimentos (abastecimento da gôndola),

Para Fernie e Grant (2008), as principais causas da ruptura estão dentro da própria loja, entre sua retaguarda e a área de venda. Essas conclusões são decorrentes das pesquisas realizadas pelos autores junto a gerentes seniores de uma rede de supermercados escocesa (FERNIE; GRANT, 2008).

O trabalho de Gruen, Corsten e Bharadwaj (2002) identificou uma taxa de ruptura estimada de 8,3\% no mundo e apontou, de maneira genérica, suas causas: previsão de demanda e pedidos $(50 \%)$, processo de reposição na área de venda $(25 \%)$ e outras causas $(25 \%)$. Esses resultados foram obtidos por meio da análise de 52 estudos realizados em todo o mundo (GRUEN; CORSTEN; BHARADWAJ, 2002).

No estudo de Aguiar e Sampaio (2014), foram investigadas e explicadas as causas da falta de estoque de um item de alta rotatividade. Os autores mostram as principais causas de rupturas e demonstram que grandes empresas possuem muitos dados, mas poucos são úteis para a tomada de decisão. Pelo método de estudo de caso, Aguiar e Sampaio (2014) investigaram o estoque de uma grande empresa varejista, com um produto que é líder de vendas no mercado brasileiro. Dessa maneira, os autores tiveram acesso a uma base de dados com informações sobre histórico de vendas, níveis de estoques diários, além de calendários de promoções que justificassem uma alta demanda. Esses dados foram utilizados para regressões múltiplas e análise de Cluster com o objetivo de identificar o índice de ruptura (AGUIAR; SAMPAIO, 2014).

De acordo com Grant e Fernie (2008), varejistas de produtos não alimentícios não são focados na disponibilidade de estoque como os varejistas de supermercados. Dessa forma, sofrem com a falta de precisão dos dados do sistema, falta de investimento em tecnologia e baixo desempenho dos fornecedores. $\mathrm{O}$ estudo contou com entrevistas qualitativas em 4 lojas diferentes nas categorias de mercadorias em geral, eletrônicos, livros e telefones celulares.

O trabalho de Aastrup e Kotzab (2009), por sua vez, concluiu que lojas com controle independente possuem maior índice de ruptura frente a lojas controladas por uma central. $\mathrm{O}$ estudo se baseou em dados de venda e estoque de dois setores de 48 lojas, em 8 cadeias de supermercados, além de entrevistas qualitativas com 17 gerentes e proprietários de loja (AASTRUP; KOTZAB, 2009). O processo chamado "Reabastecimento ou Distribuição" tem como principal objetivo otimizar dinamicamente o sortimento das lojas, em termos de produtos, 
cores e tamanhos, tentando garantir alta disponibilidade de produtos e minimizar excedentes de estoque ou falta de estoque (LANZIOTTO et al., 2015).

\subsection{COMPORTAMENTO DO CONSUMIDOR FRENTE À RUPTURA}

A experiência de compra depende de muitas variáveis, pois quando o cliente realiza uma visita em loja, existe um desejo de comprar. Mas ele pode procurar um item especifico, ou pode ter uma necessidade, ou talvez ele esteja apenas navegando, na esperança de que algum produto vá excitá-lo o suficiente para comprar (FISHER; RAMAN, 2010).

O trabalho de Marqui, Alcântara e Christopher (2010) identificou que, nos últimos cinquenta anos, há cerca de 1000 artigos relacionados ao comportamento dos consumidores.

Segundo Emmelhainz, Emmelhainz e Stock (1991), os comportamentos comumente adotados pelos consumidores diante da ruptura de estoque na área de venda são a substituição da marca, mantendo as mesmas especificações do produto (tipo e tamanho) ou a substituição das especificações, mantendo a mesma marca. O método utilizado pelos autores para chegar a essa conclusão foi a aplicação de um questionário, durante quatro dias, a 2.858 consumidores que passavam pelo ponto de venda de uma rede de supermercados.

De acordo com Campo, Gijsbrechts e Nisol (2000), varejistas podem sofrer perdas e gerar um impacto negativo ao resultado (perda de venda, perda de fidelidade do cliente) frente a uma ruptura. Ainda de acordo com o estudo, as reações dos consumidores podem ser muito adversas, num contínuo entre o aceite da falta do produto e o aborrecimento. Os autores identificaram novas variáveis sobre as reações dos consumidores frente às características dos produtos e concluíram que apenas alguns consumidores mudariam de loja para adquirir o produto faltante. O método utilizado para chegar a essas afirmações foi a aplicação de questionários sobre produtos com alto giro de estoque, como cereais matinais e margarinas, totalizando 449 para os cereais e 544 para margarina (CAMPO; GIJSBRECHTS; NISOL, 2000).

A pesquisa de Zinn e Liu (2001), por sua vez, mostrou a influência e a reação do consumidor frente à falta do produto desejado. Os resultados do estudo mostraram algumas reações esperadas, como, por exemplo, abrir mão do produto, buscar um similar de outra marca, comprar em outro estabelecimento e aguardar até que o item seja reposto. Os autores concluíram que a ruptura de estoque pode ocasionar um marketing negativo do estabelecimento, afetando seus resultados financeiros. Além disso, os resultados do trabalho demonstraram que a qualidade do produto em questão influencia na escolha de sua substituição. Na pesquisa, 
foram utilizados questionários com uma amostragem de 283 consumidores para analisar as principais variáveis das reações dos consumidores (ZINN ; LIU, 2001).

Já para Sloot, Verhoef e Franses (2005), as implicações práticas da ruptura podem ser analisadas de acordo com a reação dos consumidores em produtos que são mais caros ou mais baratos. Os autores demonstram que marcas que possuem status e, consequentemente, um valor maior de venda, não estão propensas a serem trocadas pelos consumidores. Para chegar a essa conclusão, realizaram uma pesquisa em 8 grupos de produtos em 8 redes de varejo com 450 consumidores.

Nos termos de van Woensel et al. (2007), no caso dos perecíveis, consumidores estão mais dispostos a substituir um produto não encontrado na prateleira. Essa conclusão veio por meio da análise de 3.800 entrevistas feitas com consumidores em 3 lojas de uma rede holandesa de supermercados, além de dados sobre disponibilidade e falta de um determinado item na prateleira ao longo do dia.

Os clientes podem se comportar de maneira diferente frente à ruptura de estoque: decidir comprar outro produto na mesma loja, comprar o mesmo produto em outra loja ou por meio de canais web e móveis (LANZIOTTO et al., 2015). Pesquisas sugerem que a inabilidade do varejista em atender a um pedido acarreta uma reação negativa nos consumidores com a possibilidade de queda em futuras vendas (PEINKOFER; ESPER; HOWLETT, 2016). A experiência de não encontrar o produto desejado pode afetar negativamente a percepção do cliente em relação à loja e diminuir o número de visitas futuras (ZHANG; FITZSIMONS, 1999). Também Caro e Gallien (2010) identificaram que consumidores têm reação de insatisfação no processo de compra, quando, após dedicar seu tempo na análise das características do produto desejado, não o encontram disponível na loja.

Contudo, segundo a literatura apresentada por Peinkofer, Esper e Howlett (2016), há benefícios em gerar uma sensação de futura ruptura. Isso porque existe uma prática de marketing utilizada que usa os efeitos da escassez para estimular a demanda de consumo. Em outras palavras, a noção da disponibilidade limitada de itens em estoque estimula a competição dos consumidores pelos produtos. A competição do consumidor é definida como ato de um consumidor em competir com outros consumidores para a obtenção do desejo econômico ou preço psicológico (AGGARWAL; JUN; HUH, 2011).

Muitos estudos demonstram que a compra não intencional/não planejada pode contribuir com aproximadamente sessenta por cento da cesta de consumo (MATTILA; WIRTZ, 2008). Em alguns casos, a contribuição pode aumentar até oitenta por cento (HAUSMAN, 2000; KACEN; HESS; WALKER, 2012). Esse efeito significativo do comportamento de 
impulso na compra dos consumidores é um importante fator para o negócio do varejo (BAYLEY; NANCARROW, 1998).

Applebaum (1951) explica que o comportamento da compra por impulso, como uma compra não planejada, é desencadeado por uma promoção de vendas na loja. De acordo com Stern (1962), o comportamento de compra por impulso consiste em qualquer compra que um cliente faça que não tenha sido planejada com antecedência. Pesquisadores posteriores cimentaram o conceito de compra por impulso em torno de duas dimensões básicas de compra: a "não intencional" e a "espontânea" (FISHER, 1995; ROOK, 1987). O processo da compra por impulso obstrui a consideração pensativa e deliberada de informações e escolhas alternativas. Assim, o comportamento de compra de impulso é um desejo repentino, persuasivo, de comprar instantaneamente, sem considerar as alternativas (BAYLEY; NANCARROW, 1998).

Além de articular o termo, Block e Morwitz (1999) descreveram a compra por impulso como a aquisição de um item sem qualquer planejamento ou pouquíssima deliberação, como o resultado de um poderoso impulso imprevisto de compra. O desencadeamento das compras por impulso é o resultado da manifestação de diversos fatores antecedentes que incluem o ambiente na loja, hedonismo, produto e dicas promocionais e socialização. (PRASHAR; PARSAD; VIJAY, 2015).

A tendência hedonista de um comprador é uma das significantes variáveis que antecedem e causam as compras não planejadas. Segundo psicanalistas, esse comportamento pode estar relacionado a "diversão e prazer" (INMAN; WINER; FERRARO, 2009). De acordo com Holbrook e Hirschman (1982), os principais motivos da compra são fantasias, sentimentos e diversão no local de compra. Esse comportamento de compra de impulsos é caracterizado por uma conduta de compra inesperada, emocionante e hedonicamente complexa (KHANNA; KARANDIK, 2013).

Em relação ao papel da família na compra, o estudo de Khanna e Karandikar (2013) aponta que fazer compras com familiares reduz a intensidade de desejo de comprar espontaneamente. Embora a companhia de pares possa aumentar a probabilidade de compra de impulso dos consumidores, a presença da família pode reduzi-la (HECKLER; CHILDERS; ARUNACHALAM, 1989).

Avlijas et al. (2015) identifica que a satisfação de longo prazo é um pré-requisito essencial para a construção da lealdade dos clientes a uma marca e a uma cadeia de varejo. Segundo Aguiar e Sampaio (2014), clientes fiéis a um estabelecimento têm a tendência de substituir os produtos frente à ruptura de estoque, ou seja, não deixam de comprar na loja. 
De acordo com Gruen, Corsten e Bharadwaj (2002), quando deparado com a ruptura, a principal reação do consumidor é comprar o item ou produto em outra loja, resultado que representa $32 \%$ do total das reações mapeadas. Os autores acrescentam que, no caso de uma ruptura, o consumidor pode decidir entre: substituir o produto ou não comprá-lo; adiar a compra; sair da loja e esquecer-se da compra; e procurar o produto em outra loja, o que leva à perda da venda e de receita. Os resultados do estudo dos autores é ilustrado no Gráfico 3.

Gráfico 3 - Resposta do consumidor à ruptura

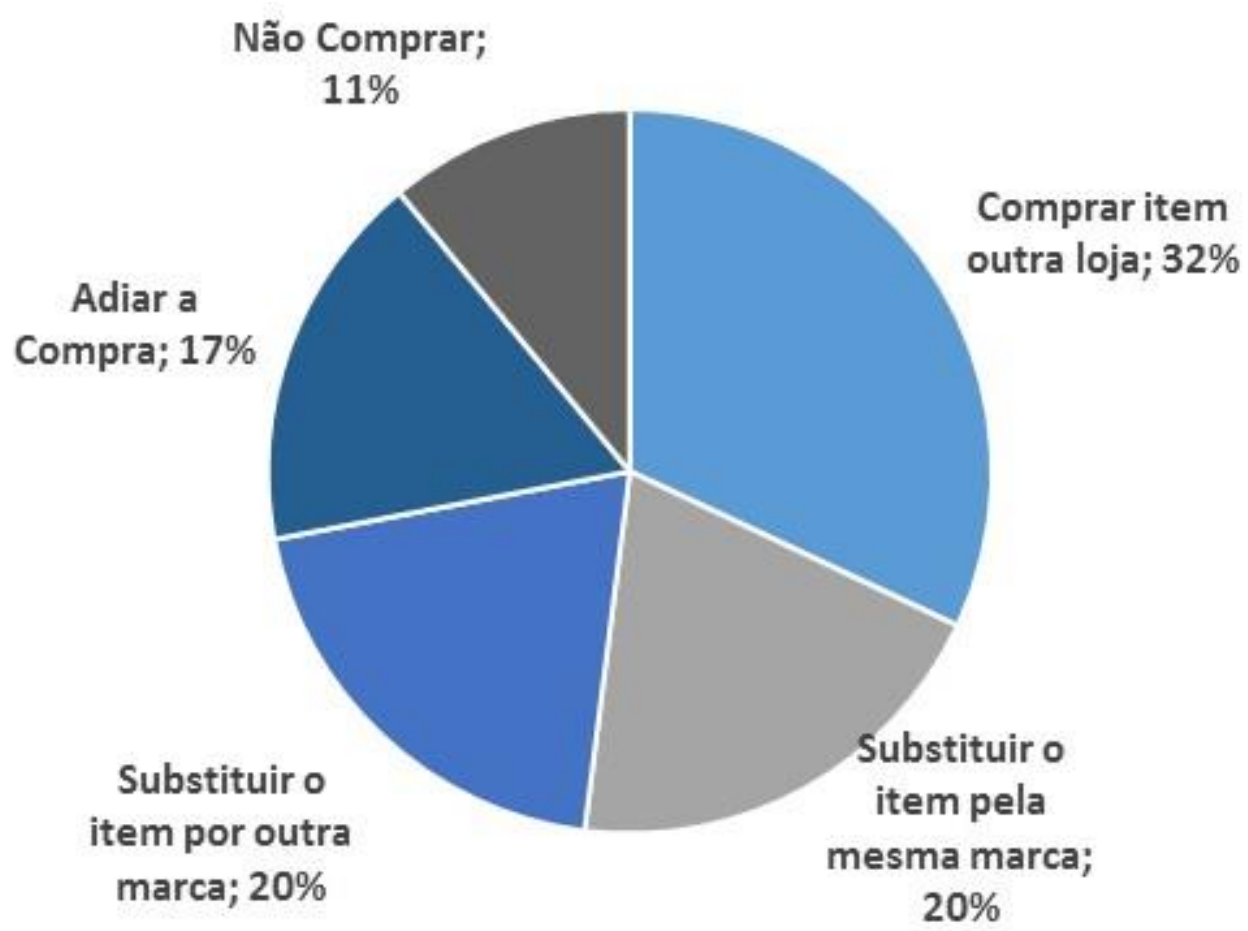

Fonte: Autor "Adaptado de" Gruen, Corsten e Bharadwaj 2002, p. 52.

Segundo Corsten e Gruen (2003), com o aumento da quantidade de lojas de varejo e outros canais de venda, a tendência de o consumidor buscar diversas opções de consumo é crescente.

\subsection{IDENTIFICAÇÃO DA RUPTURA}

Existem duas formas de analisar a ruptura de estoque. Uma delas é analisar a quantidade de SKU's indisponíveis para a venda em um determinado período (CORSTEN; GRUEN, 2003). Por exemplo, uma loja que possuí 100 SKU's ativos para sortimento de venda e apresenta indisponibilidade em 10 SKU's, teve uma taxa de ruptura de 10\% (Número de SKU's indisponíveis/Número total de SKU's ativos). 
Outra forma é a verificação do número de vezes que algum SKU ficou indisponível (USMAN, 2008). Assim, uma loja que teve um período de dez dias analisado e apresentou indisponibilidade de um determinado SKU por dois dias teve a taxa de ruptura de $20 \%$ (Número de dias que o SKU esteve indisponível/ Número total de períodos analisados). Esse estudo utilizou a segunda abordagem para identificar a ruptura.

O total de casos de ruptura analisados é dado por:

$\mathrm{Y}=(\mathrm{S} \times \mathrm{D} \times \mathrm{L})$

Sendo:

$\mathrm{Y}=$ Número total de casos analisados;

$\mathrm{S}=$ Número de SKU's analisados;

$\mathrm{D}=$ Número de dias analisados;

$\mathrm{L}=$ Número de lojas analisadas.

A taxa de ruptura é dada por:

$\mathrm{T}=\mathrm{R} / \mathrm{Y}$

Sendo,

$\mathrm{T}=$ Taxa de Ruptura;

$\mathrm{R}=$ Número de rupturas encontradas.

\subsection{NÍVEL IDEAL DE DISPONIBILIDADE}

Segundo Chopra e Meindl (2016), um importante elemento para a lucratividade de uma cadeia de suprimentos é o nível ideal de disponibilidade da mercadoria a ser ofertada aos clientes. Esse nível é mensurado pelo indicador nível de serviço de ciclo (NSC) que consiste na quantia demandada pelo cliente que é satisfeita pelo estoque disponível.

Os gestores empresariais podem facear diversos cenários no momento de escolha do melhor nível de disponibilidade. Podem, por exemplo, aumentar o nível de disponibilidade para melhorar a capacidade de responsividade, cativar o cliente e aumentar receita. Entretanto, essas ações possuem o contratempo de elevar os custos com estoques e com a cadeia de suprimentos (CHOPRA; MEINDL, 2016).

O desafio da tomada de decisão sobre o nível de disponibilidade ideal a ser adotado depende da percepção da organização sobre o nível de disponibilidade ideal que pode maximizar o lucro da sua cadeia de suprimentos (CHOPRA; MEINDL, 2016).

No caso do varejo de moda, o elevado nível de disponibilidade de um produto comercializado apenas em uma estação do ano pode satisfazer a demanda do mercado. No 
entanto, pode haver consequências de um elevado investimento e exposição ao risco de que parcela dos produtos não seja vendida no final da estação. Ainda nesse contexto, a empresa de moda pode optar por um nível baixo de disponibilidade com a consequente redução no índice de produtos não vendidos. Contudo, há exposição ao risco de não vender o produto devido ao seu esgotamento, o que pode incorrer na perda de clientes e receita. Portanto, a tomada de decisão sobre a escolha do nível ideal de disponibilidade deve buscar o equilíbrio entre a possibilidade de perda de investimento consequente de produtos não vendidos ao final da estação e a possibilidade de perda de receita decorrente da escassez de produtos para atender à demanda dos clientes durante a estação (CHOPRA; MEINDL, 2016).

$\mathrm{O}$ custo de estoque em falta $\left(C_{u}\right)$ é definido como a margem perdida por uma empresa a cada venda perdida ocasionada pela indisponibilidade do produto durante a estação de vendas. Neste caso, duas perdas devem ser consideradas: a perda da margem das vendas atuais; e a perda das margens futuras, devido a clientes insatisfeitos que não retornarão em uma futura compra (CHOPRA; MEINDL, 2016).

Já o custo do estoque em excesso $\left(C_{o}\right)$ é definido como a perda decorrente por cada produto não vendido durante a estação de vendas (CHOPRA; MEINDL, 2016).

A tomada de decisão sobre o nível ideal de disponibilidade de um produto apenas é válida quanto o fator da incerteza é considerado. Nesse cenário, a decisão da quantidade a ser comprada para revenda não deve estar atrelada a uma previsão de consenso baseada numa demanda histórica média. Essa deliberação deve ser baseada em outros tipos de abordagens, como, por exemplo, estimar a distribuição de demanda de um produto com base na demanda dos últimos anos (CHOPRA; MEINDL, 2016).

No caso dos produtos sazonais que devem ser liquidados ao final da estação, os autores fazem uma proposta para o cálculo do NSC ideal, que considera a hipótese de que os produtos restantes de uma estação anterior não podem ser utilizados para atender à demanda da estação vigente. Para um preço de revenda por unidade $(p)$, custo $(c)$ e um valor residual $(s)$, Chopra e Meindl (2016) consideram as seguintes entradas:

a) custo do estoque em excesso de um produto $\left(C_{o}\right)$

$C_{o}=\mathrm{c}-\mathrm{s}$

b) custo da falta de uma produto $\left(C_{u}\right)$

$C_{u}=\mathrm{p}-\mathrm{c}$

c) nível de serviço de ciclo ideal $\left(N S C^{*}\right)$

d) tamanho de pedido ideal correspondente $\left(O^{*}\right)$;

Os autores também realizam as seguintes observações para a elaboração da posposta: 
a) $\mathrm{NSC}^{*}$ como a probabilidade de que a demanda ao decorrer da estação esteja em $O^{*}$ ou abaixo;

b) para NSC* a contribuição marginal de um produto adicional é zero.

Caso seja aplicado um aumento na quantidade do pedido de $O^{*}$ para $O^{*}+1$, o produto adicional é vendido se a demanda for maior do que $O^{*}$. Esse cenário ocorre com a probabilidade $1-N S C^{*}$ e tem como resultado uma contribuição de $p-c$. Assim, o benefício esperado da compra de uma unidade extra é dado pela seguinte equação:

Benefício esperado da compra de uma unidade extra $=\left(1-N S C^{*}\right)(p-c)$

Se demanda estiver em $O^{*}$ ou abaixo de $O^{*}$, o produto adicional permanece sem ser vendido. Esse fato ocorre com probabilidade $N S C^{*}$, resultando em um custo de $c-s$. Assim, o custo esperado da compra de produto extra é dado pela seguinte equação:

Custo esperado da compra de produto extra $=\operatorname{NSC} *(\mathrm{c}-\mathrm{s})$

É possível determinar a contribuição marginal esperada consequente do aumento do tamanho de pedido de $O^{*}$ para $O^{*}+1$ por intermédio da seguinte equação:

$$
\left(1-\mathrm{NSC}^{*}\right)(\mathrm{p}-\mathrm{c})-\mathrm{NSC}^{*}(\mathrm{c}-\mathrm{s})
$$

Na proposta dos autores, a contribuição marginal esperada deve ser zero para o nível de serviço de ciclo ideal. Assim, tem-se a seguinte equação:

$$
\mathrm{NSC}^{*}=\operatorname{Prob}\left(\text { Demanda } \leq O^{*}\right)=\frac{(p-c)}{(p-s)}=\frac{C_{u}}{C_{u}+C_{o}}=\frac{1}{1+\left(\frac{C_{o}}{C_{u}}\right)}
$$

Nesse ponto, a quantidade do pedido ideal resultante maximiza o lucro da organização. Se no decorrer da estação a demanda (F) segue uma distribuição normal com uma média de $\mu$ e um desvio padrão de $\sigma$, a medida da quantidade de pedido ideal $\left(O^{*}\right)$ é dada por:

$$
O^{*}=F^{-1}\left(\mathrm{NSC}^{*}, \mu, \sigma\right)
$$

No caso da demanda distribuída normalmente, com média de $\mu$ e com desvio padrão de $\sigma$, pode-se determinar o lucro esperado do pedido $O$ unidades por:

Lucro esperado $=(p-s) \mu F_{S}\left(\frac{O-\mu}{\sigma}\right)-(p-s) \sigma f_{s}\left(\frac{O-\mu}{\sigma}\right)-O(c-s) F(O, \mu, \sigma)+$ $O(p-c)[1-F(O, \mu, \sigma)]$

Uma organização que realiza um pedido $O$ pode ter escassez ou excesso de estoque em função da demanda pelo produto. No cenário onde a demanda segue uma distribuição normal com um valor esperado de $\mu$ e desvio padrão $\sigma$, os valores esperados de estoque em excesso e estoque em falta podem ser definidos nas fórmulas abaixo:

a) Estoque em excesso esperado $=(O-\mu) F_{S}\left(\frac{O-\mu}{\sigma}\right)+\sigma f_{S}\left(\frac{O-\mu}{\sigma}\right)$
b) Estoque em falta esperado $=(\mu-O)\left[1-F_{S}\left(\frac{O-\mu}{\sigma}\right)\right]+\sigma f_{S}\left(\frac{O-\mu}{\sigma}\right)$ 


\subsection{RUPTURA NO VAREJO DE MODA}

Segundo Martino et al. (2016), em um ambiente de rápida mudança como a indústria varejista, o problema de alocação de estoque de um centro de distribuição para vários locais com o objetivo de atender a demandas distintas, é considerada uma das questões mais importantes, especialmente para as empresas que gerenciam uma rede estendida de lojas. Especificamente no caso da indústria de moda e vestuário, a demanda do mercado é significativamente afetada pelo nível de estoque, isto é, pela disponibilidade de produtos nas lojas (COLLADO; MARTÍNEZ-DE-ALBÉNIZ, 2014).

O varejo de moda de fato apresenta uma série de características, como, por exemplo, uma ampla variedade de produtos e clientes, um ciclo de vida do produto muito curto e uma demanda altamente imprevisível, sazonal e impulsiva, também influenciada pela disponibilidade de produtos nas prateleiras (LANZIOTTO et al., 2015).

Um dos desafios encontrados pelas organizações é como efetivamente divulgar e comunicar a disponibilidade de estoque, quando falhas no fluxo de reposição levam à ruptura (PEINKOFER; ESPER; HOWLETT, 2016).

Acadêmicos e executivos da área têm focado na disponibilidade de estoque como um modo de avaliar a eficiência de uma operação varejista (EHRENTHAL; STÖLZLE, 2013). Os processos que garantam disponibilidade de estoque, como, por exemplo, reposição de estoque, alocação, distribuição e visibilidade são importantes fatores que sinalizam uma efetiva operação varejista (PEINKOFER; ESPER; HOWLETT, 2016).

Normalmente, as empresas varejistas enfrentam dificuldades para mensurar a ruptura (AGUIAR; SAMPAIO, 2014). Aumentar a disponibilidade dos produtos leva a investimentos em tecnologias e modos de gestão que talvez não possam gerar o retorno necessário em vendas. (GRANT; FERNIE, 2008). Além do mais, empresas varejistas possuem diversos dados, mas poucos podem ser considerados como informações assertivas para a tomada de decisão gerencial (AGUIAR; SAMPAIO, 2014).

A pesquisa de Morgan e Dewhurst (2008) destaca que a importância da relação entre os agentes da cadeia varejista é essencial para a melhoria do nível de serviço de entrega e na disponibilidade de produtos nas gôndolas/área de vendas.

De acordo com Aguiar e Sampaio (2013), no atual varejo, cada vez mais competitivo e com margens decrescentes, é de grande importância que os agentes da cadeia varejista garantam que o produto certo esteja disponível na hora certa no lugar certo. Por outro lado, o número de produtos (SKU's) nas lojas é crescente, tornando a gestão de estoque ainda mais complexa. 
Em seu estudo pioneiro, Kollat e Willett (1967) levantaram a hipótese de que os estímulos na loja (de preço, apresentação do produto/item e volume de estoque) estão diretamente relacionados à compra por impulso. O efeito de fatores em lojas, como displays (estoque mínimo para ficar visualmente agradável), tanto no varejo quanto sobre o comportamento de compra por impulso tem sido amplamente abrangido por vários estudos (DHOLAKIA, 2000; MATTILA; WIRTZ, 2008; HULTÉN; VANYUSHYN, 2011; WU et al., 2013). Um conjunto igualmente vasto de estudos postulou que os estímulos atmosféricos da loja são elementos vitais que despertam o desejo dos consumidores de comprar espontaneamente (ROOK; FISHER, 1995). Essas variáveis de loja criam um efeito positivo em seus desejos hedônicos que leva à compra impulsivamente. Wu et al. (2013) acrescentou a dimensão do ambiente, afirmando que o calor e a frieza de tons/cores nas lojas de varejo de moda podem gerar um efeito arco-íris, criando prazer para os compradores e resultando em compras impulsivas.

O impacto direto das ferramentas de promoção/merchandising no comportamento impulsivo dos compradores também tem sido investigado por vários pesquisadores (HULTÉN; VANYUSHYN, 2011). Os autores observam que essas ferramentas agregam valor positivo ao ambiente na loja, fator fundamental na criação do desejo de compra. Hultén e Vanyushyn (2011) acrescentam que diversas ferramentas podem levar a melhorias do tempo gasto na loja. O impacto do tempo gasto na loja em compras impulsivas tem sido posicionado positivamente (GRANBOIS, 1968; BEATTY; FERRELL, 1998; DITTMAR; DRURY, 2000). Esses estudos identificam uma correlação direta entre o tempo gasto na loja e a tendência de compra impulsiva dos compradores. Park, Iyer e Smith (1989) demonstram que maiores índices de compra impulsiva podem ocorrer no caso de lojas desconhecidas e com ausência de pressão de tempo sobre os compradores.

O trabalho de Prashar, Parsad e Vijay (2015) confirma os resultados dos estudos de Areni e Kim (1994) e Wu et al. (2013) de que o ambiente de varejo afeta as compras dos clientes, uma vez que os ajuda a fazer vendas adicionais facilmente, a custos mais baixos. Atingir uma boa imagem de marca por meio de uma gestão eficaz das variáveis do ambiente da loja no varejo encorajaria vendas não planejadas, comportamento de compra mais frequentes, visitas dos clientes e maior ticket por visita, e durante o período contribuiria para o desenvolvimento de lealdade (PRASHAR; PARSAD; VIJAY, 2015).

Os varejistas recentemente enfrentam novos desafios, como, por exemplo, o espaço reduzido nas prateleiras devido ao aumento da competição e proliferação de produtos (AVLIJAS et al., 2015). 
O foco na execução em nível de loja pode aumentar as vendas por meio de melhorias na disponibilidade dos produtos, de uma vasta gama de opções de produtos e da exasperação do deleite do cliente (FISHER; RAMAN, 2010).

\subsection{SIMULAÇÃO}

Embora não possa responder a todos os desafios enfrentados pelo dinâmico segmento varejista, a tecnologia pode prover ferramentas de suporte à tomada de decisão e contribuir para a melhoria da eficiência do segmento. (AVLIJAS et al., 2015).

O estudo de Choi e Kang (2013) define a simulação como a técnica de imitar um comportamento ou uma situação real por intermédio de um comportamento ou situação análoga com o foco de obter informações. Ainda de acordo com os autores, a coleta de dados é relacionada ao termo simulação analítica que tem como objetivo principal analisar quantitativamente o sistema de origem com base em dados "exatos" e de maneira eficaz gerar um cenário capaz de reproduzir com precisão a sequência de eventos do sistema de origem (real). Já Chwif e Medina (2015) definem simulação como a representação de um sistema, que pode ser real ou não, e que simula as interações que podem ocorrer no sistema. Miguel (2010) e Pidd (2004) definem a simulação como uma técnica experimental, executada em um sistema computacional, para analisar interações de todo um sistema real sem movimentar nada no ambiente real. Na perspectiva de Bateman et al. (2013), simulação é a experimentação de um sistema real por meio de modelos. Os autores acrescentam que a possibilidade de criar e simular um fenômeno desejado permite conferir quão representativas seriam as mudanças, dessa forma, contribuindo para a tomada de decisões.

O estudo de Manuj, Mentzer e Bowers (2009) explica que a experimentação de simulação baseada em computador tem diversas particularidades a serem consideradas. Por exemplo, para alguns processos, é muito caro ou impossível obter observações do mundo real, pois as perturbações organizacionais podem não permitir revisões extensivas dos sistemas. Como a experimentação "real" de sistemas logísticos e de cadeia de abastecimento é extremamente difícil, e eventualmente muito custosa, os projetos experimentais usando modelos de simulação computacional se tornam uma alternativa atraente para entender o comportamento do sistema e os efeitos dessas mudanças podem ser observados com facilidade.

Segundo Chwif e Medina (2015), os modelos de simulação podem ser classificados em três categorias básicas: simulação de monte carlo, simulação contínua e simulação de eventos discretos. A simulação de monte carlo utiliza-se de geradores de números aleatórios para 
simular sistemas físicos ou matemáticos, nos quais não se considera o tempo explicitamente como uma variável. Esse tipo de simulação é útil para solução de problemas complexos que surgem no cálculo integral. Já as simulações contínua e de eventos discretos levam em consideração as mudanças de estado do sistema ao longo do tempo; a simulação contínua é utilizada para modelar sistemas cujo estado varia continuamente no tempo.

A simulação de eventos discretos baseada em computador tem sido uma ferramenta para a análise de sistemas de logística e cadeias de abastecimento, pois as incertezas e as variações resultantes nesses sistemas são considerações significativas. Portanto, a capacidade de simulação para incluir as situações estocásticas torna a simulação uma poderosa ferramenta de pesquisa e de tomada de decisão (LEE et al., 2002; LONGO; MIRABELLI, 2008). A simulação de eventos discretos baseada em computador pode aprimorar a compreensão dos sistemas de logística e das cadeias de abastecimento, oferecendo a flexibilidade para entender o comportamento do sistema quando os parâmetros e políticas de custos são alterados (ROSENFIELD et al., 1985) e permite a compactação de tempo (CHANG; MAKATSORIS, 2001). A simulação também facilita o exame de processos ou sistemas dinâmicos ao longo do tempo, permitindo a compressão do tempo real. Como execuções de simulação representando anos podem ser realizadas em questão de horas, podem ser extraídas inferências sobre o comportamento do sistema durante um período de tempo, possibilitando tomar decisões oportunas (CHANG; MAKATSORIS, 2001).

Segundo Chwif e Medina (2015), simulação de eventos discretos é o tipo de modelagem utilizada como uma ferramenta para o alcance de respostas a sentenças do tipo "O que ocorre se", como, por exemplo:

a) o que ocorre se aumentar o estoque inicial em $30 \%$ ?;

b) o que ocorre se reduzir o estoque inicial em $30 \%$ ?

Ainda segundo Chwif e Medina (2015), a lista de alternativas para esse tipo de pergunta pode ser infinita, o que leva à conclusão de que um modelo de simulação pode ser capaz de analisar diversos aspectos do sistema.

A pesquisa de Ross (2013) aponta que, dependendo dos motivos para o desenvolvimento de uma simulação, a observação do fluxo resultante do modelo ao longo do tempo exige que quantidades de interesse sejam estabelecidas. No entanto, como a evolução do modelo ao longo do tempo frequentemente envolve uma complexa estrutura lógica de seus elementos, nem sempre é aparente como acompanhar essa evolução para determinar essas quantidades de interesse. Para fazer a simulação de eventos discretos, é necessário acompanhar certas variáveis. 
Em geral, há três tipos de variáveis frequentemente utilizadas, expostas no Quadro 2 (ROSS, 2013).

Quadro 2 - Tipos de variáveis

\begin{tabular}{|c|l|l|}
\hline Índice & \multicolumn{1}{|c|}{ Variaveis } & \multicolumn{1}{c|}{ Descrição } \\
\hline 1 & Variáveis de tempo $t$ & Refere-se à quantidade de tempo (simulado) decorrido \\
\hline 2 & Variáveis de contador & $\begin{array}{l}\text { Estas variáveis mantêm uma contagem do número de vezes que } \\
\text { determinados eventos ocorreram no tempo } t\end{array}$ \\
\hline 3 & Variáveis de estado do sistema & Descreve o " Estado do sistema" no tempo $t$ \\
\hline Fonte: Autor "adaptado de" Ross, 2013, p. 303
\end{tabular}

\subsubsection{Etapas para o desenvolvimento e aplicação de um modelo de simulação}

A revisão de literatura realizada por Manuj, Mentzer e Bowers (2009) revela que a pesquisa pautada em revistas de logística e cadeia de suprimentos não aborda e/ou relata satisfatoriamente os esforços feitos para manter o rigor dos estudos de simulação. Os autores acrescentam que, embora os estudos sejam executados rigorosamente, faltam descrições detalhadas dos critérios utilizados e dos processos seguidos na concepção de modelos de simulação. Esse cenário limita a compreensão da aplicabilidade de um estudo de pesquisa, levanta questões sobre a credibilidade e torna difícil a replicação e a generalização dos resultados. Desse modo, é preciso melhorar a qualidade geral das publicações acerca da pesquisa de simulação na logística e na cadeia de suprimentos (MANUJ; MENTZER; BOWERS, 2009). Para solucionar essa lacuna, Manuj, Mentzer e Bowers (2009) elaboraram uma extensa revisão da literatura no intuito de identificar os estudos sobre logística e cadeia de suprimentos que empregam a simulação de eventos discretos. Os autores elaboraram um processo de oito passos, denominado processo de desenvolvimento de modelos de simulação (Figura 3). Assim, buscou-se garantir uma implementação de qualidade, contemplando uma avaliação do modelo de simulação e identificando critérios de rigor para cada etapa. 
Figura 3 - Processo de desenvolvimento de modelos de simulação

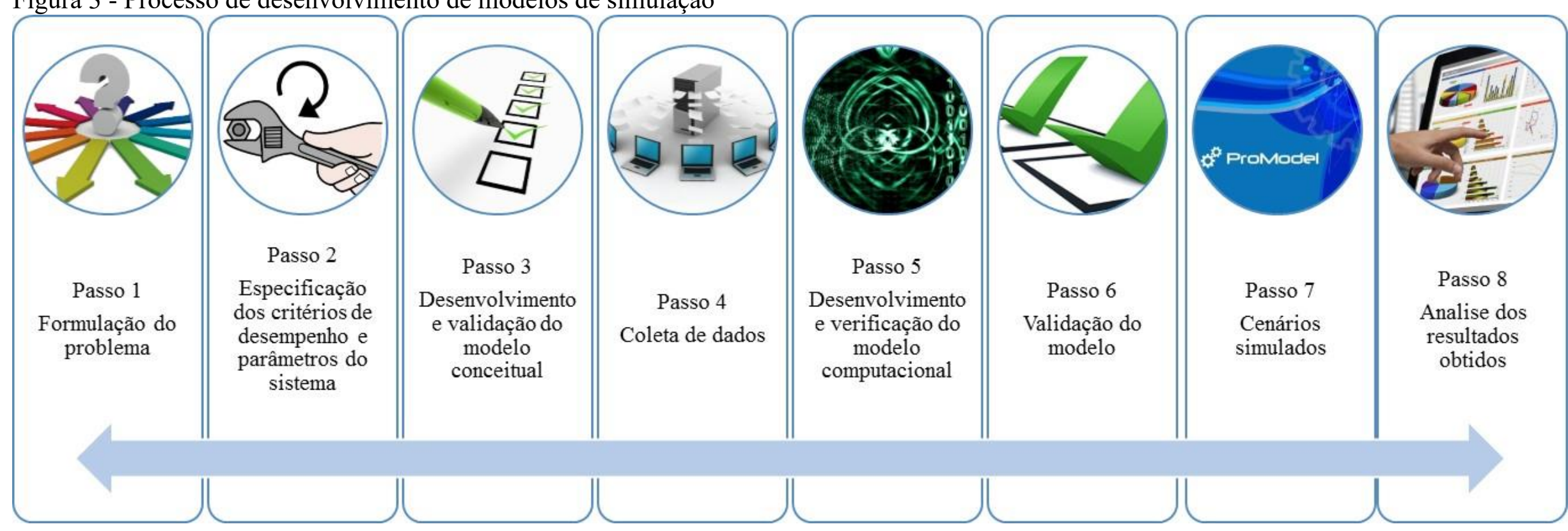

Fonte: Autor "Adaptado de" Manuj, Mentzer e Bowers (2009), p. 176 
Os tópicos seguintes, 2.7.1.1 a 2.7.1.8, são descritos com base na revisão bibliográfica realizada por Manuj, Mentzer e Bowers (2009).

\subsubsection{Formulação do problema - passo 1}

O objetivo da formulação do problema é definir objetivos globais e perguntas a serem respondidas com o modelo de simulação. A falta de atenção para esse passo é uma das principais causas de falha dos modelos em funcionar satisfatoriamente. O propósito ambíguo pode resultar em análises incorretas, perda de tempo, decisões ruins ou ineficazes, além de inferências incorretas. O problema não pode inicialmente ser indicado precisamente ou em termos quantitativos. Assim, muitas vezes um processo iterativo é necessário para facilitar a formulação do problema. Nesse contexto, é uma boa prática envolver os indivíduos que lidam com o problema para garantir que ele seja abordado de forma correta e relevante. Quando o problema é claramente definido, as medidas de desempenho de interesse, o escopo do modelo, o período de tempo e os recursos necessários podem ser especificados com precisão e de forma mais eficiente.

\subsubsection{Especificação dos critérios de desempenho e parâmetros do sistema-passo 2}

As variáveis dependentes refletem os critérios de desempenho e as variáveis independentes incluem os parâmetros do sistema. Em um modelo de simulação, são manipuladas variáveis independentes e seu efeito sobre variáveis dependentes é registrado e analisado. As análises de valores de variáveis dependentes fornecem respostas ao problema formulado no passo 1. O resultado de um modelo depende do que está incluído nele. Portanto, o objetivo da pesquisa e as questões específicas a serem respondidas, utilizando o modelo de simulação, orientam a seleção de variáveis independentes e dependentes. Dependendo do problema, os fatores que influenciam as respostas buscadas devem ser fatores técnicos, jurídicos, gerenciais, econômicos, psicológicos, organizacionais, monetários e históricos. As variáveis do modelo devem corresponder às representadas no sistema real.

\subsubsection{Desenvolvimento e validação do modelo conceitual - passo 3}

Um modelo conceitual é uma abstração do sistema do mundo real sob investigação, fazendo uso de relações matemáticas e lógicas relativas aos componentes e à estrutura do 
sistema. Declarações explícitas de suposições e descrições detalhadas das relações incluídas no modelo conceitual asseguram que o modelo se desenvolva de acordo com a declaração do problema. A validade do resultado de um sistema depende do que está incluído em sua descrição. Portanto, é importante construir um modelo conceitual que possa ser verificado antes de investir recursos no desenvolvimento de um modelo computacional.

Essa etapa assegura os objetivos, pois as medidas de desempenho, os componentes do modelo e as relações entre componentes, conceitos, suposições, algoritmos, resumos de dados e outros aspectos do modelo de interesse são corretas e suficientemente pormenorizadas. Além disso, essa etapa garante que a representação da entidade problema seja "razoável" para o propósito pretendido do modelo. Realizar e documentar a validação conceitual no início do processo de desenvolvimento do modelo e descrever a estrutura do problema e o modelo acompanhante, em linguagem clara e simples, aumenta a credibilidade dos pesquisadores e praticantes do modelo.

\subsubsection{Coleta de dados - passo 4}

A coleta de dados pode ser um desafio, já que os dados podem não estar prontamente disponíveis nos formatos requeridos ou em um nível de detalhe apropriado. A coleta de dados pode seguir ou prosseguir simultaneamente com o desenvolvimento do modelo conceitual. Os requisitos de dados devem primeiro ser estabelecidos para especificar parâmetros do modelo, layout do sistema, procedimentos operacionais e distribuições de probabilidade de variáveis de interesse. Os dados incluem bases de dados da empresa, entrevistas, pesquisas, livros e/ou outras fontes publicadas. Os dados também podem ser gerados com o uso de computadores, se os dados reais puderem ser razoavelmente aproximados por distribuições normalmente usadas como normal, poisson, exponencial ou várias outras. Antes da incorporação ao modelo, os dados podem precisar ser digitalizados, limpos e atualizados para atender a discrepâncias e /ou a dados ausentes.

\subsubsection{Desenvolvimento e verificação do modelo computacional - passo 5}

A modelagem deve começar de maneira simples e a complexidade deve ser adicionada gradualmente em etapas até que um modelo com detalhes e complexidade aceitáveis tenha sido desenvolvido. A verificação e a determinação da implementação no computador do modelo conceitual são processos contínuos e assertivamente implementados quando realizados 
simultaneamente com o desenvolvimento do modelo. A verificação inclui examinar as saídas de submodelos e o modelo de simulação completo no intuito de garantir que seja executado com comportamento aceitável, depurando quaisquer erros na lógica de programação e código. Dois importantes benefícios relacionados à verificação podem ser destacados: a identificação de comportamentos indesejados do sistema e a determinação de uma subestrutura de simulação analítica ou simples que pode ser substituída por uma complexa.

Embora haja várias linguagens de programação e pacotes de software para simular sistemas logísticos e de cadeia de suprimentos, a literatura não destaca evidências sobre a preferência de um pacote de software específico que claramente supere os outros.

A verificação do modelo pode ser abordada de quatro maneiras. Em primeiro lugar, o código deve ser verificado por pelo menos uma pessoa diferente daquela que codificou o modelo. Em segundo lugar, a saída de partes do modelo pode ser comparada com soluções calculadas manualmente para determinar o comportamento aceitável. Ao executar o modelo usando uma variedade de valores de entrada, os resultados podem ser averiguados com o objetivo de verificar valores de saída razoáveis, esperados ou conhecidos. Terceiro, os resultados de simulação para piloto de corridas curtas e casos simples para o modelo completo podem ser comparados com cálculos manuais no intuito de verificar se o modelo inteiro (estrutura) se comporta de forma aceitável. Em quarto lugar, os eventos podem ser verificados manualmente por meio de cada modelo de segmento: primeiramente com corridas determinísticas simples, seguidas de distribuições de probabilidade simples, e finalizando por cheques estocásticos com integração crescente de atividades. Também contribuem para o processo de verificação o desenvolvimento de fluxogramas detalhados e a elaboração do modelo como auto documentação, bem como a animação computacional.

\subsubsection{Validação do modelo - passo 6}

A validação do modelo é o processo para determinar se o modelo desenvolvido reflete o sistema sob investigação. Um modelo válido pode ser usado para tomar decisões semelhantes às que seriam feitas, se fosse viável e rentável experimentar com o próprio sistema real. $\mathrm{Ou}$ seja, contribui para a prevenção de conclusões e decisões erradas.

A questão da validação do modelo de simulação pode ser abordada de várias maneiras, muitas das quais são semelhantes às utilizadas para validar o modelo conceitual (Passo 3). Em primeiro lugar, acadêmicos e profissionais podem ser consultados no desenvolvimento conceitual de componentes do modelo e das relações entre os componentes para assegurar que 
o problema correto seja resolvido e a realidade seja adequadamente modelada. Em segundo lugar, pode ser conduzida uma abordagem estruturada do modelo de simulação e uma revisão dos resultados da simulação quanto à razoabilidade. Se os resultados forem consistentes com o modo como percebem que o sistema deve operar, o modelo é dito ter validade de face. A validade facial pode ser ainda confirmada por meio da revisão da literatura de modelos de simulação em pesquisas anteriores, comparando-se os resultados com os conhecimentos e achados existentes.

Se possível, a saída de simulação computadorizada deve ser comparada com os dados de saída do próprio sistema para a validação dos elementos de entrada e saída. Uma técnica estatística utilizada para analisar séries temporais reais ou simuladas é a análise espectral que produz magnitudes de desvios em relação aos níveis médios de uma dada atividade e ao período ou comprimento desses desvios.

Embora a validação seja desejável, nem sempre é possível. Assim, cada pesquisador tem a responsabilidade de entender e atribuir a importância dos seus resultados. Quando não há experiência disponível para comparação, um pesquisador deve prosseguir em etapas: primeiramente, deve implementar resultados com base em modelos simples bem compreendidos e, em seguida, utilizar os resultados dessa implementação para projetar modelos mais sofisticados que produzem resultados mais fortes. Apenas por meio de um desenvolvimento gradual completo, uma simulação pode fazer qualquer alegação aproximada da realidade.

Finalmente, as análises de sensibilidade podem ser realizadas no modelo programado a fim de identificar os fatores do modelo que têm maior impacto nas medidas de desempenho, testar a estabilidade do modelo e verificar a sensibilidade da análise às mudanças nos pressupostos. A análise de sensibilidade sistemática facilita o reconhecimento explícito de importantes pressupostos, melhora a compreensão do problema por quem toma a decisão e é uma maneira útil de identificar e eliminar erros lógicos e metodológicos.

\subsubsection{Cenários simulados - passo 7}

Para cada configuração do sistema de interesse, as decisões devem ser tomadas sobre o número de repetições de modelo (tamanho da amostra), duração da execução e período de aquecimento. Do conjunto de amostras, três em cada dez estudos não especificam o tamanho da amostra e apenas dois elaboram o procedimento utilizado para determinar a abrangência da amostra. Na simulação, os benefícios do aumento do tamanho da amostra podem ser obtidos de 
três maneiras: aumentando o número de repetições (simulações) para cada condição experimental; reduzindo a unidade de tempo com o objetivo de proporcionar mais subintervalos para o mesmo período de execução; e ampliando o tempo da simulação para aumentar o número de subintervalos. Para fazer simulações adicionais, cada uma dessas práticas deve ser ponderada em relação ao custo em tempo e dinheiro.

O poder de um teste estatístico para detectar um efeito aumenta com o número de repetições. Aumentar o número de execuções reduz o desvio padrão da distribuição de amostragem, resultando em um aumento na precisão absoluta da estimativa da população de interesse.

Uma alternativa para aumentar a precisão absoluta é permitir que o número de repetições seja guiado por um grau de precisão prático. Ou seja, um grau de precisão razoável, dada a magnitude da média populacional que está sendo estimada. Uma discussão detalhada do método de precisão relativa pode afirmar que as conclusões extraídas dos resultados são mais significativas tanto em termos de objetivos de pesquisa quanto de soluções de problemas práticos. No entanto, essa técnica é apropriada para sucessivas replicações independentes de execuções de simulação. Ela não é apropriada para a determinação da precisão relativa obtida em subintervalos de uma única corrida de simulação ou em desenhos experimentais que utilizam técnicas de redução da variância.

\subsubsection{Análise dos resultados obtidos - passo 8}

Os estudos da amostra podem empregar várias técnicas de análise, tais como inspeção visual de saídas gráficas, limites médios, inferior e superior, desvio padrão e percentuais de variáveis dependentes, bem como análise de variância e diferentes métodos de comparações múltiplas. Modeladores, revisores e especialistas devem estar cientes de pressupostos adotados que podem afetar a adequação de uma determinada técnica estatística para uma dada situação. Como as escolhas das técnicas de análise variam consideravelmente, dependendo da distribuição de variáveis de entrada e de saída, o pesquisador deve explicar a escolha realizada.

\subsubsection{ProModel}

Harrell e Price (2003) expõem que a ferramenta de simulação para o suporte a decisão, especificamente o software ®ProModel, é projetado para modelar sistemas de produção, sistemas flexíveis de manufatura e de cadeia de suprimento. Lu e Wong (2005) descreveram o 
®ProModel como uma ferramenta de simulação poderosa e fácil de usar para modelar todos os tipos de sistemas e processos. Shannon (1998) enfatiza que a simulação é uma das ferramentas mais poderosas utilizadas para tomada de decisões em projetos e operações de sistemas e processos complexos.

Nesse cenário, a simulação computacional poderá dar o suporte necessário à tomada de decisão do trade-off entre investimento em estoque e perda de venda por falta de estoque (ruptura de estoque).

Entre os softwares de simulação encontrados no mercado, o escolhido para o desenvolvimento deste estudo é o software comercial ${ }^{\circledR}$ ProModel. O pacote do software inclui três softwares principais, sendo o $®$ ProModel (para simulação de eventos discretos), SimRunner (para otimização de modelos matemáticos) e StatFit (para estudos de distribuição de probabilidade).

De acordo com Bateman et al. (2013), bons resultados não dependem apenas dos dados de entrada, mas também de um software que processe bem as informações, tornando-as factíveis para o sistema. O ${ }^{\circledR}$ ProModel, além de possuir uma interface amigável e ser de fácil utilização, encaixa-se em todos esses requisitos.

$\mathrm{O}$ ®ProModel é um software que oferece a conveniência de um ambiente de simulação direcionado por menus que não necessitam de uma programação complexa. Dessa forma, traz flexibilidade para as linguagens de modelagem, permitindo que sistemas relativamente complexos possam ser modelados rapidamente. Além disso, o ${ }^{\circledR}$ ProModel tem uma lógica familiar à maioria dos engenheiros e gerentes de produção, pois a facilidade para a compreensão torna o software popular nas salas de aula em cursos onde a simulação é uma das técnicas de pesquisa ensinadas (BATEMAN et al., 2013).

Ainda de acordo com Bateman et al. (2013), embora direcionado para sistemas de manufatura, a flexibilidade do $®$ ProModel também levou à sua adoção em outros segmentos, como, por exemplo, no sistema de saúde e em outras empresas de serviço.

A programação do modelo é simples e interativa. Sua sequência de programação obedece à definiçãa e à programação de um conjunto de seis etapas descritas a seguir, conforme o trabalho de Bateman et al. (2013).

A primeira etapa é a definição dos locais que são pontos fixos onde as entidades podem ser movimentadas e localizadas. Esses pontos podem estar em qualquer lugar onde uma entidade é processada. Eles também podem ser áreas para enfileiramento, locais de armazenamento ou esteiras. Uma fresa ou um torno poderiam ser definidos como locais em um modelo orientado para a produção e uma mesa de operação em um centro cirúrgico poderia ser 
um local num estudo de um hospital. A capacidade, definida como quantidade de entidades que podem estar presentes em um local ao mesmo tempo, deve ser especificada. A quantidade de locais similares, ou unidades, também podem ser definidas de acordo com a necessidade. $\mathrm{O}$ tempo de parada deve ser especificado para cada local, de acordo com a quantidade de ciclos de operação efetuados ou por períodos de tempo, tempo de uso ou setup necessário. A regra de enfileiramento a ser empregada também deve ser especificada. O acompanhamento estatístico das atividades em cada local pode ser especificado ou omitido. As figuras usadas para representar os locais podem ser aumentadas ou diminuídas e posicionadas na tela de layout. Elas também podem ser editadas para mostrar informações adicionais, tais como o nome do local, contadores e medidores de nível. Filas e esteiras podem também ser definidas com seus comprimentos, velocidades e outras características.

A segunda etapa é destinada à definição das entidades, que são os itens processados por meio do sistema. As entidades podem representar peças, pessoas, documentos de trabalho ou tudo mais que requeira recursos do sistema. Cada entidade pode possuir diversos ícones gráficos para representá-la em diferentes estágios de processamento ou em vários pontos do sistema. Se uma entidade é autotransportável ou vai ser tratada como tal no modelo, a velocidade de movimentação deve ser também definida. Embora a modelagem de clientes, pacientes ou outras entidades humanas seja a utilização mais comum dessa ferramenta, as peças em um ambiente de manufatura podem também ser modeladas como entidades autotransportáveis em alguns casos. Os níveis de saída estatística dos relatórios para cada tipo de entidade podem também ser selecionados neste módulo.

A terceira etapa é a definição da lógica de processamento que define as operações efetuadas e o roteamento de cada tipo de entidade em cada local no sistema. O processamento é definido para cada tipo de entidade em cada local onde recebe alguma ação ou simplesmente aguarda o acesso a um local subsequente. As sentenças de operação podem considerar os tempos, incluindo as distribuições de tempo, e qualquer quantidade de passos lógicos, tais como juntar peças ou capturar recursos. As informações de roteamento indicarão normalmente o nome da entidade quando esta deixa determinado local e o local de destino ao qual a entidade se dirigirá. Pode-se definir também uma lógica que irá escolher qual será o próximo local. Os tempos e os recursos necessários para a movimentação entre dois locais, assim como outra lógica relacionada com o movimento, também podem ser incluídos.

$\mathrm{Na}$ quarta etapa, a introdução de entidades no sistema é especificada em chegadas. Uma chegada num local é especificada como sendo a quantidade ou o tamanho do lote para cada tipo de entidade. A quantidade de chegadas programadas deve ser definida, mas ela pode ser infinita 
(isto é, as chegadas continuam à medida que o modelo roda). O tempo entre as chegadas é especificado como inverso da frequência. Tanto o intervalo de tempo entre chegadas como a quantidade de chegadas podem ser definidos por uma distribuição de probabilidade. Chegadas cíclicas, tais como a variação na quantidade de clientes que entram num banco em cada período do dia, podem ser definidas utilizando um ciclo de chegadas. Sentenças lógicas podem ser também disparadas por chegadas. As chegadas podem ser habilitadas ou desabilitadas conforme a necessidade, com o objetivo de testar combinações de programações. Outra prática comum na avaliação de programações é ler as chegadas diretamente em uma planilha externa.

A quinta etapa contempla a definição dos recursos que, no ${ }^{\circledR}$ ProModel, podem ser representados por diversos elementos. Por exemplo, uma pessoa ou um equipamento ou um transportador necessário para efetuar uma ação, não é um local, como descrito anteriormente. Em muitos casos, um recurso será compartilhado por vários locais e deverá se mover por uma rede de caminho predeterminada. Em outros casos, um recurso poderá ser estático. Cada recurso deve ser único ou fazer parte de um grupo de recursos similares. O tempo de parada pode ser atribuído a recursos baseados no tempo ou no uso. Níveis variáveis de acompanhamento estatístico podem ser aplicados às atividades. Ícones gráficos diferenciados podem ser especificados para representar os recursos assim que estes mudam de estado. Por exemplo, quando um recurso passar de ocupado para ocioso, ou quando se mover em direções diferentes. O submódulo especificações permite que sejam definidos: velocidade de movimentação, tempo para pegar as entidades e detalhes de percurso.

Os caminhos de local a local são definidos na sexta etapa como redes de caminho. Entidades autotransportáveis, tais como pacientes de hospital, podem seguir esses caminhos por si próprios, se especificado no processo. Recursos que devem se mover entre locais também seguem em caminhos designados neste módulo, carregando ou transportando entidades. Várias entidades ou recursos podem compartilhar uma mesma rede. $\mathrm{O}$ transporte pode ser definido em termos de tempo ou pela inclusão de parâmetros de velocidade e distância. Os caminhos devem permitir que os recursos ultrapassem uns aos outros ou se mantenham em filas. Redes de caminho especiais são utilizadas para definir operações de graus e pontes rolantes. 


\section{DESENVOLVIMENTO}

O modelo foi desenvolvido tendo como referência os oito passos sugeridos pela pesquisa de Manuj, Mentzer e Bowers (2009).

\subsection{FORMULAÇÃO DO PROBLEMA - PASSO 1}

A unidade de análise é uma empresa nacional do varejo têxtil que possui mais de 100 lojas espalhadas pelo território brasileiro, além de centros de distribuição próprios. O sortimento consiste em mais de 10.000 SKU's ativos.

De acordo com a revisão da literatura, há um problema critico que é a política de reposição adequada que previna a falta de estoque e seu excesso. A falta de estoque, também chamada de ruptura, pode gerar ausência de receita, ou seja, não é possível vender um item/produto se ele não está disponível para venda. No caso do excesso de estoque, o problema é oposto: embora exista uma alta disponibilidade de item/produto, a venda é muito inferior a esse investimento de estoque. Sendo assim, é um investimento sem retorno de receita.

De acordo com entrevistas feitas com gerentes sêniores da empresa estudada, há uma dinâmica organizacional para a disponibilização de sortimento e profundidade nas lojas que é realizada em cinco etapas. A primeira etapa é o plano financeiro, que determina o potencial de venda para a estação e o volume de investimento/compra necessário por categoria de produtos. A segunda etapa é o planograma, que verifica a quantidade de peças que cabe na área de vendas ou gôndola. A terceira etapa é o plano de sortimento, que especifica o volume e a profundidade de sortimento a ser comprado e posteriormente enviado à loja. A quarta etapa é o plano de alocação de produtos novos (PN), que, baseado no plano de sortimento, estabelece um painel de alocação de PN com quantidade de sortimento e profundidade por loja. A quinta etapa é o plano de reposição do centro de distribuição para loja, que tem como propósito garantir, por meio da reposição, a disponibilidade do sortimento planejado na loja até o final da estação.

No contexto da loja, a reposição de produtos já vendidos ou produtos de reposição (PR) da retaguarda para área de vendas é realizada diariamente no período da manhã, devido ao menor fluxo de clientes. Um equipamento chamado coletor é utilizado por um repositor (colaborador) para conferir todo o estoque da retaguarda e apontar se existiu venda sem reposição. O coletor dispõe de um software que relaciona dados de venda e estoque para realizar os apontamentos de necessidade de reposição. Durante a conferência, é sinalizado no coletor os 
produtos que devem ser separados pelo repositor e, na sequência, movimentados até a área de vendas.

Existe uma política ou orientação corporativa que sugere que a área de vendas seja coberta ou preenchida com o máximo sortimento possível. Caso o estoque disponível não seja suficiente para cobrir toda a área de vendas, estamos diante da problemática abordada neste estudo. De modo geral, a solução desse problema reside em aumentar a profundidade de cada sortimento para que a área de vendas seja coberta. No entanto, deparamo-nos com alguns pontos ou questões a serem respondidas. Aumentando a profundidade do mesmo produto aumenta a chance de venda? Caso o estoque investido não se realize em venda, é um investimento sem retorno que acarreta perdas financeiras?

O modelo desenvolvido deve permitir e contemplar uma modelagem de simulação para avaliar as políticas de abastecimento na loja entre sua retaguarda e sua área de vendas. $\mathrm{O}$ objetivo é verificar a relação ideal entre nível de estoque e índice de ruptura que propicia a melhor relação entre receita e custo, resultando no maior lucro possível.

Para realizar esta pesquisa, foi escolhido um SKU que é um produto de moda do segmento de vestuário cuja venda é influenciada pela sazonalidade característica dos produtos de moda com venda limitada a clima e período do ano. Também é um produto com grande representatividade dentro de sua categoria e com uma alta performance de giro.

A loja escolhida para realizar a simulação é localizada na região sudeste, está entre as 20 lojas de maior faturamento da empresa estudada e possui todo sortimento de SKU's ativo para a venda.

\subsection{ESPECIFICAÇÃO DOS CRITÉRIOS DE DESEMPENHO E PARÂMETROS DO SISTEMA - PASSO 2}

Para que seja possível construir e validar um modelo, é necessário especificar critérios de desempenho e variáveis de parâmetros.

As variáveis dependentes refletem os critérios de desempenho:

a) índice de ruptura;

b) lucro bruto = venda líquida - custo líquido

Variáveis independentes incluem os parâmetros do sistema:

a) lead time de abastecimento (da retaguarda para a área de vendas);

b) lead time de abastecimento (do centro de distribuição para a loja);

c) capacidade disponível (área de vendas); 
d) volume de estoque físico;

e) custo do volume de estoque (investimento);

f) venda física (faturamento físico);

g) venda financeira (faturamento financeiro);

h) venda financeira líquida $=$ faturamento - impostos;

i) custo líquido da venda = custo do produto vendido.

\subsection{DESENVOLVIMENTO E VALIDAÇÃO DO MODELO CONCEITUAL - PASSO 3}

Para obter um modelo conceitual robusto e com o objetivo de gerar transparência ao modelo proposto, foi elaborado um esquema, ilustrado na Figura 4, que elucida como funciona o fluxo de estoque, desde o centro de distribuição, passando por todas as etapas do processo até uma possível compra do cliente na loja. 
Figura 4 - Modelo conceitual do fluxo de estoque

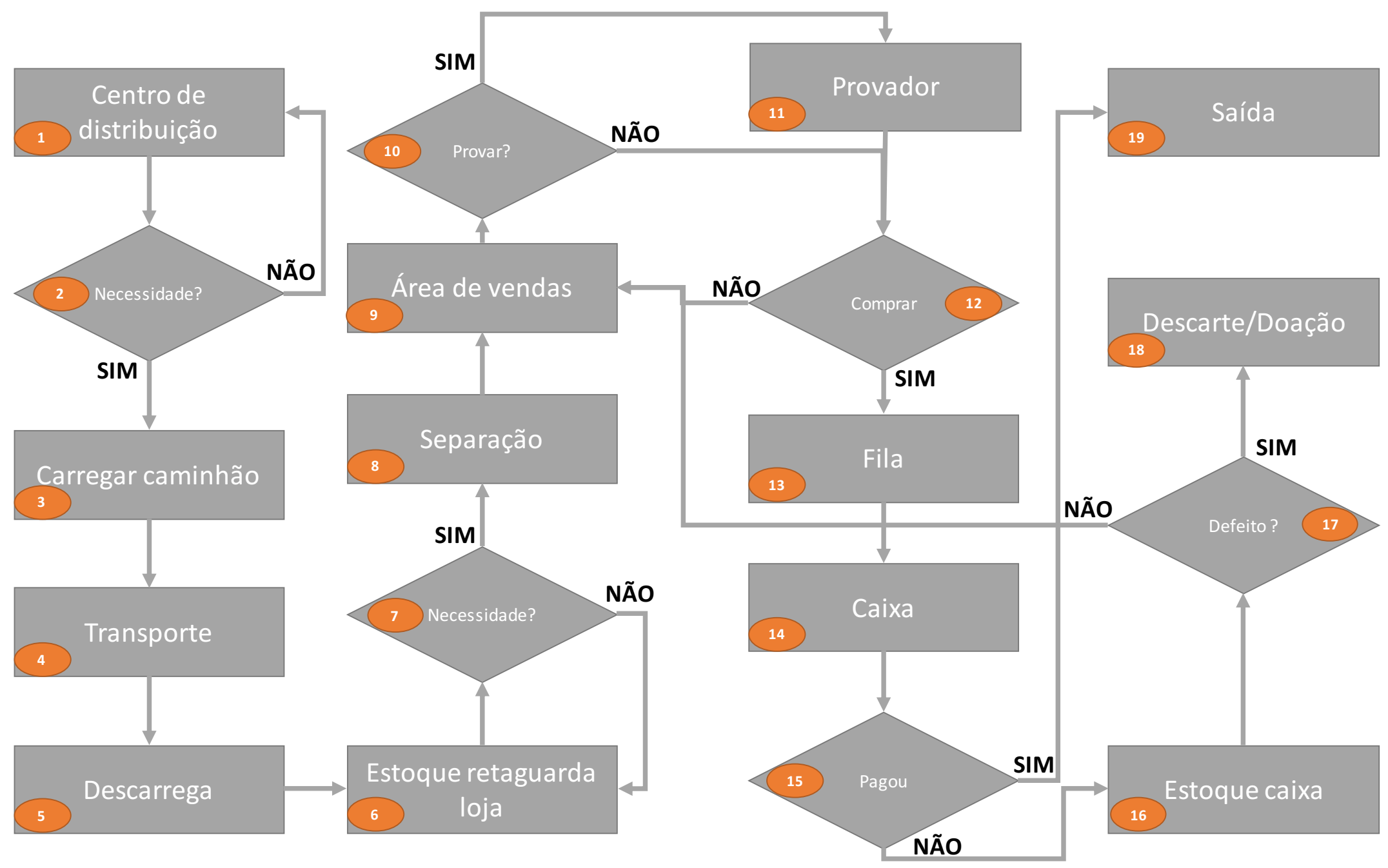

Fonte: Autor 
O índice 1 representa o centro de distribuição, local onde o estoque é armazenado. $O$ índice 2 representa a necessidade de demanda solicitando reabastecimento do centro de distribuição para as lojas. No índice 3, após a demanda ser solicitada e a verificação da disponibilidade de estoque do produto exigido ser realizada, é feito o abastecimento do caminhão. O índice 4 representa o transporte do centro de distribuição até a loja. No índice 5, após a chegada do caminhão, é realizada a descarga. No índice 6, o estoque é armazenado e organizado na retaguarda da loja (estoque não disponível ao cliente). O índice 7 verifica a disponibilidade de abastecimento da retaguarda para a área de vendas. No índice 8 , se a demanda de necessidade é confirmada, é feita a separação do produto para ser enviado à área de vendas. No índice 9, o produto é destinado à área de venda (disponível para o cliente comprar). No índice 10, o cliente, ao entrar na loja e se deparar com a disponibilidade do produto, tem a opção de prová-lo. No índice 11, caso decida provar, o cliente poderá experimentar o produto. No índice 12, concluída a prova do produto, é chegado o momento de decidir se irá comprar. No índice 13, o cliente decidiu comprar e foi para a fila do caixa com o produto em mãos. No índice 14, é feita a cobrança no caixa. No índice 15, o cliente ainda tem a opção de declinar da compra ou efetuar o pagamento. O índice 16 , mostra que, caso o cliente desista da compra, o produto é direcionado ao estoque do caixa. No índice 17, caso exista defeito no produto, ele é direcionado à área de descarte ou, caso não exista defeito, o produto é devolvido para a área de vendas. O índice 18 apresenta a área de descarte e doação. O índice 19, saída da loja, mostra que o cliente pode ou não ter feito uma compra.

\subsection{COLETA DE DADOS - PASSO 4}

Para garantir a acuracidade do levantamento dos dados quantitativos, foram utilizadas duas chaves primárias concatenadas, loja e material. Como cada loja foi atrelada a um SKU, foi possível evitar possíveis duplicidades da base de dados. Por exemplo: a cada 100 lojas analisadas, podem ser gerados 100 registros no máximo, pois cada loja só pode gerar 1 registro de SKU, sendo eles obrigatoriamente diferentes uns dos outros (100 multiplicado por 1 igual a 100 registros por dia).

A chave primária foi definida e relacionada a uma tabela de prazo padrão com nove bases de dados, a saber: base de estoque, base de venda, base carteira em aberto, base gestão de estoque do centro de distribuição, base gestão de estoque loja, base balanço mensal loja, base estoque em trânsito, base estoque alocado e base venda planejada versus realizada, totalizando 
aproximadamente cem mil registros. A Figura 5 apresenta a estrutura da base de dados utilizada neste trabalho.

Figura 5 - Estrutura da base de dados

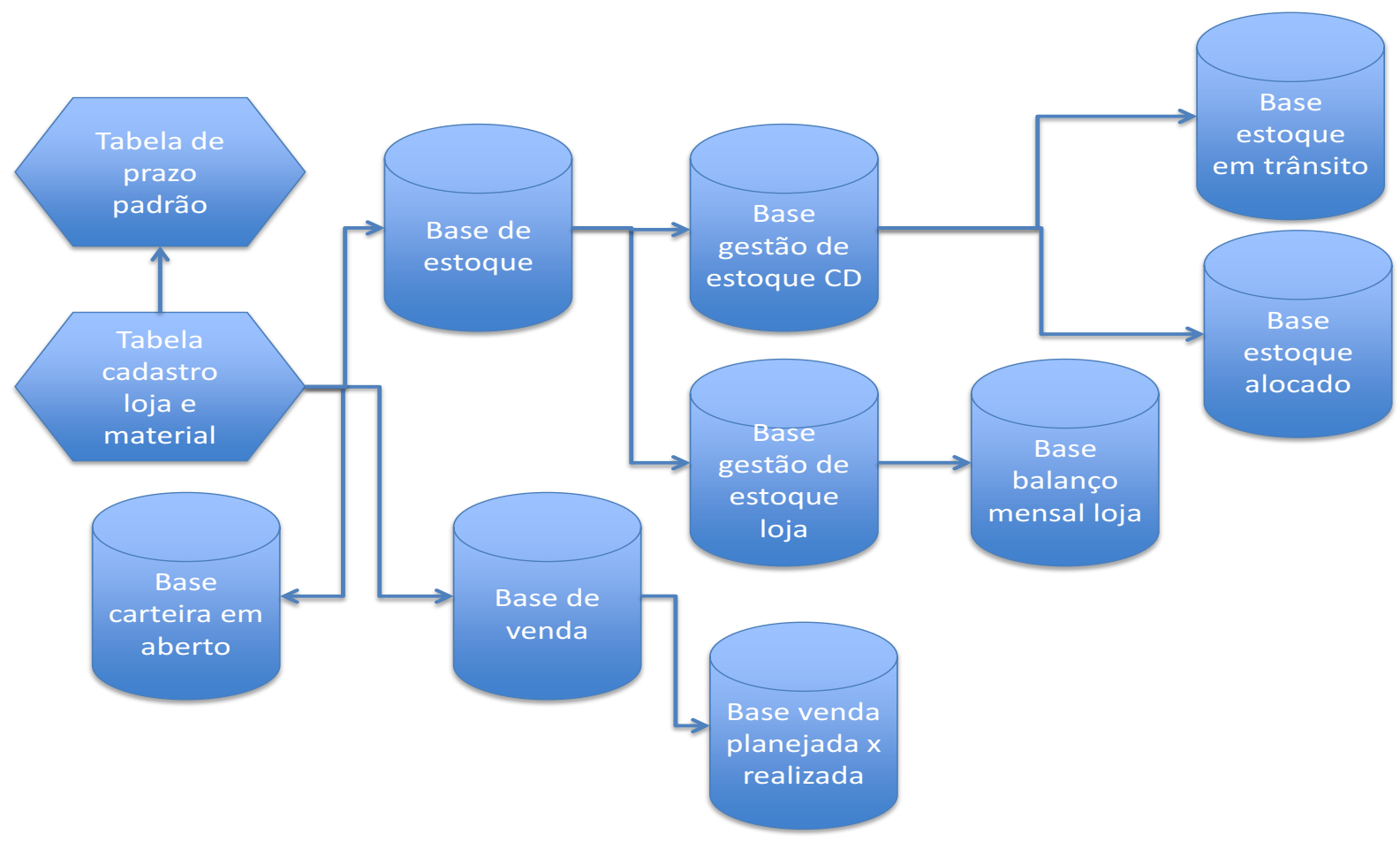

Fonte: Autor

O levantamento da base de dados contemplou os principais relatórios disponíveis que foram extraídos diariamente, tendo sido consolidados de acordo com a estrutura apresentada na Figura 5. Todas as verificações realizadas em cada um dos relatórios são descritas a seguir:

a) relatório diário de venda e estoque: verificaram-se posições diárias para identificar casos em que a venda foi igual a zero (SKU para todas as lojas);

b) relatório diário de venda e estoque: verificaram-se posições diárias para identificar a existência ou não de estoque em loja;

c) relatório de gestão de estoque loja: verificou-se a localização do estoque loja, ou seja, se o estoque estava disponível na área de vendas ou estava no seu depósito;

d) relatório de gestão de estoque do centro de distribuição: verificou-se a existência de estoque no centro de distribuição disponível para alocação (envio do centro de distribuição para loja);

e) relatório de carteira: verificou-se a existência de pedido de compra do fornecedor para o centro de distribuição;

f) relatório de carteira: verificou-se a data de emissão do pedido de compra; 
g) tabela de prazos de entrega fornecedor: verificou-se o tempo da emissão de pedido para o fornecedor até seu efetivo recebimento no centro de distribuição);

h) relatório diário de gestão de estoque do centro de distribuição: verificou-se a existência de estoque alocado do centro de distribuição para a loja;

i) relatório de gestão de estoque do centro de distribuição: verificou-se há quanto tempo a alocação havia sido realizada;

j) tabela de prazos logísticos: verificou-se o prazo de envio para a loja (tempo da alocação até o efetivo recebimento do produto pela loja);

k) relatório de gestão de estoque do centro de distribuição: verificou-se a existência de estoque alocado parado no centro de distribuição;

1) relatório de gestão de estoque do centro de distribuição: verificou-se a existência de estoque em trânsito do centro de distribuição para a loja;

m) relatório de gestão de estoque do centro de distribuição: verificou-se a data de expedição do estoque em trânsito;

n) relatório de venda planejada versus realizada: verificou-se a venda realizada e a venda planejada.

Após a coleta de dados em tabelas estruturadas e disponíveis no banco de dados oficial da empresa, teve início a segunda captura de dados não estruturados da operação de loja. Ou seja, dados que não estão disponíveis no banco de dados oficial da companhia e que são necessários para calibrar os tempos do modelo. Nessa etapa, foi medido o tempo médio e o desvio padrão de vinte e cinco processos; essas medições foram repetidas por trinta vezes cada. As repetições são necessárias para qualificar os dados e mitigar erros operacionais. Desse modo foi possível obter a Tabela 1, que apresenta os processos relacionados à operação da loja analisada. Também está disponível no apêndice A uma base completa que engloba todos os dados coletados. 
Tabela 1 - Informações quantitativas coletadas na operação da loja analisada

(continua)

\begin{tabular}{|c|c|c|c|c|c|c|c|c|}
\hline \multirow[t]{2}{*}{ Índice } & \multirow[t]{2}{*}{\begin{tabular}{|l|} 
ENTIDADE \\
\end{tabular}} & \multirow[t]{2}{*}{ LOCAL } & \multirow[t]{2}{*}{ OPERAÇÃO } & \multicolumn{3}{|c|}{ FREQUÊNCIA (MÉDIA) } & \multirow{2}{*}{$\begin{array}{c}\text { Desvio } \\
\text { Padrão } \\
\text { (Min) }\end{array}$} & \multirow[t]{2}{*}{ DESCRIÇÃO } \\
\hline & & & & MIN & HORAS & DIA & & \\
\hline 1 & CLIENTE & CHEGADA_CLIENTE & CHEGADA & $2.448,00$ & 40,80 & 1,70 & 1,34 & TEMPO PARA CHEGADA DE CLIENTES \\
\hline 2 & PRODUTO & LPR_GERAL & CHEGADA & $3.360,00$ & 56,00 & 2,33 & 0,00 & $\begin{array}{l}\text { TEMPO PARA CHEGADA DE PRODUTO NO } \\
\text { LPR GERAL }\end{array}$ \\
\hline 3 & PRODUTO & LPR_GERAL & PROCESSAMENTO & 121,50 & 2,03 & 0,08 & 12,91 & $\begin{array}{l}\text { TEMPO PARA PROCESSAMENTO NO LPR } \\
\text { GERAL }\end{array}$ \\
\hline 4 & PRODUTO & LPR_GERAL & MOVIMENTAÇÃO & 10,70 & 0,18 & 0,01 & 3,99 & $\begin{array}{l}\text { TEMPO PARA MOVER PRODUTO DO LPR } \\
\text { GERAL PARA LPR_BIPADO }\end{array}$ \\
\hline 5 & PRODUTO & LPR_BIPADO & MOVIMENTAÇÃO & 92,93 & 1,55 & 0,06 & 15,44 & $\begin{array}{l}\text { TEMPO PARA MOVER PRODUTO DO } \\
\text { LPR_BIPADO PARA GONDULA_ADV }\end{array}$ \\
\hline 6 & PRODUTO & LPR_BIPADO & MOVIMENTAÇÃO & 3,60 & 0,06 & 0,00 & 1,90 & $\begin{array}{l}\text { TEMPO PARA MOVER PRODUTO COM } \\
\text { DEFEITO DO LPR_BIPADO PARA } \\
\text { LPR_DEFEITOS }\end{array}$ \\
\hline 7 & PRODUTO & GONDULA_ADV & SAIDA & $1.680,00$ & 28,00 & 1,17 & 1,26 & TEMPO PARA VENDA DE PEÇAS \\
\hline 8 & PRODUTO & GONDULA_ADV & AGUARDANDO & 2,20 & 0,04 & 0,00 & 1,45 & $\begin{array}{l}\text { TEMPO PARA CLIENTE ESCOLHER O } \\
\text { PRODUTO }\end{array}$ \\
\hline 9 & CLIENTE & CHEGADA_CLIENTE & MOVIMENTAÇÃO & 7,20 & 0,12 & 0,01 & 4,21 & $\begin{array}{l}\text { TEMPO PARA CLIENTE CIRCULAR NA LOJA } \\
\text { ATÉ CHEGAR NA GONDULA_ADV }\end{array}$ \\
\hline 10 & CLIENTE & PEGA_PRODUTO & MOVIMENTAÇÃO & 2,00 & 0,03 & 0,00 & 0,87 & $\begin{array}{l}\text { TEMPO PARA MOVER CLIENTE DO PEGA } \\
\text { PRODUTO PARA PROVADOR }\end{array}$ \\
\hline
\end{tabular}


Tabela 1 - Informações quantitativas coletadas na operação da loja analisada

(continuação)

\begin{tabular}{|c|c|c|c|c|c|c|c|c|}
\hline \multirow[t]{2}{*}{ Índice } & \multirow[t]{2}{*}{ ENTIDADE } & \multirow[t]{2}{*}{ LOCAL } & \multirow[t]{2}{*}{ OPERAÇÃO } & \multicolumn{3}{|c|}{ FREQUÊNCIA (MÉDIA) } & \multirow{2}{*}{$\begin{array}{c}\text { Desvio } \\
\text { Padrão } \\
\text { (Min) }\end{array}$} & \multirow[t]{2}{*}{ DESCRIÇÃO } \\
\hline & & & & MIN & HORAS & DIA & & \\
\hline 11 & CLIENTE & PEGA_PRODUTO & MOVIMENTAÇÃO & 2,10 & 0,04 & 0,00 & 0,80 & $\begin{array}{l}\text { TEMPO PARA MOVER CLIENTE DO } \\
\text { PEGA_PRODUTO PARA FILA }\end{array}$ \\
\hline 12 & CLIENTE & PROVADOR & PROCESSAMENTO & 31,50 & 0,53 & 0,02 & 12,44 & $\begin{array}{l}\text { TEMPO DO PRODUTO E CLIENTE PARADO } \\
\text { NO PROVADOR }\end{array}$ \\
\hline 13 & CLIENTE & PROVADOR & MOVIMENTAÇÃO & 1,90 & 0,03 & 0,00 & 0,76 & $\begin{array}{l}\text { TEMPO PARA MOVER PRODUTO E CLIENTE } \\
\text { DO PROVADO PARA FILA }\end{array}$ \\
\hline 14 & PRODUTO & PROVADOR & MOVIMENTAÇÃO & 0,00 & 0,00 & 0,00 & 0,00 & $\begin{array}{l}\text { TEMPO PARA MOVER PRODUTO DO } \\
\text { PROVADOR PARA ESTOQUE_PROVADOR }\end{array}$ \\
\hline 15 & PRODUTO & ESTOQUE_PROVADOR & AGUARDANDO & 80,07 & 1,33 & 0,06 & 45,08 & $\begin{array}{l}\text { TEMPO DO PRODUTO PARADO NO } \\
\text { ESTOQUE_PROVADOR }\end{array}$ \\
\hline 16 & CLIENTE & FILA & AGUARDANDO & 11,60 & 0,19 & 0,01 & 5,78 & $\begin{array}{l}\text { TEMPO DO PRODUTO E CLIENTE PARADO } \\
\text { NA FILA }\end{array}$ \\
\hline 17 & CLIENTE & FILA & MOVIMENTAÇÃO & 0,00 & 0,00 & 0,00 & 0,00 & $\begin{array}{l}\text { TEMPO PARA MOVER PRODUTO E CLIENTE } \\
\text { DA FILA PARA O CAIXA_PG }\end{array}$ \\
\hline 18 & CLIENTE & CAIXA_PG & \begin{tabular}{|l|} 
PROCESSAMENTO \\
\end{tabular} & 4,00 & 0,07 & 0,00 & 2,21 & $\begin{array}{l}\text { TEMPO PARA CLIENTE PAGAR O PRODUTO } \\
\text { OU DESISTIR DA COMPRA }\end{array}$ \\
\hline 19 & CLIENTE & CAIXA_PG & MOVIMENTAÇÃO & 1,90 & 0,03 & 0,00 & 0,84 & $\begin{array}{l}\text { TEMPO PARA MOVER CLIENTE DO } \\
\text { CAIXA_PG PARA SAIDA (COMPROU) }\end{array}$ \\
\hline
\end{tabular}


Tabela 1 - Informações quantitativas coletadas na operação da loja analisada

(conclusão)

\begin{tabular}{|c|c|c|c|c|c|c|c|c|}
\hline \multirow[t]{2}{*}{ Índice } & \multirow[t]{2}{*}{ ENTIDADE } & \multirow[t]{2}{*}{ LOCAL } & \multirow[t]{2}{*}{ OPERAÇÃO } & \multicolumn{3}{|c|}{ FREQUÊNCIA (MÉDIA) } & \multirow{2}{*}{$\begin{array}{c}\text { Desvio } \\
\text { Padrão } \\
\text { (Min) }\end{array}$} & \multirow[t]{2}{*}{ DESCRIÇÃO } \\
\hline & & & & MIN & HORAS & DIA & & \\
\hline 20 & CLIENTE & CAIXA_PG & MOVIMENTAÇÃO & 0,57 & 0,01 & 0,00 & 0,50 & $\begin{array}{l}\text { TEMPO PARA MOVER PRODUTO DO } \\
\text { CAIXA_PG PARA CAIXA_ESTOQUE } \\
\text { (DESISTIU DA COMPRA) }\end{array}$ \\
\hline 21 & PRODUTO & CAIXA_ESTOQUE & AGUARDANDO & 50,23 & 0,84 & 0,03 & 5,91 & $\begin{array}{l}\text { TEMPO DO PRODUTO PARADO NO } \\
\text { CAIXA_ESTOQUE ATÉ O RETORNO PARA } \\
\text { GONDULA_ADV }\end{array}$ \\
\hline 22 & PRODUTO & CAIXA_ESTOQUE & MOVIMENTAÇÃO & 1,90 & 0,03 & 0,00 & 0,88 & $\begin{array}{l}\text { TEMPO PARA MOVER PRODUTO DO } \\
\text { CAIXA_ESTOQUE PARA GONDULA_ADV }\end{array}$ \\
\hline 23 & PRODUTO & CAIXA_ESTOQUE & MOVIMENTAÇÃO & 1,50 & 0,03 & 0,00 & 1,25 & $\begin{array}{l}\text { TEMPO PARA MOVER O PRODUTO DO } \\
\text { CAIXA_ESTOQUE PARA LPR_DEFEITO }\end{array}$ \\
\hline 24 & PRODUTO & LPR_DEFEITO & AGUARDANDO & $3.360,00$ & 56,00 & 2,33 & 0,00 & $\begin{array}{l}\text { TEMPO DO PRODUTO PARADO NO } \\
\text { LPR_DEFEITO ATÉ QUE O CAMINHÃO } \\
\text { CHEGUE }\end{array}$ \\
\hline 25 & PRODUTO & LPR_DEFEITO & MOVIMENTAÇÃO & 63,80 & 1,06 & 0,04 & 9,15 & $\begin{array}{l}\text { TEMPO PARA MOVER LPR_DEFEITO PARA } \\
\text { SAIDA/ CAMINHÃO }\end{array}$ \\
\hline
\end{tabular}

Fonte: Autor 


\subsection{DESENVOLVIMENTO E VERIFICAÇÃO DO MODELO COMPUTACIONAL - PASSO 5}

O desenvolvimento do modelo de simulação começou de maneira simples e a complexidade foi sendo adicionada gradualmente em etapas até que o modelo contemplasse todos os detalhes e complexidades necessárias para retratar o ambiente estudado. A verificação e a determinação da implementação no computador do modelo conceitual foram processos contínuos, compartilhados e validados constantemente com o ambiente estudado por meio de entrevistas com os gerentes sêniores de loja da empresa estudada. A verificação incluiu examinar as saídas e entradas do modelo para garantir que fosse executado com comportamento aceitável, mitigando erros na lógica de programação e código.

A verificação do modelo foi realizada de quatro maneiras. Primeiro, o código foi validado por um professor, doutor em engenharia, que avaliou se a lógica de programação e o código estavam aceitáveis. Segundo, as saídas do modelo foram comparadas com soluções calculadas manualmente no Excel para assim determinar se o modelo apresentava um comportamento adequado. Terceiro, os resultados de simulação foram comparados de modo integral com a estrutura do ambiente estudado, constatando-se que o comportamento da estrutura representa o ambiente estudado de forma integra e aceitável. Foi possível fazer esta constatação por meio da validação do modelo por seis gerentes da empresa estudada: três gerentes de loja sêniores, dois gerentes nível pleno e um gerente de planejamento nível pleno. Por fim, em quarto lugar, o modelo computacional foi comparado ao modelo conceitual estabelecido no tópico 3.3, constatando-se a verificação do processo. A animação também foi uma ferramenta útil para auxiliar no processo de validação e pode ser visualizada na Figura 6. A modelagem pode ser verificada do APÊNDICE B. 
Figura 6 - Modelo computacional

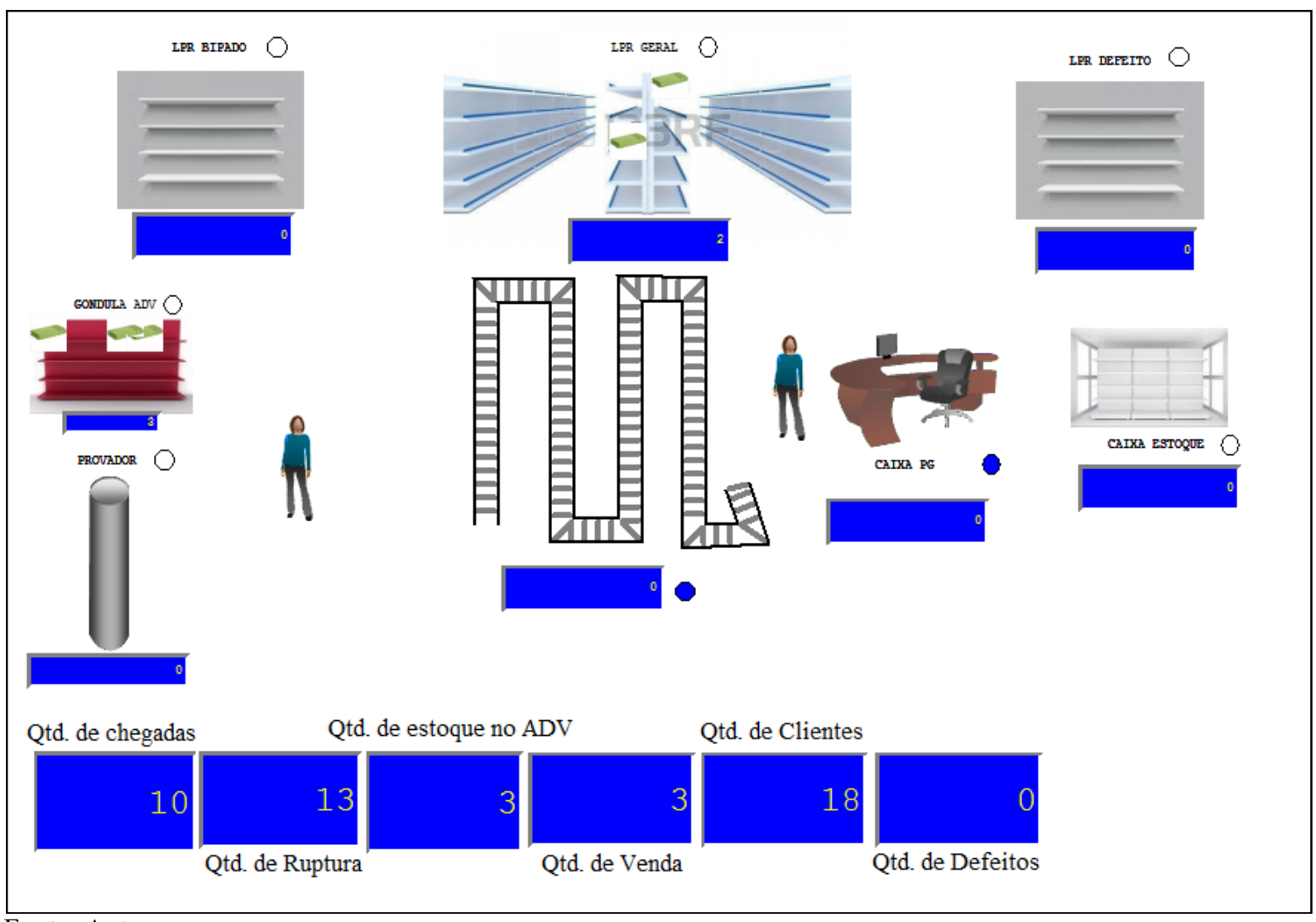

Fonte: Autor

A Figura 6 é composta por oito locais, descritos e explicados local a local: Lpr bipado (linha de produção e reposição de estoque bipado) é um estoque intermediário entre a área de venda e a retaguarda. Esse local é utilizado para separação dos produtos a serem levados para a área de vendas ou gôndola. Lpr geral (linha de produção e reposição de estoque geral) é a retaguarda da loja, que tem por objetivo armazenar e organizar todo o estoque a ser disponibilizado para área de vendas. Lpr defeito (linha de produção e reposição estoque com defeito) é uma área que armazena o estoque a ser descartado. Esse estoque não é mais saudável para venda, seja porque possui algum defeito, seja por algum detalhe no produto que impede a venda. Gôndola ou ADV (área disponível para venda) é o lugar onde o estoque é exposto para ser vendido. Provador é o local que permite aos clientes provar os produtos. Fila é o lugar delimitado para o cliente aguardar em ordem e, posteriormente, ser atendido no caixa. Caixa para pagamento é o local que permite que o cliente pague pelo produto. Caixa estoque armazena o estoque quando os clientes desistem da compra e já estão no local caixa para pagamento. 


\subsection{VALIDAÇÃO DO MODELO - PASSO 6}

O processo de validação foi realizado com o objetivo de confirmar que o modelo computacional desenvolvido é uma representação precisa da dinâmica do fluxo de SKU entre a retaguarda e a área de vendas. Outro propósito da validação é verificar a confiabilidade do modelo computacional em fornecer os dados necessários para gerar as análises para esta pesquisa e prevenir conclusões errôneas ou equivocadas. Primeiramente, a validação do modelo contemplou a interação com seis especialistas da empresa estudada: três gerentes de loja sêniores, dois gerentes nível pleno e um gerente de planejamento nível pleno. Essa ação foi realizada com o intuito de assegurar que a dinâmica de movimentação do modelo simulado é análoga à realidade existente na unidade de análise. Essa validação possibilitou que a realidade fosse adequadamente modelada e o problema analisado de maneira correta. Em segundo lugar, foi estruturada uma comparação dos resultados obtidos na simulação do modelo com os resultados extraídos no período de janeiro a agosto de 2017 das bases de dados descritas no tópico coleta de dados 3.4. Esse comparativo teve o propósito de assegurar a consistência das saídas numéricas do modelo computacional comparado aos dados reais. A Tabela 2 apresenta os erros percentuais da comparação das informações obtidas na simulação computadorizada com os dados de saída obtidos dos elementos que representam a realidade. Os erros percentuais identificados ou encontrados foram inferiores a $2 \%$.

Tabela 2 - Erro percentual da comparação entre os resultados reais e os resultados extraídos do modelo de simulação

\begin{tabular}{|c|c|c|c|}
\hline Métricas & Dados reais & Cenário I & Desvio \\
\hline 0 - Volume de venda física (unidades) & 187 & 189 & $1,07 \%$ \\
\hline 1 - Receita Bruta & $5.591,30$ & $\mathrm{R} \$ \quad 5.651,10$ & $1,07 \%$ \\
\hline (-) Impostos sobre venda & $1.537,61$ & $\mathrm{R} \$ \quad 1.554,05$ & $1,07 \%$ \\
\hline (=) Receita Líquida (1a) & $4.053,69$ & $4.097,05$ & $1,07 \%$ \\
\hline 2 - Custo dos produtos vendidos & $2.026,85$ & $\mathrm{R} \$ \quad 2.048,52$ & $1,07 \%$ \\
\hline 3 - Lucro Bruto (3 = 1a - 2) & $\mathbf{2 . 0 2 6 , 8 5}$ & R\$ 2.048,52 & $1,07 \%$ \\
\hline 4 - Margem de Venda Liquida $\%(4=(3 / 1 a)$ & $50,00 \%$ & $50,00 \%$ & $0,00 \%$ \\
\hline $\begin{array}{l}5 \text { - Capacidade disponível na área de vendas } \\
\text { (Unidades) }\end{array}$ & 1 & 1 & $0,00 \%$ \\
\hline $\begin{array}{l}6 \text { - Custo do volume de estoque (investimento) | (6 } \\
=7 \times 8 \text { ) }\end{array}$ & $2.948,14$ & R\$ $2.991,50$ & $1,47 \%$ \\
\hline 7 - Custo unitário de estoque & 10,84 & 10,84 & $0,00 \%$ \\
\hline 8 - Volume de estoque físico (unidades) & 272 & 276 & $1,47 \%$ \\
\hline
\end{tabular}

Fonte: Autor 
As duas iniciativas de validação descritas viabilizaram o desenvolvimento e a concepção de um modelo computacional capaz de suportar a realização de análises e conclusões aproximadas da realidade. A validação do modelo computacional também possibilitou a identificação dos fatores que impactam as variáveis de ruptura e lucro bruto. Desse modo, foi possível obter um refinamento da compreensão do problema estudado e a prevenção de erros de modelagem ou lógicos.

\subsection{CENÁRIOS SIMULADOS - PASSO 7}

Foram estabelecidos dez cenários para a simulação da dinâmica do fluxo de abastecimento de SKU's entre a retaguarda e a área de vendas que contemplam variações da política de abastecimento. Nesses cenários, por exemplo, variou-se a política de abastecimento: o cenário 1 foi simulado com uma unidade de profundidade (vale destacar que o termo profundidade é utilizado quando há mais estoque do mesmo produto). Aos cenários subsequentes, foram acrescidos ou incrementados de maneira acumulativa uma unidade de profundidade até que o último cenário atingisse dez unidades de profundidade disponível na área de vendas (métrica 4 da Tabela 3). As métricas 0, 1, 2, 3, 5, 6 e 7 são resultantes da combinação com a métrica 4 e todas as métricas podem ser observadas na Tabela 3.

Para todos os cenários, foram consideras as seguintes métricas como fixas:

a) margem de venda liquida em $50 \%$, pois o custo unitário não foi variado;

b) leadtime de abastecimento do centro de distribuição para loja, foi fixado com frequência de três vezes por semana;

c) lead time de abastecimento da retaguarda para área de venda, foi fixado com frequência diária;

d) este estudo não teve abrangência no foco de ruptura do abastecimento do centro de distribuição para loja. Assim, foi fixado o investimento em estoque de R \$2.991,50, com um custo unitário de $\mathrm{R} \$ 10,84$, o que resulta em um total físico de duzentos e setenta e seis peças. 
Tabela 3 - Comparação dos cenários simulados

\begin{tabular}{|c|c|c|c|c|c|c|c|c|c|c|}
\hline Demonstrativo do Resulta & Ido do Exercí́ & cio $(02 / 01 / 201$ & 7 até $31 / 08 / 20$ & & & & & & & \\
\hline Métricas & Cenário I & Cenário II & Cenário III & Cenário IV & Cenário V & Cenário VI & Cenário VII & Cenário VIII & Cenário IX & Cenário $\mathrm{X}$ \\
\hline $\begin{array}{l}0 \text { - Volume de venda } \\
\text { física (unidades) }\end{array}$ & 189 & 274 & 274 & 274 & 274 & 274 & 274 & 274 & 274 & 274 \\
\hline 1 - Receita Bruta (R\$) & 5651,10 & 8192,60 & 8192,60 & 8192,60 & 8192,60 & 8192,60 & 8192,60 & 8192,60 & 8192,60 & 8192,60 \\
\hline $\begin{array}{l}\text { (-) Impostos sobre venda } \\
\text { (R\$) }\end{array}$ & 1554,05 & 2252,97 & 2252,97 & 2252,97 & 2252,97 & 2252,97 & 2252,97 & 2252,97 & 2252,97 & 2252,97 \\
\hline $\begin{array}{l}\text { (=) Receita Líquida (1a) } \\
(\mathrm{R} \$)\end{array}$ & 4097,05 & 5939,64 & 5939,64 & 5939,64 & 5939,64 & 5939,64 & 5939,64 & 5939,64 & 5939,64 & 5939,64 \\
\hline $\begin{array}{l}2 \text { - Custo dos produtos } \\
\text { vendidos }(\mathrm{R} \$)\end{array}$ & 2048,52 & 2969,82 & 2969,82 & 2969,82 & 2969,82 & 2969,82 & 2969,82 & 2969,82 & 2969,82 & 2969,82 \\
\hline $\begin{array}{l}3 \text { - Lucro Bruto }(3=1 a- \\
\text { 2) }(\mathrm{R} \$)\end{array}$ & 2048,52 & 2969,82 & 2969,82 & 2969,82 & 2969,82 & 2969,82 & 2969,82 & 2969,82 & 2969,82 & 2969,82 \\
\hline $\begin{array}{l}4 \text { - Capacidade disponível } \\
\text { na área de vendas } \\
\text { (Unidades) }\end{array}$ & 1 & 2 & 3 & 4 & 5 & 6 & 7 & 8 & 9 & 10 \\
\hline $\begin{array}{l}5 \text { - Índice de Ruptura } \\
\text { Loja para Loja }(5=7 / \\
6)\end{array}$ & $45,19 \%$ & $22,96 \%$ & $20,25 \%$ & $21,98 \%$ & $18,02 \%$ & $20,00 \%$ & $19,01 \%$ & $19,01 \%$ & $19,01 \%$ & $19,01 \%$ \\
\hline $\begin{array}{l}6 \text { - Número de clientes } \\
\text { que visitaram a loja }\end{array}$ & 405 & 405 & 405 & 405 & 405 & 405 & 405 & 405 & 405 & 405 \\
\hline $\begin{array}{l}7 \text { - Quantidade de vezes } \\
\text { que o cliente se deparou } \\
\text { com ausência de estoque }\end{array}$ & 183 & 93 & 82 & 89 & 73 & 81 & 77 & 77 & 77 & 77 \\
\hline
\end{tabular}

Fonte: Autor 
Para cada configuração do sistema, foram estabelecidas lógicas de programação baseadas nos dados empíricos coletados em campo, no modelo conceitual disponível na Figura 4 e no amadurecimento das análises desenvolvidas durante as simulações de cenários. Primeiro, foi estabelecido o número de repetições do modelo, chegando-se a 10 repetições. Com esse número de repetições, foi possível identificar uma tendência e sequência lógica nos resultados obtidos. Todas as 10 repetições foram realizadas com a mesma duração e com intervalo de simulação delimitado de 02/01/2017 até 31/08/2017. Esse período contempla uma estação completa do varejo de moda (inverno), ressaltando-se que, embora o inverno comercial comece efetivamente no mês de março, o abastecimento e venda tem início a partir de janeiro.

\section{ANÁLISE DOS RESULTADOS OBTIDOS - PASSO 8}

Com base na análise quantitativa dos dados gerados na simulação, foi possível relacionar o processo de abastecimento com as vendas atingidas. Os resultados podem ser visualizados nos Gráficos 4, 5 e 6 .

O Gráfico 4 correlaciona a venda física, o índice de ruptura e o valor de ruptura. Realizando uma breve análise do gráfico, é possível observar que a venda física se estabiliza no cenário II do Gráfico 4, que considera uma política de abastecimento de manter duas peças na área de vendas. Também é possível concluir que, apesar de aumentar repetidas vezes o estoque disponível na área de vendas, a venda não aumenta mais do que 274 unidades. Avaliando o índice de ruptura, é possível observar que existe uma estabilidade de resultados, a partir do cenário VII do Gráfico 4, que corresponde a um índice de 19,01\% de ruptura. Esse percentual equivale a 77 clientes que entraram na loja em busca de um determinado SKU e se depararam com a ausência desse estoque na área de vendas. Apesar de haver uma correlação entre a venda física e o índice de ruptura, apenas no cenário I do Gráfico 4 foi possível observar uma perda de venda no valor de 85 peças, se comparado ao total de venda possível. 
Gráfico 4 - Taxa de ruptura vs. volume de venda física

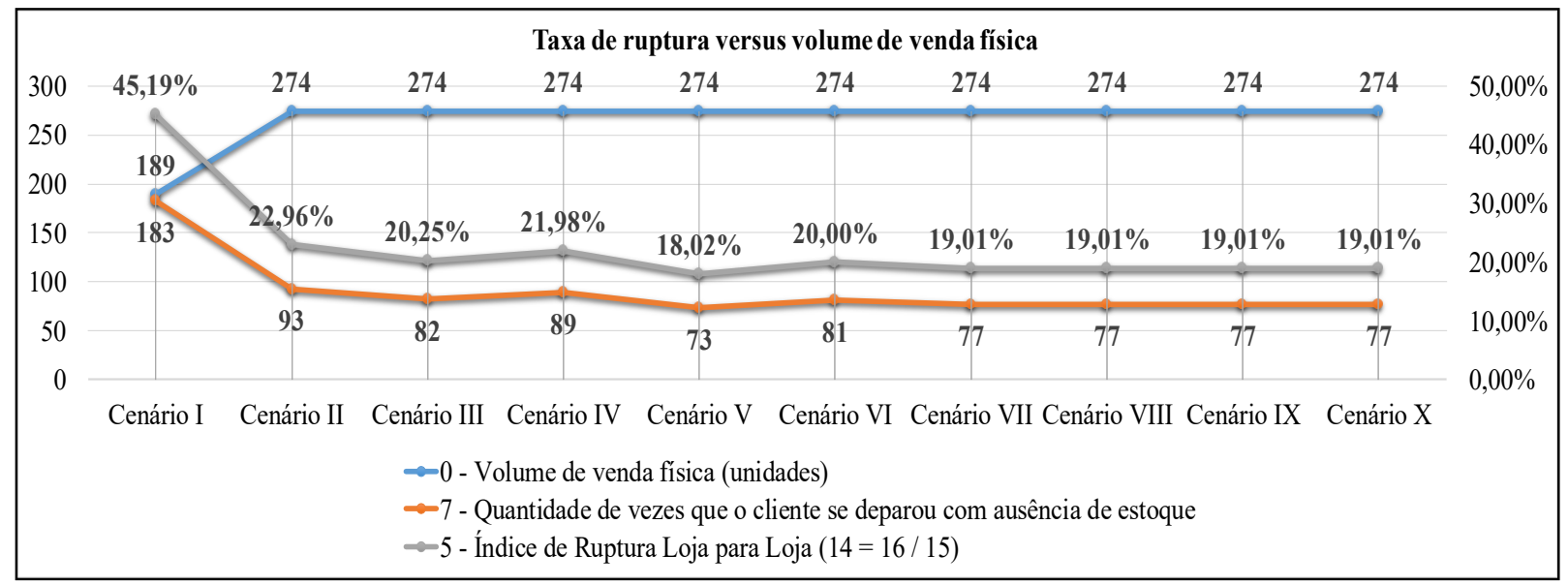

Fonte: Autor

O Gráfico 5 relaciona o lucro bruto versus o valor de ruptura. De maneira similar ao Gráfico 4, também é possível perceber no Gráfico 5 a existência de uma grande lacuna no cenário I do Gráfico 5. Isso ocorre quando a política de abastecimento mantém apenas uma unidade na área de vendas, isto é, há uma constatação de perda de venda e lucro bruto gerada pelo alto índice de ruptura. Nos demais cenários do Gráfico 5, não há perda de lucro, mas uma melhora no valor de ruptura. Assim, embora essa redução no valor de ruptura não gere um incremento no valor de lucro bruto, há uma melhora na atratividade da área de vendas.

Gráfico 5 - Lucro vs. valor de ruptura

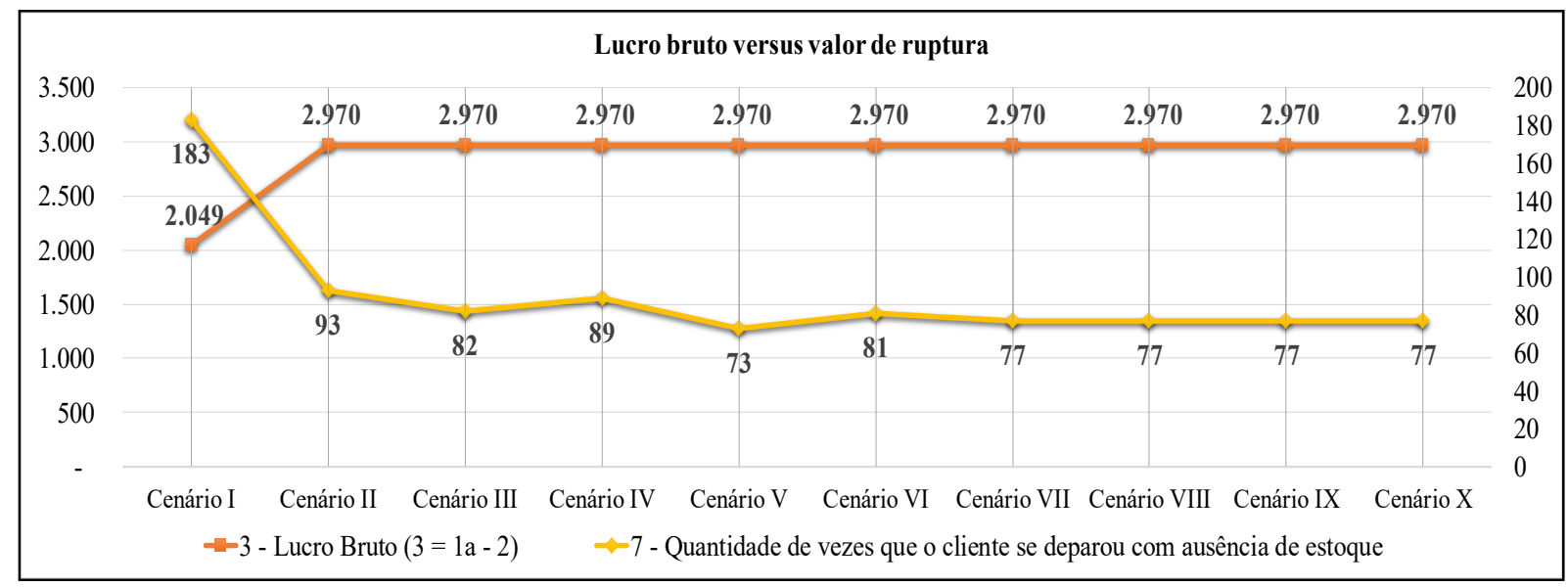

Fonte: Autor

O Gráfico 6 apresenta uma relação entre o custo de investimento em estoque versus a receita liquida capturada da venda física. Analogamente aos Gráficos 4 e 5, foi possível evidenciar que o cenário foi afetado por uma política de abastecimento sem profundidade de estoque, ou seja, com apenas uma unidade em estoque. Esse fato gerou perda de venda, altos 
índices de ruptura e consequentes perdas de receitas. Os demais cenários se mantiveram preservados em termos de receita e custo.

Gráfico 6 - Custo do investimento em estoque versus receita líquida

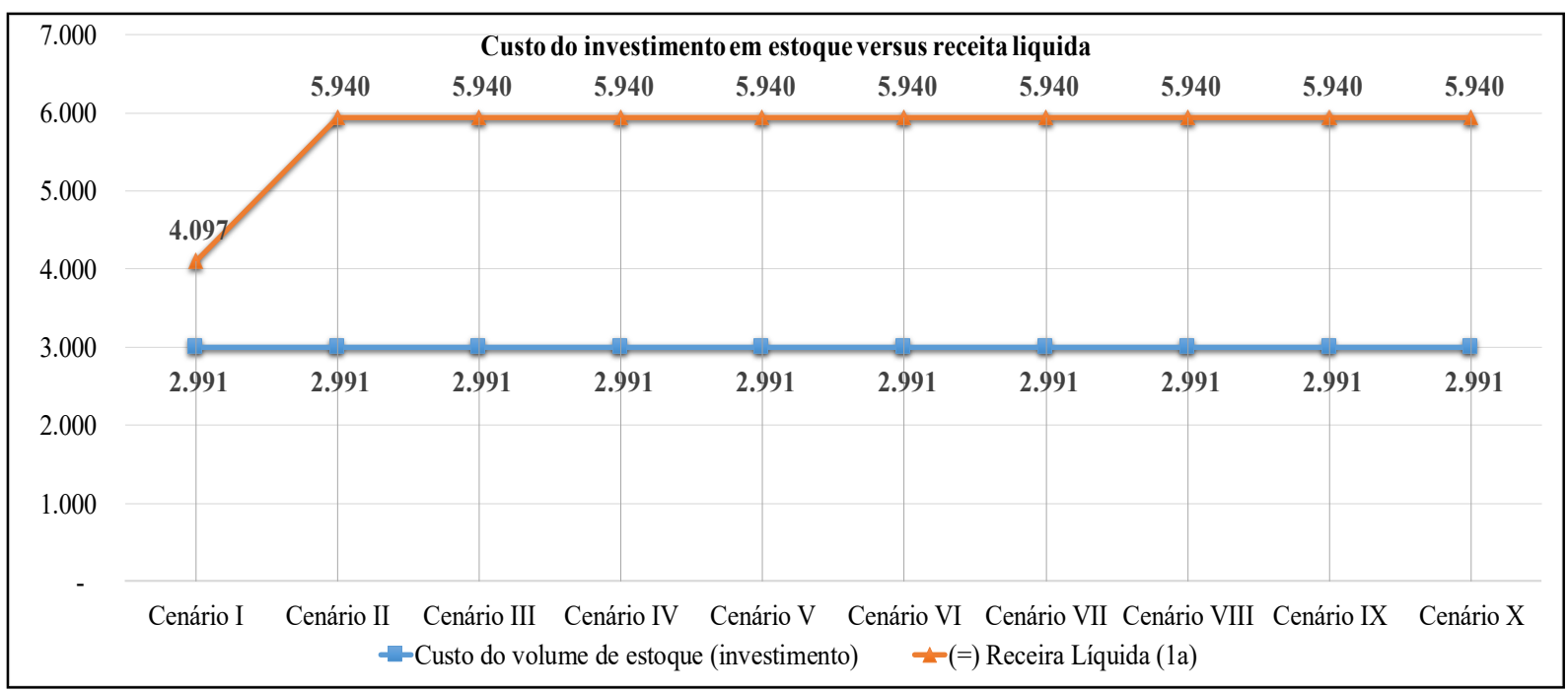

Fonte: Autor

Com base nas análises dos cenários apresentados, é possível constatar que há um equilíbrio de todas as métricas analisadas a partir do cenário VII. Em outras palavras, mesmo variando a política de abastecimento, os demais valores se mantêm inalterados. Isso mostra que o espaço para a tomada de decisão não é amplo, e sim delimitado em poucas opções que possam reduzir a ruptura e aumentar o lucro bruto. 


\section{CONCLUSÕES E CONSIDERAÇÕES FINAIS}

Com a realização deste estudo, pode-se constatar que a variação da política de abastecimento da retaguarda para a área de vendas interfere diretamente no índice de ruptura e que há um nível ideal de ruptura que propicia o maior lucro possível.

Até onde é do nosso conhecimento, é a primeira vez que é utilizada a técnica de simulação para reduzir a ruptura em uma rede de varejo de moda no Brasil. Os resultados e as lições aprendidas nesta pesquisa são de grande valia para o desenvolvimento de novas políticas de abastecimento das empresas do ramo, visando ao nível adequado de ruptura a fim de manter o maior lucro.

Como o modelo permitiu a avaliação de várias políticas de abastecimento, foi possível verificar seus efeitos sobre as métricas de ruptura e lucro. Assim foi possível constatar que existe alta correlação entre profundidade de estoque e potencial de vendas. Entretanto, há um limite para esse progresso de estoque que gera incremento no lucro bruto. Também é valido salientar que reduzir a ruptura a zero com base em altos volumes de estoque tem como efeitos uma perda de valor na atratividade da área de vendas, além de ser um investimento que não gera retorno.

Essas constatações permitem apontar que, no segmento de varejo de moda, é possível utilizar a ferramenta de simulação além do ambiente de manufatura, inclusive para tomada de decisões. Outra contribuição deste trabalho é poder servir de base para profissionais do varejo e outros segmentos na busca de melhores soluções para a política de abastecimento da retaguarda para a área de venda em seus negócios.

Como sugestão para pesquisas futuras, considera-se oportuno realizar os seguintes estudos:

a) elaborar uma modelagem de simulação para avaliar as estratégias de abastecimento entre a retaguarda e a área de vendas, visando a verificar a relação ideal entre nível de estoque e índice de ruptura que propicia o maior lucro possível para outros produtos, no varejo de moda brasileiro;

b) realizar uma análise quantitativa no varejo de moda de luxo. 


\section{REFERÊNCIAS}

AASTRUP, Jesper; KOTZAB, Herbert. Analyzing out-of-stock in independent grocery stores: an empirical study. International Journal of Retail \& Distribution Management, [s.1.], v. 37, n. 9, p.765-789, 17 Jul. 2009. Emerald. Disponível em:

$<$ http://dx.doi.org/10.1108/09590550910975817>. Acesso em: 19 mai. 2016.

ACNIELSEN. Ruptura: causas e impactos na cadeia de abastecimento e no comportamento do consumidor. In: ECR BRAZIL CONFERENCE, 2004, São Paulo. Anais... São Paulo, 2004. Disponível em: <http://www.ecrbrasil.com.br>. Acesso em: 26 abr. 2017.

AGGARWAL, Praveen; JUN, Sung Youl; HUH, Jong Ho. Scarcity Messages. Journal of Advertising, [s.1.], v. 40, n. 3, p.19-30, Out. 2011. Informa UK Limited. Disponível em: $<$ http://dx.doi.org/10.2753/joa0091-3367400302>. Acesso em: 29 abr. 2017.

AGUIAR, Fernando Henrique et al. Case study to identify the causes of stock-out of a textile retailer. Revista Gestão da Produção, Operações e Sistemas, [s.1.], v. 9, n. 3, p.29-42, 5 Set. 2014. A Fundação para o Desenvolvimento de Bauru (FunDeB). Disponível em: <http://dx.doi.org/10.15675/gepros.v9i3.1070>. Acesso em: 22 abr. 2017.

AGUIAR, Fernando Henrique Oliveira de; SAMPAIO, Mauro. Definição de processo para tratar a ruptura de estoque no varejo de alimentos. Gepros. Gestão da Produção, Operações e Sistemas, Bauru, v. 8, n. 2, p.67-82, 2013. Disponível em:

$<$ https://search.proquest.com/docview/1723112996?accountid=27260>. Acesso em: 22 abr. 2017.

AGUIAR, Fernando Henrique Oliveira de; SAMPAIO, Mauro. Identificação dos fatores que afetam a ruptura de estoque utilizando análise de agrupamentos. Produção, [s.1.], n. , p.57-70, 2014. FapUNIFESP (SciELO). Disponível em: <http://dx.doi.org/10.1590/S010365132013005000020>. Acesso em: 22 abr. 2017.

APPLEBAUM, William. Studying Customer Behavior in Retail Stores. Journal of Marketing, [s.1.], v. 16, n. 2, p.172-178, Out. 1951. JSTOR. Disponível em: $<$ http://dx.doi.org/10.2307/1247625>. Acesso em: 29 abr. 2017.

ARAUJO, Marcel Souza de; HRISTOV, Mauricio Domingues; CORREA, Rafael Martins Pedreira. Estudo de caso para identificação das causas de ruptura de uma empresa varejista têxtil. 2013. 50 f. TCC (Graduação) - Curso de Engenharia de Produção, Engenharia, Pontifícia Universidade Católica de São Paulo, São Paulo, 2013.

ARENI, Charles S.; KIM, David. The influence of in-store lighting on consumers' examination of merchandise in a wine store. International Journal of Research in Marketing, [s.1.], v. 11, n. 2, p.117-125, mar. 1994. Elsevier BV. Disponível em: $<$ https://doi.org/10.1016/0167-8116(94)90023-X>. Acesso em: 03 maio 2017. 
AVLIJAS, Goran et al. Measuring the impact of stock-keeping unit attributes on retail stockout performance. Operations Management Research, [s.1.], v. 8, n. 3-4, p.131-141, 5 Ago. 2015. Springer Nature. Disponível em: $<\mathrm{http}$ ://dx.doi.org/10.1007/s12063-015-0104-6>. Acesso em: 26 abr. 2017.

BATEMAN, Robert E. et al. Simulação de sistemas: aprimorando processos de logística, serviços e manufatura. 5. ed. Rio de Janeiro: Elsevier, 2013. 161 p.

BAYLEY, Geoff; NANCARROW, Clive. Impulse purchasing: a qualitative exploration of the phenomenon. Qualitative Market Research: An International Journal, [s.1.], v. 1, n. 2, p.99-114, Ago. 1998. Emerald. Disponível em:

<http://dx.doi.org/10.1108/13522759810214271>. Acesso em: 29 abr. 2017.

BEATTY, Sharon E.; FERRELL, M. Elizabeth. Impulse buying: Modeling its precursors. Journal of Retailing, [s.1.], v. 74, n. 2, p.169-191, Jun. 1998. Elsevier BV. Disponível em: $<$ https://doi.org/10.1016/S0022-4359(99)80092-X>. Acesso em: 03 maio 2017.

BIJVANK, Marco; BHULAI, Sandjai; HUH, Woonghee Tim. Parametric replenishment policies for inventory systems with lost sales and fixed order cost. European Journal of Operational Research, [s.1.], v. 241, n. 2, p.381-390, Mar. 2015. Elsevier BV. Disponível em: <http://dx.doi.org/10.1016/j.ejor.2014.09.018>. Acesso em: 29 abr. 2017.

BLOCK, Lauren G.; MORWITZ, Vicki G.. Shopping Lists as an External Memory Aid for Grocery Shopping: Influences on List Writing and List Fulfillment. Journal of Consumer Psychology, [s.1.], v. 8, n. 4, p.343-375, Jan. 1999. Elsevier BV. Disponível em: $<$ https://doi.org/10.1207/s15327663jcp0804_01>. Acesso em: 29 abr. 2017.

CAMPO, Katia; GIJSBRECHTS, Els; NISOL, Patricia. Towards understanding consumer response to stock-outs. Journal of Retailing, [s.1.], v. 76, n. 2, p.219-242, Jun. 2000. Elsevier BV. Disponível em: <https://doi.org/10.1016/S0022-4359(00)00026-9>. Acesso em: 17 abr. 2017.

CARO, Felipe; GALLIEN, Jérémie. Inventory Management of a Fast-Fashion Retail Network. Operations Research, [s.1.], v. 58, n. 2, p.257-273, Abr. 2010. Institute for Operations Research and the Management Sciences (INFORMS). Disponível em: $<$ http://dx.doi.org/10.1287/opre.1090.0698>. Acesso em: 22 abr. 2017.

CHANG, Yoon; MAKATSORIS, Harris. Supply chain modeling using simulation. International Journal of Simulation, Athens, p.24-30, 2001. Disponível em: $<$ http://ijssst.info/Vol-02/No-1/Chang.pdf $>$. Acesso em: 03 maio 2017.

CHOI, Byoung Kyu; KANG, Donghun. Modelling and simulation of discrete-event systems. New Jersey: Wiley, 2013. 400 p.

CHOPRA, Sunil; MEINDL, Peter. Gestão da cadeia de suprimentos: estratégia, planejamento e operações. 6. ed. São Paulo: Pearson, 2016. 523 p. 
CHWIF, Leonardo; MEDINA, Afonso C. Modelagem e Simulação de eventos discretos: teoria e aplicações. 4. ed. Rio de Janeiro: Elsevier, 2015. 289 p.

COLLADO, Pol Boada; MARTÍNEZ-DE-ALBÉNIZ, Victor. Estimating and optimizing the impact of inventory on consumer choices in a fashion retail seting. European Research Council, Barcelona, p.1-26, 2014. Disponível em:

$<$ http://webprofesores.iese.edu/valbeniz/ImpactInventory_web.pdf $>$. Acesso em: 03 mai. 2017.

CORSTEN, Daniel; GRUEN, Thomas. Desperately seeking shelf availability: an examination of the extent, the causes, and the efforts to address retail out-of-stocks. International Journal of Retail \& Distribution Management, [s.1.], v. 31, n. 12, p.605-617, Dez. 2003. Emerald. Disponível em: <http://dx.doi.org/10.1108/09590550310507731>. Acesso em: 19 mai. 2016.

D'AVOLIO, Elisa et al. Exploring replenishment in the luxury fashion Italian firms: evidence from case studies. International Journal of Retail \& Distribution Management, [s.1.], v. 43, n. 10/11, p.967-987, 6 out. 2015. Emerald. Disponível em:

<http://dx.doi.org/10.1108/IJRDM-07-2014-0098>. Acesso em: 26 abr. 2017.

DHOLAKIA, Utpal M.. Temptation and resistance: An integrated model of consumption impulse formation and enactment. Psychology and Marketing, [s.1.], v. 17, n. 11, p.955-982, 2000. Wiley-Blackwell. Disponível em: <http://dx.doi.org/10.1002/15206793(200011)17:113.0.co;2-j>. Acesso em: 26 abr. 2017.

DIAS, Cláudia Augusto. Grupo focal: técnica de coleta de dados em pesquisas qualitativas. 2000. 12 f. Dissertação (Mestrado) - Curso de Mestrado em Ciência da Informação, Universidade de Brasília, João Pessoa, 2000. Disponível em: $<$ https://search.proquest.com/docview/1494039227?accountid=27260 >. Acesso em: 03 mai. 2017.

DITTMAR, Helga; DRURY, John. Self-image - is it in the bag? A qualitative comparison between "ordinary" and "excessive" consumers. Journal of Economic Psychology, [s.1.], v. 21, n. 2, p.109-142, Abr. 2000. Elsevier BV. Disponível em: <https://doi.org/10.1016/S01674870(99)00039-2>. Acesso em: 03 mai. 2017.

EHRENTHAL, Joachim C.f.; STÖLZLE, Wolfgang. An examination of the causes for retail stockouts. International Journal of Physical Distribution \& Logistics Management, [s.1.], v. 43, n. 1, p.54-69, 25 Jan. 2013. Disponível em:

$<$ http://dx.doi.org/10.1108/09600031311293255>. Acesso em: 21 abr. 2017.

EMMELHAINZ, Larry W.; EMMELHAINZ, Margaret A.; STOCK, James R.. Logistics implications of retail stockouts. Journal of Business Logistics, Hoboken, p.129-142, 1991. Disponível em: $<$ https://search.proquest.com/docview/212649869?accountid=27260 $>$. Acesso em: 17 mai. 2016. 
FERNIE, John; GRANT, David B.. On-shelf availability: the case of a UK grocery retailer. The International Journal of Logistics Management, [s.1.], v. 19, n. 3, p.293-308, 7 nov. 2008. Emerald. Disponível em: <http://dx.doi.org/10.1108/09574090810919170>. Acesso em: 18 mai. 2016.

FISHER, Marshall; RAMAN, Ananth. The new science of retailind: how analytics are transforming the supply chain na imporving performance. Massachusetts: Harvard Business Press, 2010. 252 p.

FLORES, J E; BOADA, P; MOSCOSO, Philip German. An empirical analysis of sell-through in a fashion setting. International Journal of Supply Chain Management, Madrid, v. 3, n. 4, p.13-22, Dez. 2014. Disponível em: $<$ http://www.ojs.excelingtech.co.uk/index.php/IJSCM/article/view/1005/pdf > . Acesso em: 29 abr. 2017.

GODOY, Arllda Schmidt. Introdução à pesquisa qualitativa e suas possibilidades. Revista de Administração de Empresas, São Paulo, v. 35, n. 2, p.57-63, 1995. Disponível em: $<$ http://www.scielo.br/pdf/rae/v35n2/a08v35n2.pdf>. Acesso em: 03 mai. 2017.

GRANBOIS, Donald H.. Improving the Study of Customer In-Store Behavior. Journal of Marketing, [s.1.], v. 32, n. 4, p.28-33, Out. 1968. JSTOR. Disponível em: $<$ http://dx.doi.org/10.2307/1249334>. Acesso em: 03 mai. 2017.

GRANT, David B.; FERNIE, John. Exploring out-of-stock and on-shelf availability in nongrocery, high street retailing. International Journal of Retail \& Distribution Management, [s.1.], v. 36, n. 8, p.661-672, 20 Jun. 2008. Emerald. Disponível em: $<$ http://dx.doi.org/10.1108/09590550810883496>. Acesso em: 19 mai. 2017.

GRANT, David B.; FERNIE, John. Research note: Exploring out-of-stock and on-shelf availability in non-grocery, high street retailing. International Journal of Retail \& Distribution Management, [s.1.], v. 36, n. 8, p.661-672, 20 Jun. 2008. Emerald. Disponível em: <http://dx.doi.org/10.1108/09590550810883496>. Acesso em: 03 abr. 2017.

GRUEN, Thomas W.; CORSTEN, Daniel S.; BHARADWAJ, Sundar. Retail out-of-stocks: A worldwide examination of extent, causes and consumer responses. The Food Business Fórum, In: The Food Marketing Institute and CIES, Amsterdam, p.1-80, 2002. Disponível em: $<$ http://itsoutofstock.com/wp-content/uploads/2013/04/GMA_2002_Worldwide_OOS_Study.pdf $>$. Acesso em: 04 mai. 2017.

GUBA, Egon G.; LICOLN, Yvonna S. Competing paradigms in qualitative research. Amsterdam: Elsevier, 1994.

HARRELL, C.r.; PRICE, R.n.. Simulation modeling using ProModel technology. Proceedings Of The 2003 International Conference on Machine Learning And Cybernetics (IEEE Cat. No.03ex693), [s.1.], p.175-181, 2003. IEEE. Disponível em: $<$ http://dx.doi.org/10.1109/wsc.2003.1261421>. Acesso em: 29 abr. 2017. 
HAUSMAN, Angela. A multi-method investigation of consumer motivations in impulse buying behavior. Journal of Consumer Marketing, [s.1.], v. 17, n. 5, p.403-426, Set. 2000. Emerald. Disponível em: <http://dx.doi.org/10.1108/07363760010341045>. Acesso em: 29 abr. 2017.

HECKLER, Susan E.; CHILDERS, Terry L.; ARUNACHALAM, Ramesh. Intergenerational Influences in adult buying behaviors: An examination of moderating factors. Advances in Consumer Research, Michigan, v. 16, p.276-284, 1989. Disponível em:

$<$ http://acrwebsite.org/volumes/6915/volumes/v16/NA-16>. Acesso em: 29 abr. 2017.

HOLBROOK, Morris B.; HIRSCHMAN, Elizabeth C.. The Experiential Aspects of Consumption: Consumer Fantasies, Feelings, and Fun. Journal of Consumer Research, [s.1.], v. 9, n. 2, p.132-140, set. 1982. Oxford University Press (OUP). Disponível em: $<$ https://doi.org/10.1086/208906>. Acesso em: 29 abr. 2017.

HULTÉN, Peter; VANYUSHYN, Vladimir. Impulse purchases of groceries in France and Sweden. Journal of Consumer Marketing, [s.1.], v. 28, n. 5, p.376-384, 2 Ago. 2011. Emerald. Disponível em: <http://dx.doi.org/10.1108/07363761111150026>. Acesso em: 26 abr. 2017.

INMAN, J. Jeffrey; WINER, Russell S; FERRARO, Rosellina. The Interplay Among Category Characteristics, Customer Characteristics, and Customer Activities on In-Store Decision Making. Journal of Marketing, [s.1.], v. 73, n. 5, p.19-29, Set. 2009. American Marketing Association (AMA). Disponível em: $<\mathrm{http}: / / \mathrm{dx}$. doi.org/10.1509/jmkg.73.5.19>. Acesso em: 29 abr. 2017.

KACEN, Jacqueline J.; HESS, James D.; WALKER, Doug. Spontaneous selection: The influence of product and retailing factors on consumer impulse purchases. Journal of Retailing and Consumer Services, [s.1.], v. 19, n. 6, p.578-588, Nov. 2012. Elsevier BV.Disponível em: <http://dx.doi.org/10.1016/j.jretconser.2012.07.003>. Acesso em: 03 maio 2017.

KHANNA, Monica; KARANDIKAR, Manisha. Impact of relational collectivism on impulse buying for others. International Journal of Indian Culture and Business Management, [s.1.], v. 7, n. 4, p.589-605, 2013. Inderscience Publishers. Disponível em: $<$ http://dx.doi.org/10.1504/ijicbm.2013.056664>. Acesso em: 29 abr. 2017.

KING JR., Martin Luther. Se não puder voar, corra. Se não puder correr, ande. Se não puder andar, rasteje, mas continue em frente de qualquer jeito. Disponível em: $<$ https://www.pensador.com/frase/ODcxMTI/>. Acesso em: 07 out. 2017.

KOLLAT, David T.; WILLETT, Ronald P.. Customer Impulse Purchasing Behavior. Journal of Marketing Research, [s.1.], v. 4, n. 1, p.21-31, Fev. 1967. JSTOR. Disponível em: $<$ http://dx.doi.org/10.2307/3150160>. Acesso em: 26 abr. 2017. 
LANZILOTTO, Alessandra et al. Impact analysis of a cross-channel retailing system in the fashion industry by a simulation approach. In: CONFERENCE ON MODELING AND APPLIED SIMULATION, 1., 2015, Lecce. .. .. ., 2015. p. 79 - 88. Disponível em: $<$ https://www.researchgate.net/profile/Maria_Gnoni/publication/282150114_Impact_analysis _of_a_cross--

channel_retailing_system_in_the_fashion_industry_by_a_simulation_approach/links/571744d 208ae09ceb2630943.pdf>. Acesso em: 26 abr. 2017.

LEE, Young Hae et al. Supply chain simulation with discrete-continuous combined modeling. Computers \& Industrial Engineering, [s.1.], v. 43, n. 1-2, p.375-392, Jul. 2002. Elsevier BV. Disponível em: <https://doi.org/10.1016/S0360-8352(02)00080-3>. Acesso em: 03 abr. 2017.

LONGO, Francesco; MIRABELLI, Giovanni. An advanced supply chain management tool based on modeling and simulation. Computers \& Industrial Engineering, [s.1.], v. 54, n. 3, p.570-588, Abr. 2008. Elsevier BV. Disponível em:

$<$ http://dx.doi.org/10.1016/j.cie.2007.09.008>. Acesso em: 03 mai. 2017.

LU, Ming; WONG, Lap-chi. Comparing ProModel and Sdesa in Modeling Construciton Operations. Proceedings of The Winter Simulation Conference, 2005., [s.1.], p.1524-1532, 2005. IEEE. Disponível em: <http://dx.doi.org/10.1109/wsc.2005.1574420>. Acesso em: 29 abr. 2017.

MANUJ, Ila; MENTZER, John T.; BOWERS, Melissa R.. Improving the rigor of discreteevent simulation in logistics and supply chain research. International Journal of Physical Distribution \& Logistics Management, [s.1.], v. 39, n. 3, p.172-201, 17 Abr. 2009. Emerald. Disponível em: <http://dx.doi.org/10.1108/09600030910951692>. Acesso em: 02 mai. 2017.

MARQUI, Angela Cristina; ALCÂNTARA, Rosane Lucia Chicarelli; CHRISTOPHER, Martin. Using the systematic literature review procedure to identify the root causes of out-of-stock in retail supply chains. Ufscar, São Carlos, p.1-10, 2010. Disponível em: $<$ http://www.scielo.br/scielo.php?script=sci_nlinks\&ref=000212\&pid=S01036513201400010000500019\&lng=en>. Acesso em: 03 mai. 2017.

MARTINO, Giada et al. Optimisation of the replenishment problem in the Fashion Retail Industry using Tabu-Bees algorithm. Ifac-papersonline, [s.1.], v. 49, n. 12, p.1685-1690, 2016. Elsevier BV. Disponível em: <https://doi.org/10.1016/j.ifacol.2016.07.823>. Acesso em: 21 abr. 2017.

MATTILA, Anna S.; WIRTZ, Jochen. The role of store environmental stimulation and social factors on impulse purchasing. Journal of Services Marketing, [s.1.], v. 22, n. 7, p.562-567, 10 Out. 2008. Emerald. Disponível em: <http://dx.doi.org/10.1108/08876040810909686>. Acesso em: 26 abr. 2017.

MIGUEL, Paulo Auguto Cauchick et al. Metodologia de pesquisa em Engenharia de Produção e Gestão de Operações. São Paulo: Elsevier, 2010. 226 p. 
MORGAN, C.; DEWHURST, A.. Multiple retailer supplier performance: An exploratory investigation into using SPC techniques. International Journal of Production Economics, [s.1.], v. 111, n. 1, p.13-26, Jan. 2008. Elsevier BV. Disponível em:

$<$ http://dx.doi.org/10.1016/j.ijpe.2006.11.018>. Acesso em: 19 mai. 2016.

PAN, A. et al. Optimal reorder decision-making in the agent-based apparel supply chain.

Expert Systems With Applications, [s.1.], v. 36, n. 4, p.8571-8581, Mai. 2009. Elsevier BV. Disponível em: <https://doi.org/10.1016/j.eswa.2008.10.081>. Acesso em: 26 abr. 2017.

PARENTE, Juracy; BARKI, Edgard. Varejo no Brasil: Gestão e Estratégia. 2. ed. São Paulo: Atlas, 2014. $440 \mathrm{p}$.

PARK, C. Whan; IYER, Easwar S.; SMITH, Daniel C.. The Effects of Situational Factors on In-Store Grocery Shopping Behavior: The Role of Store Environment and Time Available for Shopping. Journal Of Consumer Research, [s.1.], v. 15, n. 4, p.422-433, Mar. 1989. Oxford University Press (OUP). Disponível em: $<$ https://doi.org/10.1086/209182>. Acesso em: 03 mai. 2017.

PECKHAM, James O.. The Consumer Speaks. Journal of Marketing, [s.1.], v. 27, n. 4, p.2126, Out. 1963. JSTOR. Disponível em: <http://dx.doi.org/10.2307/1248641>. Acesso em: 22 abr. 2017.

PEINKOFER, Simone T.; ESPER, Terry L.; HOWLETT, Elizabeth. Hurry! Sale Ends Soon: The Impact of Limited Inventory Availability Disclosure on Consumer Responses to Online Stockouts. Journal of Business Logistics, [s.1.], v. 37, n. 3, p.231-246, 19 Ago. 2016. WileyBlackwell. Disponível em: <http://dx.doi.org/10.1111/jbl.12136>. Acesso em: 21 abr. 2017.

PIBERNIK, Richard. Managing stock-outs effectively with order fulfilment systems. Journal of Manufacturing Technology Management, [s.1.], v. 17, n. 6, p.721-736, Ago. 2006.

Emerald. Disponível em: <http://dx.doi.org/10.1108/17410380610678765>. Acesso em: 18 mai. 2016.

PIDD, Michael. Computer simulation in management science. 5. ed. Southern Gate: Wiley, 2004. $297 \mathrm{p}$.

PIORE, Michael J.. Qualitative Research Techniques in Economics. Administrative Science Quarterly, [s.1.], v. 24, n. 4, p.560-569, Dez. 1979. JSTOR. Disponível em: $<$ http://dx.doi.org/10.2307/2392362>. Acesso em: 03 mai. 2017.

PRAMATARI, Katerina; EVGENIOU, Theodoros; DOUKIDIS, Georgios. Implementation of collaborative e-supply-chain initiatives: an initial challenging and final success case from grocery retailing. Journal of Information Technology, [s.1.], v. 24, n. 3, p.269-281, 17 Nov. 2008. Springer Nature. Disponível em: $<$ http://dx.doi.org/10.1057/jit.2008.11>. Acesso em: 19 mai. 2016. 
PRASHAR, Sanjeev; PARSAD, Chandan; VIJAY, T. Sai. Application of neural networks technique in predicting impulse buying among shoppers in India. Decision, [s.1.], v. 42, n. 4, p.403-417, 30 Out. 2015. Springer Nature. Disponível em: $<$ http://dx.doi.org/10.1007/s40622015-0109-x>. Acesso em: 26 abr. 2017.

RENEKER, Maxine H. A Qualitative Study of Information Seeking among Members of an Academic Community: Methodological Issues and Problems. The Library Quarterly, [s.1.], v. 63, n. 4, p.487-507, Out. 1993. University of Chicago Press. Disponível em: $<$ http://dx.doi.org/10.1086/602623>. Acesso em: 03 maio 2017.

RICHARDSON, Roberto Jarry. Pesquisa social: métodos e técnicas. 3. ed. São Paulo: Atlas, 1989. $334 \mathrm{p}$.

ROOK, Dennis W. The Buying Impulse. Journal of Consumer Research, [s.1.], v. 14, n. 2, p.189-199, Set. 1987. Oxford University Press (OUP). Disponível em: $<$ https://doi.org/10.1086/209105>. Acesso em: 29 abr. 2017.

ROOK, Dennis W.; FISHER, Robert J.. Normative Influences on Impulsive Buying Behavior. Journal of Consumer Research, [s.1.], v. 22, n. 3, p.305-313, Dez. 1995. Oxford University Press (OUP). Disponível em: <https://doi.org/10.1086/209452>. Acesso em: 29 abr. 2017.

ROSENFIELD, Donald B. et al. Logistics planning and evaluation when using 'What-If' simulation. Journal of Business Logistics, Massachusetts, v. 6, n. 2, p.89-107, 1985. Disponível em: <http:/web.a.ebscohost.com/ehost/pdfviewer/pdfviewer?sid=4b1bbab9-8f4b49d0-975e-0e09acc11c0@sessionmgr4008\&vid=9\&hid=4212>. Acesso em: 03 mai. 2017.

ROSS, Sheldon M.. Simulation. 5. ed. San Diego: Elsevier, 2013. 303 p.

SHANNON, R.E. Introduction to the art and science of simulation. 1998 Winter Simulation Conference. Proceedings (cat. No.98ch36274), [s.1.], p.7-14, 1998. IEEE. Disponível em: $<$ http://dx.doi.org/10.1109/wsc.1998.744892>. Acesso em: 29 abr. 2017.

SLOOT, Laurens M.; VERHOEF, Peter C.; FRANSES, Philip Hans. The impact of brand equity and the hedonic level of products on consumer stock-out reactions. Journal of Retailing, [s.1.], v. 81, n. 1, p.15-34, Jan. 2005. Elsevier BV. Disponível em: $<$ http://dx.doi.org/10.1016/j.jretai.2005.01.001>. Acesso em: 18 mai. 2016.

STERN, Hawkins. The Significance of Impulse Buying Today. Journal of Marketing, [s.1.], v. 26, n. 2, p.59-62, Abr. 1962. JSTOR. Disponível em: <http://dx.doi.org/10.2307/1248439>. Acesso em: 29 abr. 2017.

TRAUTRIMS, Alexander et al. Optimizing on-shelf availability for customer service and profit. Journal of Business Logistics, [s.1.], v. 30, n. 2, p.231-247, Set. 2009. WileyBlackwell. Disponível em: <http://dx.doi.org/10.1002/j.2158-1592.2009.tb00122.x>. Acesso em: 19 mai. 2016. 
USMAN, Khalid. Determination of drivers of stock-out performace of retail stores using data mi- ning techniques. 2008. 84 f. Dissertação (Mestrado) - Curso de Master of Engineering In Logistics, Massachusetts Institute Of Technology. Engineering Systems Division., Massachusetts Institute of Technology, Massachusetts, 2008. Disponível em: $<$ http://hdl.handle.net/1721.1/45246>. Acesso em: 03 mai. 2017.

VAN WOENSEL, Tom et al. Consumer responses to shelf out-of-stocks of perishable products. International Journal of Physical Distribution \& Logistics Management, [s.1.], v. 37, n. 9, p.704-718, 16 Out. 2007. Emerald. Disponível em: $<$ http://dx.doi.org/10.1108/09600030710840822>. Acesso em: 18 maio 2016.

WALLER, Matthew A.; TANGARI, Andrea Heintz; WILLIAMS, Brent D.. Case pack quantity's effect on retail market share. International Journal of Physical Distribution \& Logistics Management, [s.1.], v. 38, n. 6, p.436-451, 11 Jul. 2008. Emerald. Disponível em: $<$ http://dx.doi.org/10.1108/09600030810893508>. Acesso em: 15 mai. 2016.

WU, Teresa et al. Supply Chain risk management: An Agent-Based Simulation to Study the Impact of Retail Stockouts. Ieee Transactions on Engineering Management, [s.1.], v. 60, n. 4, p.676-686, Nov. 2013. Institute of Electrical and Electronics Engineers (IEEE). Disponível em: <http://dx.doi.org/10.1109/tem.2012.2190986>. Acesso em: 22 abr. 2017.

ZHANG, Shi; FITZSIMONS, Gavan J. Choice-Process Satisfaction: The Influence of Attribute Alignability and Option Limitation. Organizational Behavior and Human Decision Processes, [s.1.], v. 77, n. 3, p.192-214, Mar. 1999. Elsevier BV. Disponível em: $<$ https://doi.org/10.1006/obhd.1999.2821>. Acesso em: 29 abr. 2017.

ZINN, Walter; LIU, Peter C.. Consumer response to retail stockouts. Journal of Business Logistics, [s.1.], v. 22, n. 1, p.49-71, Mar. 2001. Wiley-Blackwell. Disponível em: $<$ http://dx.doi.org/10.1002/j.2158-1592.2001.tb00159.x>. Acesso em: 17 mai. 2016. 
APÊNDICE A - DADOS DA AMOSTRAGEM REALIZADA NA OPERAÇÃO DA LOJA 
Tabela 4 - Dados da amostragem realizada na operação da loja

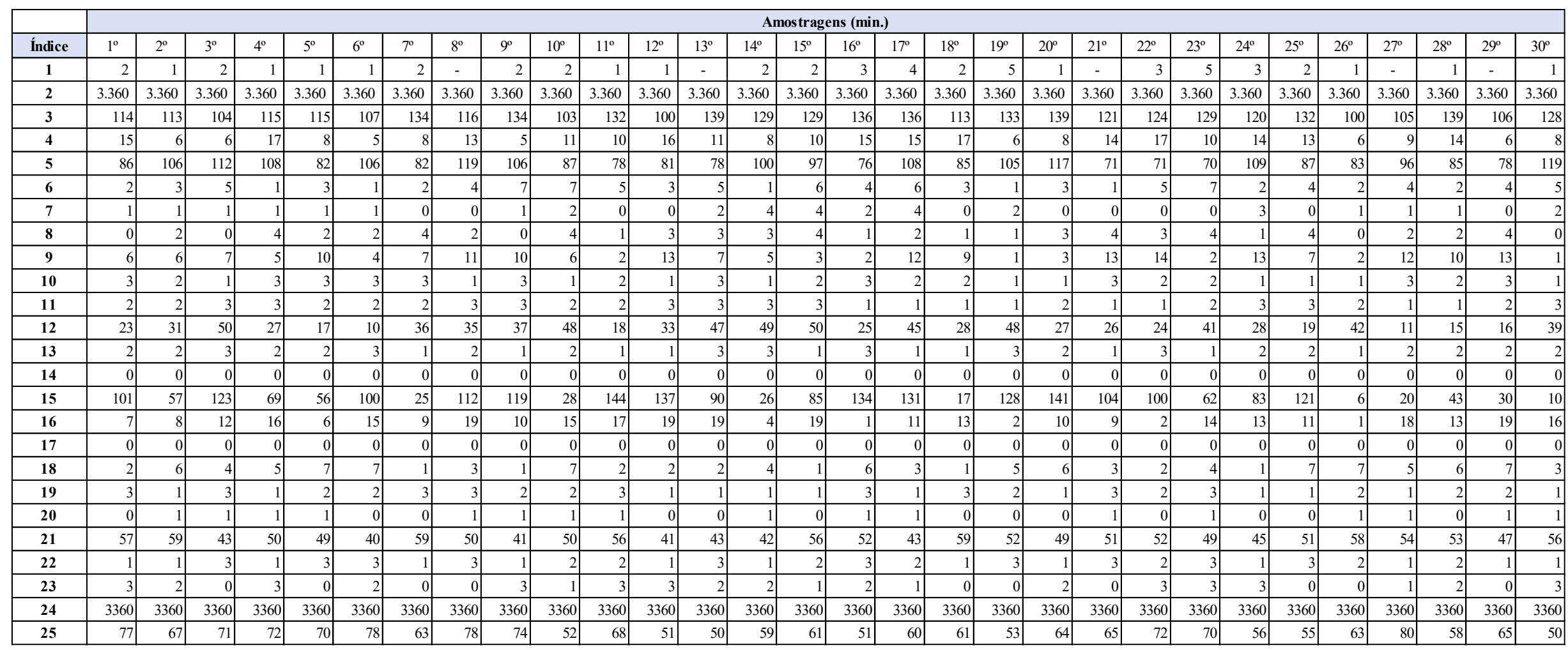

Fonte: Autor 
APÊNDICE B - DESCRIÇÃO DO MODELO COMPUTACIONAL 
Figura 7 - Descrição do modelo computacional

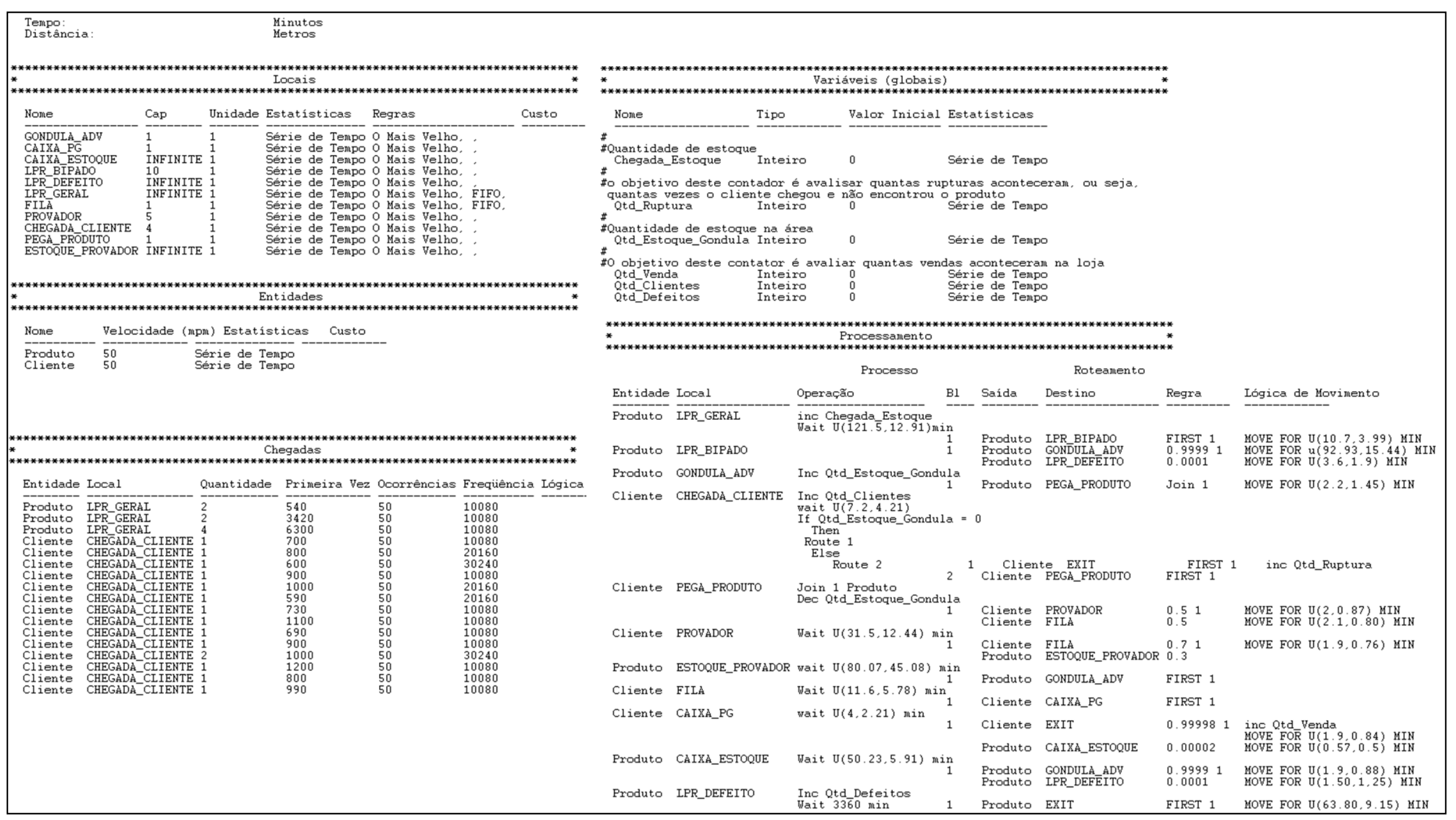

Fonte: Autor 